Review article

\title{
Why would Parkinson's disease lead to sudden changes in creativity, motivation, or style with visual art?: A review of case evidence and new, contextual, and genetic hypotheses
}

\author{
Jon O. Lauringa, ${ }^{\mathrm{a}}$, Tomohiro Ishizu ${ }^{\mathrm{b}, \mathrm{c}}$, Hana H. Kutlikova ${ }^{\mathrm{d}}$, Felix Dörflinger ${ }^{\mathrm{b}}$, Steven Haugbøle ${ }^{\mathrm{e}}$, Helmut Leder ${ }^{\mathrm{b}}$, \\ Ron Kupers ${ }^{\mathrm{a}}$, Matthew Pelowski ${ }^{\mathrm{b}, 1,}$, \\ a Department of Neurossscience, BRAINlab, University of Copenhagen, Blegdamsvej 3B, DK-2200 Copenhagen, Denmark \\ ${ }^{\mathrm{b}}$ Faculty of Psychology, Department of Basic Psychological Research and Research Methods, University of Vienna, Liebiggasse 5, A-1010 Vienna, Austria \\ ${ }^{c}$ Faculty of Biosciences, Cell and Developmental Biology, University College London, Gower Street, WC1E 6BT, London, UK

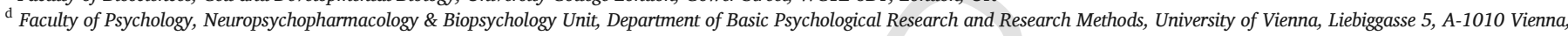 \\ Austria \\ e Department of Neurology, Copenhagen University Hospital Bispebjerg, Bispebjerg Bakke 23, DK-2400 Copenhagen, Denmark
}

\section{A R T I C L E I N F O}

\section{Keywords:}

Parkinson's disease

Visual creativity

Artists

Art making

Neurobiological bases

Dopamine system

Psychopharmacology

Brain damage

\begin{abstract}
A B S T R A C T
Parkinson's disease (PD) is a devastating diagnosis with, however, potential for an extremely intriguing aesthetic component. Despite motor and cognitive deficits, an emerging collection of studies report a burst of visual artistic output and alterations in produced art in a subgroup of patients. This provides a unique window into the neurophysiological bases for why and how we might create and enjoy visual art, as well as into general brain function and the nature of PD or other neurodegenerative diseases. However, there has not been a comprehensive organization of literature on this topic. Nor has there been an attempt to connect case evidence and knowledge on PD with present understanding of visual art making in psychology and neuroaesthetics in order to propose hypotheses for documented artistic changes. Here, we collect the current research on this topic, tie this to PD symptoms and neurobiology, and provide new theories focusing on dopaminergic neuron damage, over-stimulation from dopamine agonist therapy, and context or genetic factors revealing the neurobiological basis of the visual artistic brain.
\end{abstract}

\section{Introduction}

"I know that I am sick, and it is a horrible thing, but honestly I have never felt more artistic in my life." -Parkinson's patient, personal correspondence

Parkinson's disease (PD) is a neurodegenerative disease affecting roughly $0.3 \%$ of the population, rising rapidly to $3 \%$ over the age of sixty-five (Gillies et al., 2014). PD progressively impacts brain cells' ability to produce the neurotransmitter dopamine, and leading, along with spreading brain lesions, to a number of symptoms from issues with motor control and cognitive processes (including language and memory), as well as sensory, and emotional regulation (Chaudhuri et al., 2006; Sveinbjornsdottir, 2016). These symptoms can only be slowed but not presently cured by a combination of medications or invasive procedures, thus, in conjunction with an aging world population, making PD an increasingly pressing target for research.

At the same time, and in addition to its obvious medical importance, emerging evidence also suggests something quite surprising that can accompany the disease onset: As reported in a number of case studies, with diagnosis and antiparkinsonian treatment, a subset of individuals appear to experience a sudden awakening of artistic creativity and desire, and/or changes in the style or even in the quality of their produced art. A survey by Joutsa et al. (2012a) has in fact suggested such changes in up to $20 \%$ of respondents. This can be found with famous artists, for example Salvador Dali (Forsythe et al., 2017), and is documented on the website of the Parkinson's Disease Foundation, which until recently kept a database of visual artworks in addition to other

\footnotetext{
* Corresponding author.

Email address: matthew.pelowski@univie.ac.at (M. Pelowski)

1 These authors contributed equally.
} 
Table 1

PD stages, symptoms and main affected brain regions.

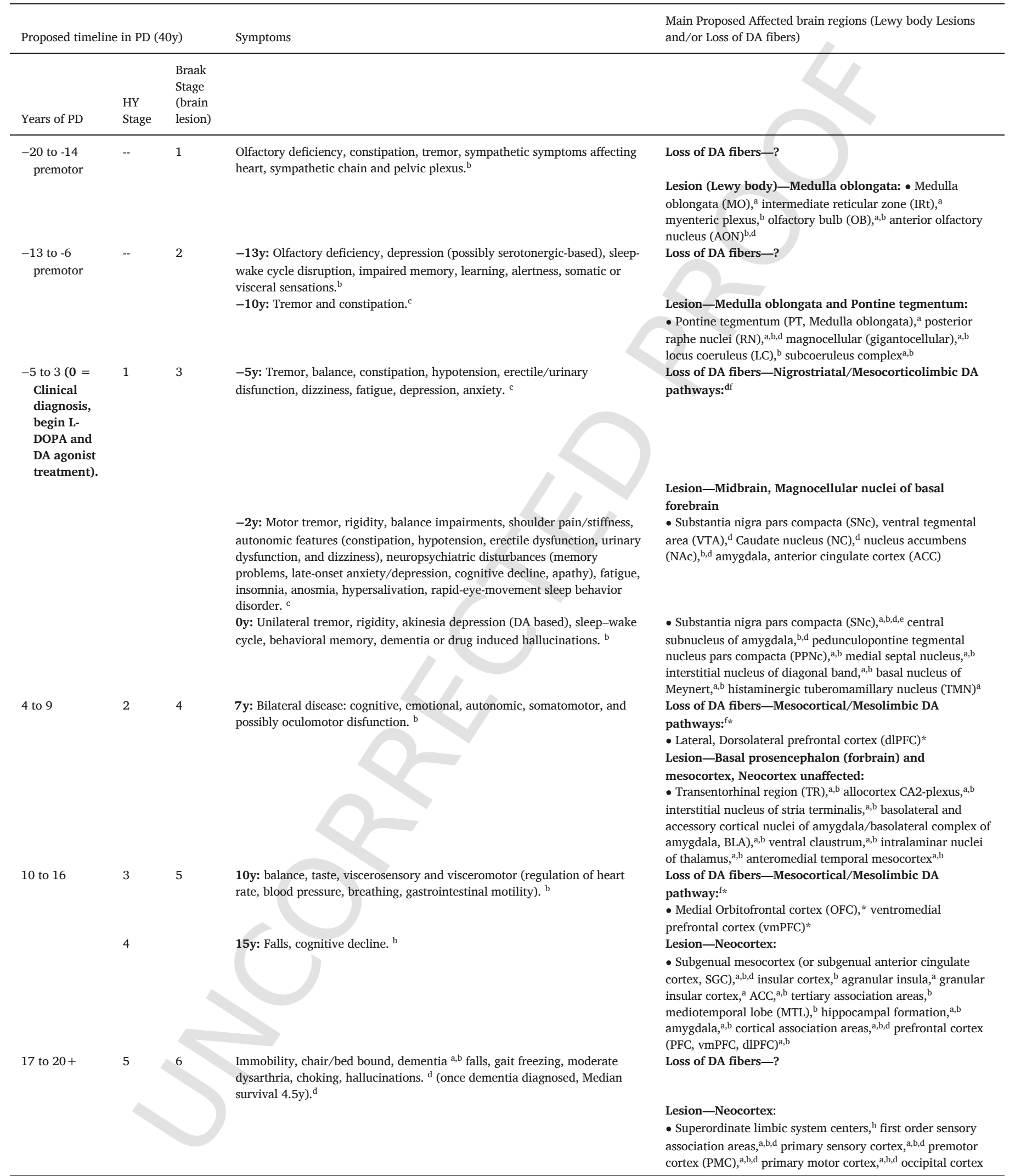

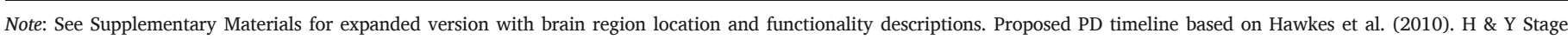

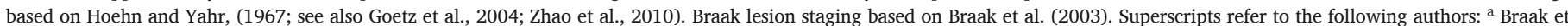

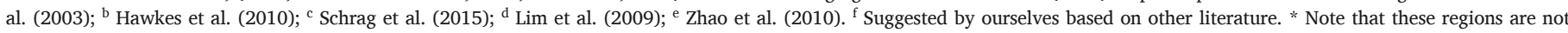

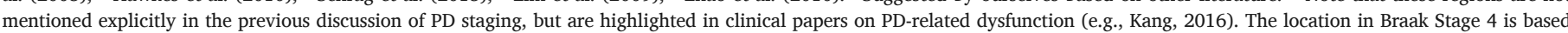

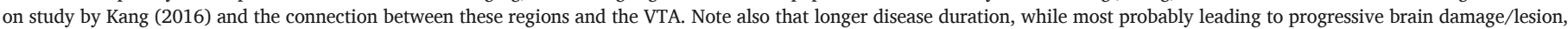
does not necessarily correlate with increased non-motor symptom severity (Chaudhuri et al., 2015). 

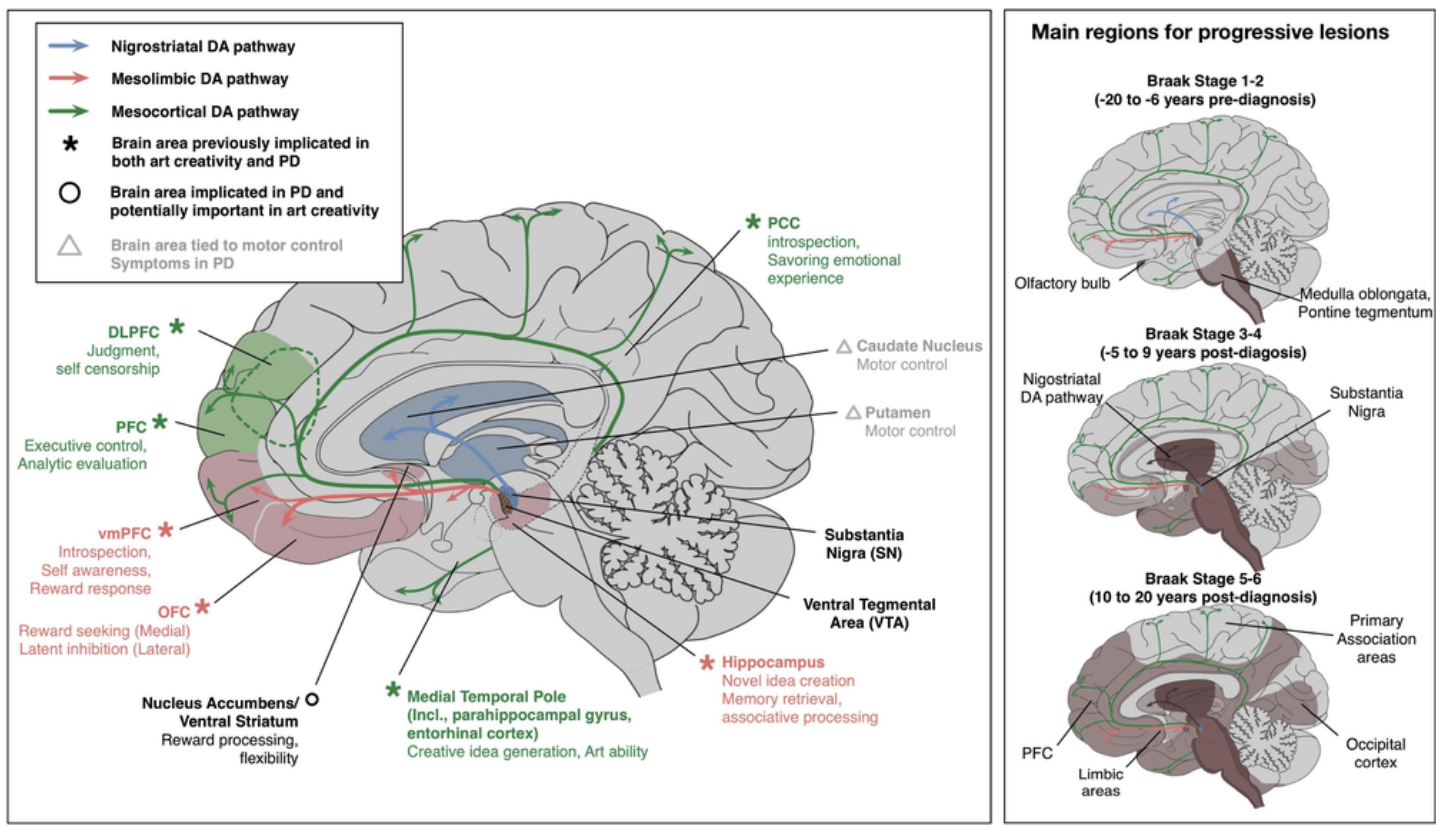

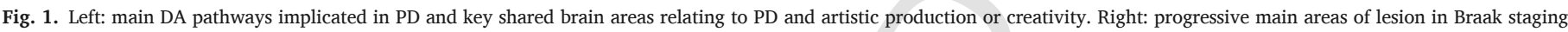
(adapted from Braak et al., 2003). Schematic figure; exact anatomical locations may differ.

creative products, accompanied by comments recounting sudden artistic growth, in many cases, by individuals who had previously not shown any particular interest in art.

Such changes - as they manifest in individuals' outward behavior, in their cognitive/affective experiences, and presumably within their brains-represent a rare treasure-trove of data with connections to multiple areas of psychological science. This offers a unique glimpse into the ability of humans to produce art-one of our most evolutionarily distinct, culturally universal, and complex human activities (Pelowski et al., 2017a). This is made all the more intriguing by the fact that PD-afflicted individuals often engage in creative production despite the fact that many of the abilities thought to be essential to art making-motor control, visuospatial processing - may be impaired (Inzelberg, 2013; McManus et al., 2010). Nor is it common, with any individual or any disorder, for post-adolescents to spontaneously begin, much less improve, their art making (Barbot and Tinio, 2015; Gardner and Winner, 1982).

This phenomenon also offers insight into a range of other areas such as how personality, context, or even genetics may contribute to visual creativity in general (Lauring, 2015), as well as to brain function and plasticity (Boot et al., 2017; Cecchetti et al., 2016). PD-evoked changes also offer important possibilities for causative studies (Chatterjee, 2011; Zaidel et al., 2013), especially for dopaminergic psychopharmacology (Spee et al., 2018), and has potential connections to other disorders (e.g., Alzheimer's, dementia) that have shown some similar motivation or artistic change (Gretton and Ffytche, 2014). For the clinical researcher or physician focused on PD, art making or viewing, combined with changes via the disease, represent intriguing potential for early diagnosis, rehabilitative therapy (Haaxma et al., 2015; Lim et al., 2009), and for understanding of especially non-motor symptoms (Chaudhuri et al., 2015; Martinez-Martin et al., 2011), which may hold insights to the neurobiological basis of PD itself.

However, despite this interest, this topic remains sparsely-and disparately-researched. While collected in an emerging handful of case studies, due to a lack of systematic review and, importantly, lack of in-depth connection to present knowledge regarding PD symptoms, stages, and the unique neurobiology or perceptual/contextual aspects in visual artists, an answer for the underlying questions of why and how
PD and related factors might actually combine to create such fascinating changes has not been addressed.

In this paper, we consider PD and changes in creativity, style and motivation for art with the aim of providing both a necessary reference for researchers - themselves coming from a number of fields with varying knowledge of PD and production of art, but with a shared interest in this topic-and targeted new explanatory hypotheses. We combine the key biological, neurological, and symptomatic factors of PD with a systematic consideration of case evidence. Based on this, we unite these findings and main features with present understanding of visual creativity and art making from the fields of psychology, neuroaesthetics, and neuropathology, leading to several arguments for behavioral, genetic, and especially neurobiological factors that underlie sudden changes in artistic production. We conclude with outstanding questions and implications for future brain imaging, causative, and behavioral research. Although studies have also considered PD involvement in general creativity and with some non-visual media (e.g., see Boot et al., 2017; Inzelberg, 2013), due to the emerging cluster of case findings and the unique importance of this topic as a distinct human action and field of study in its own right, we focus on visual art.

\section{Background: PD pathology, symptoms, and antiparkinsonian treatments}

Table 1 provides a detailed summary of main PD disease stages, symptoms, and affected brain areas; Fig. 1 shows key brain areas in PD as they overlap with findings on art making.

PD onset appears to result from a still largely undetermined interplay of genetic and environmental factors (Kalia and Lang, 2015). It is, however, a neurodegenerative disease involving a pattern of changes to the brain. Most saliently, the disease involves the degeneration of the brain's ability to produce dopamine (DA), a chemical compound synthesized from the precursor levodopa, which acts as a neurotransmitter primarily evoking action potential in postsynaptic neurons, and is thus a major component of brain functioning and interconnectivity. The main site of PD-related DA production is the ventral tier of the substantia nigra pars compacta (vSNc, Fig. 1), a region in the midbrain (Betchen and Kaplitt, 2003; Cameron et al., 2010). The vSNc is func- 


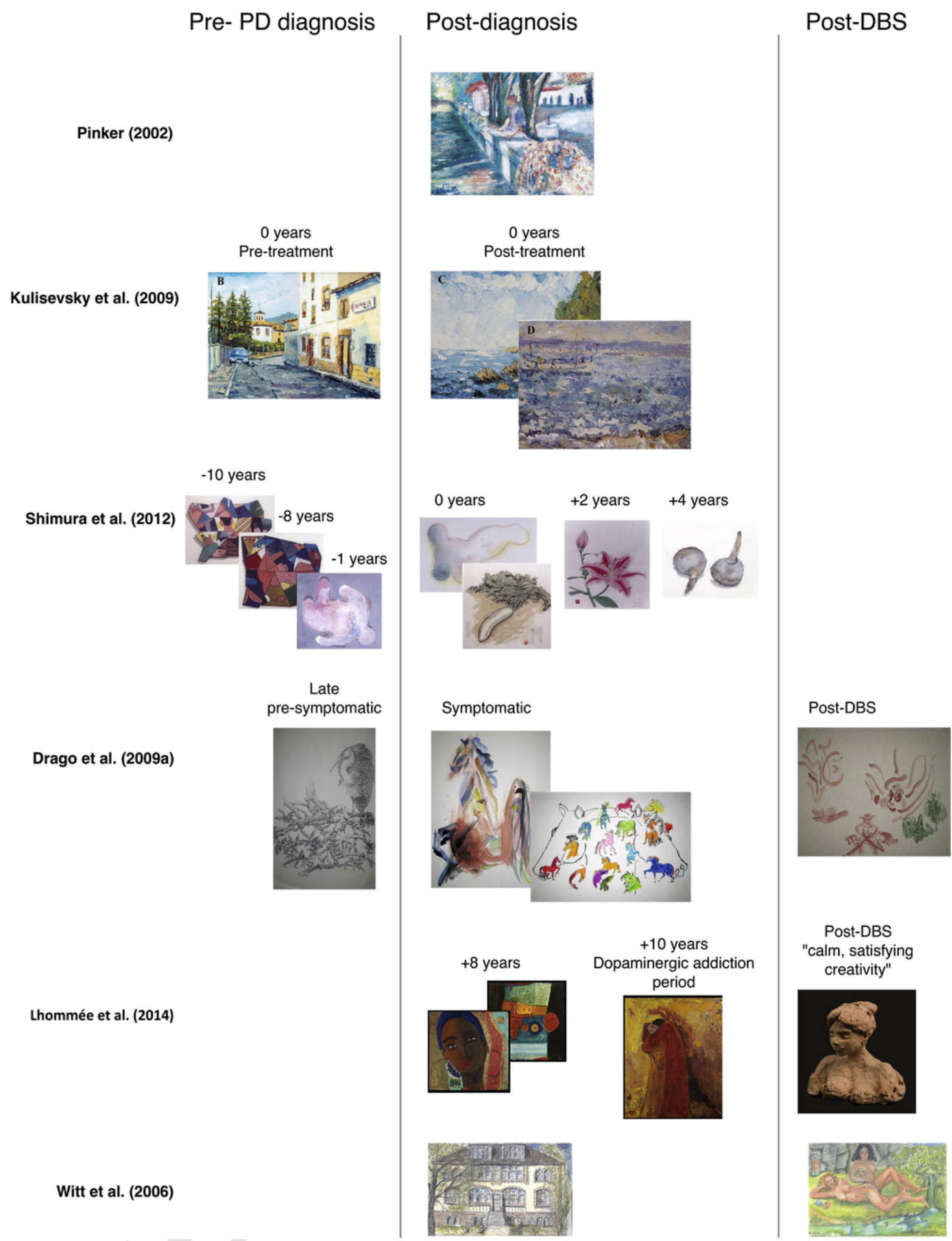

Fig. 2. Examples of artworks presented in previous PD and art production papers organized by main events in disease/medication progression. (Labels for individual artworks based on author descriptions).

tionally connected, via the nigrostriatal dopamine pathway (one of four DA pathways; blue arrows in Fig. 1), to the basal ganglia with the endpoint appearing to be the head of the caudate nucleus (Grahn et al., 2008). This is a diverse set of subcortical nuclei-including, among others, the striatum (caudate nucleus and putamen), substantia nigra, and subthalamic nucleus - with a primary function involving action selection, habit formation, and regulation of motor and premotor areas. Thus, its degeneration is the pathological focus of most initial diagnoses of PD (Fig. 2).
Neuronal depletion and thus dysfunction has also been identified in the ventral tegmental area. This is a component of both the mesolimbic and the mesocortical pathways (red and green arrows, Fig. 1). The mesolimbic pathway connects to the ventral striatum (primarily nucleus accumbens, NAcc), associated with motivation and reward effects or learning, as well as to the hippocampus (memory formation, navigation, emotion), and to the ventromedial prefrontal cortex (vmPFC; motivation, reward response and anticipation, introspection), and the orbitofrontal cortex (OFC), a key site, especially in its medial portions, of 
Table 2

Studies on PD and previous artists—changes in artistic creativity, motivation, or style.

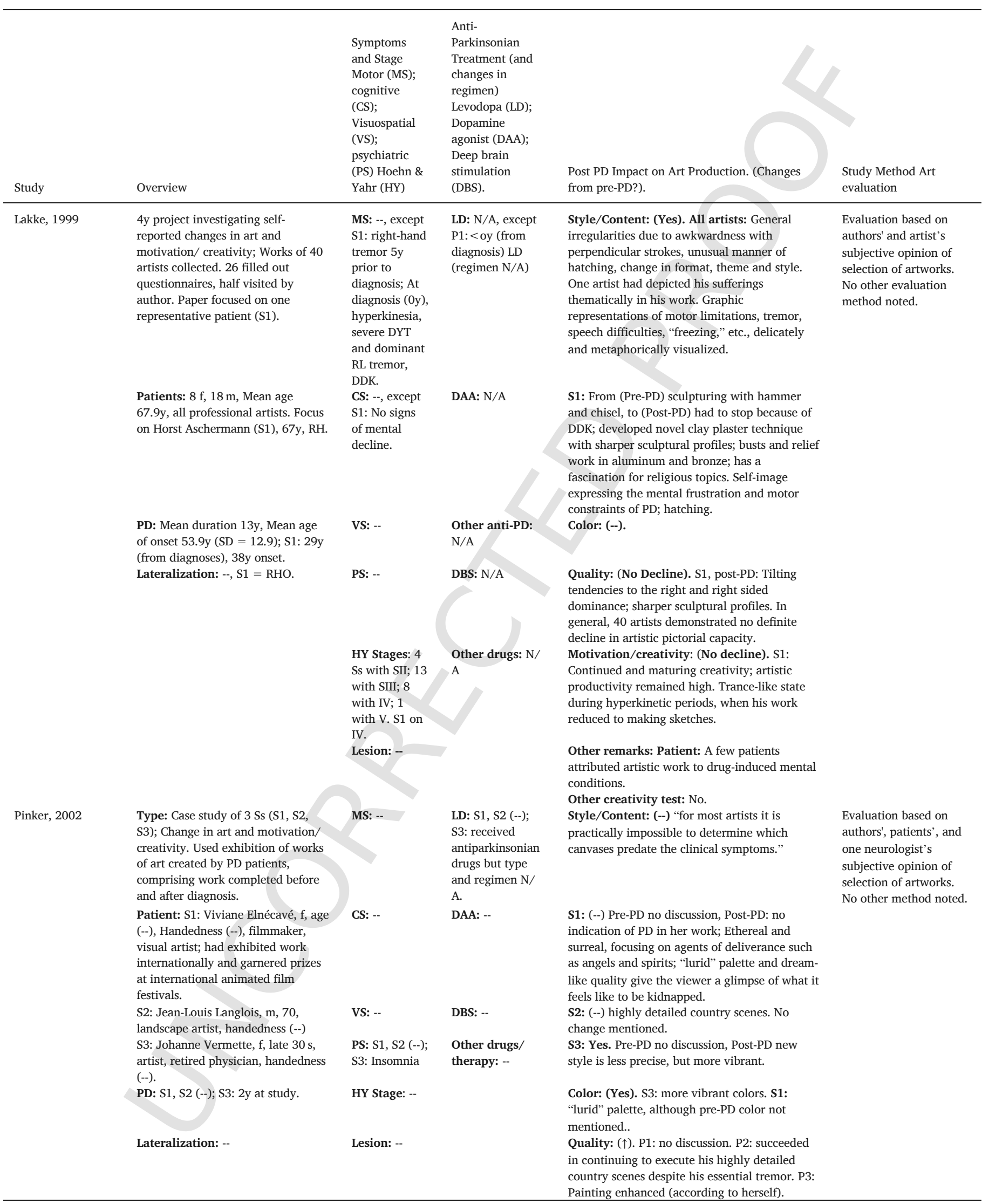




\begin{tabular}{|c|c|c|c|c|c|}
\hline Study & Overview & $\begin{array}{l}\text { Symptoms } \\
\text { and Stage } \\
\text { Motor (MS); } \\
\text { cognitive } \\
\text { (CS); } \\
\text { Visuospatial } \\
\text { (VS); } \\
\text { psychiatric } \\
\text { (PS) Hoehn \& } \\
\text { Yahr (HY) }\end{array}$ & $\begin{array}{l}\text { Anti- } \\
\text { Parkinsonian } \\
\text { Treatment (and } \\
\text { changes in } \\
\text { regimen) } \\
\text { Levodopa (LD); } \\
\text { Dopamine } \\
\text { agonist (DAA); } \\
\text { Deep brain } \\
\text { stimulation } \\
\text { (DBS). }\end{array}$ & $\begin{array}{l}\text { Post PD Impact on Art Production. (Changes } \\
\text { from pre-PD?). }\end{array}$ & $\begin{array}{l}\text { Study Method Art } \\
\text { evaluation }\end{array}$ \\
\hline
\end{tabular}

Kulisevsky et al., 2009
Case study of $1 \mathrm{Ss}$; Changes in art, and motivation/creativity.

Patient: $\mathrm{m}, 47$, amateur painter, handedness (--).

PD: report from 0y,

Lateralization: $\mathrm{LHO}$

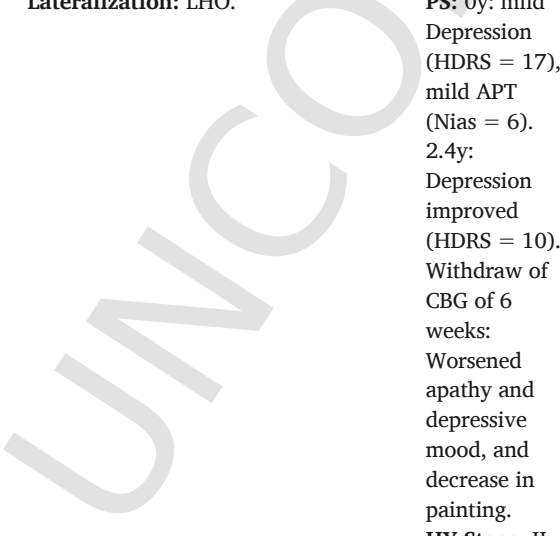

MS: Tremor, rigidity, left arm BK. (UPDRS III = 32)

CS: None (MMSE 30/

VS: N/A

HY Stage: II
Motivation/creativity: ( $\uparrow$. P1, P2: N/A; P3: "I have a need to express myself more. I let myself go, sometimes painting with enraged fingers." Felt more creative since the PD onset. Other remarks: Author: P1's painting takes much longer and more tired afterward. Patient: P3: Wonder whether her medication is playing a role in enhancing imagination. "When I paint I'm in the best place because I'm doing only that. There's no planning, no hierarchy of actions, but just the urgency of living."

Other creativity test: No.

Style: (Yes). From (Pre-PD) detailed and figurative painting taking months to complete, concern with achieving accurate reflection of reality, to (Post-PD) increasingly impressionistic style with emphasis on color and light rather than shape and detail.

DAA: 0-2y: CBG $4 \mathrm{mg}$ /day; withdrawal of CBG over a

period of 6 weeks; Reinitiating CBG $4 \mathrm{mg}$; CBG tapered down to

$2 \mathrm{mg} /$ day; $\mathrm{CBG}$ changed with PR X 0.7 mg t.i.d.; then PR X $0.35 \mathrm{mg}$ t.i.d. DBS: --

Color: (Yes). Increasing emphasis on color and light.

Quality: ( $\uparrow$ ). From (Pre-PD) "not remarkable" paintings to (Post-PD) exhibition of his work with a certain degree of commercial success in the local art community.

Motivation/creativity: $(\uparrow)$. After DAA therapy initiation (0-2y), he increased production from 1 painting/several months to 1 painting/week. Painting became primary interest. 3y: began to paint into the night, interfering with sleep. Withdrawal of CBG ( 6 weeks) resulted in decrease in artistic activity (apathy and depressive mood worsened); Increase of LD to $750 \mathrm{mg} /$ day did not make the patient resume painting; Re-initiation of CBG $4 \mathrm{mg}$ /day: patient quickly showed a renewed interest in painting day and night. CBG $2 \mathrm{mg}$ /day: painted at day, not at night; PR X $0.7 \mathrm{mg}$ t.i.d.:

disruptive pattern of excessive painting activity; PR X $0.35 \mathrm{mg}$ t.i.d: painted at day, not at night.

Other remarks: Author: Remarkable change in style and attitude towards his art observable after onset of DAergic treatment. Patient: regarded his art work as positive for him as he was able to move more easily and felt emotionally relieved. Justified changes in style as a need to express refreshed inner emotions.
Evaluation based on authors' subjective opinion of selection of artworks (and exhibitions/ commercial success). No other eval. method noted. 


\begin{tabular}{|c|c|c|c|c|c|}
\hline Study & Overview & $\begin{array}{l}\text { Symptoms } \\
\text { and Stage } \\
\text { Motor (MS); } \\
\text { cognitive } \\
\text { (CS); } \\
\text { Visuospatial } \\
\text { (VS); } \\
\text { psychiatric } \\
\text { (PS) Hoehn \& } \\
\text { Yahr (HY) }\end{array}$ & $\begin{array}{l}\text { Anti- } \\
\text { Parkinsonian } \\
\text { Treatment (and } \\
\text { changes in } \\
\text { regimen) } \\
\text { Levodopa (LD); } \\
\text { Dopamine } \\
\text { agonist (DAA); } \\
\text { Deep brain } \\
\text { stimulation } \\
\text { (DBS). }\end{array}$ & $\begin{array}{l}\text { Post PD Impact on Art Production. (Changes } \\
\text { from pre-PD?). }\end{array}$ & $\begin{array}{l}\text { Study Method Art } \\
\text { evaluation }\end{array}$ \\
\hline $\begin{array}{l}\text { Schwingenschuh } \\
\text { et al., } 2010\end{array}$ & $\begin{array}{l}\text { Case studies of } 2 \text { PD Ss (S1 and S2) } \\
\text { concerning the risk factor of artists } \\
\text { with PD developing DA } \\
\text { dysregulating syndrome. Art and } \\
\text { behavior assessed over multiple } \\
\text { time periods. S1: TP1, following PD } \\
\text { diagnosis y0-2; TP2, y2-5; TP3, } \\
\text { y5-8; TP4 y9. S2: TP1, (year and age } \\
\text {--); TP2 3yrs later, TP3, TP4, and } \\
\text { TP5 are defined by changes in drug } \\
\text { type and regimen as year or age are } \\
\text { not available (--). } \\
\text { Patient: S1: m, 37, Advertising } \\
\text { artist and hobby painter. S2: f, 66y; } \\
\text { professional painter. PD: S1: 9y at } \\
\text { study (age 28). S2: 18y prior to } \\
\text { study (age 48) }\end{array}$ & $\begin{array}{l}\text { VS: S1 --, S2 -- } \\
\text { PS: S1: } \\
\text { Tending to } \\
\text { DDS, S2: TP1 - } \\
\text {-, TP2 (3y } \\
\text { later) Severe } \\
\text { mood } \\
\text { fluctuations, } \\
\text { depression, } \\
\text { anxiety; TP5: } \\
\text { Hypomanic, } \\
\text { persecutory } \\
\text { delusions, } \\
\text { hallucinations, } \\
\text { punding, } \\
\text { suicide threats } \\
\text { and } \\
\text { parasuicidal } \\
\text { acts }\end{array}$ & $\begin{array}{l}\text { DAA: S1: TP1 } \\
\text { CBG; TP2 CBG } \\
4 \text { mg/day; Self- } \\
\text { medicated with } \\
\text { double that dose } \\
\text { of CBG; TP3 CBG } \\
\text { withdrawn; TP4 } \\
\text { RGT } 4 \text { mg/day. } \\
\text { S2: TP3: CBG } \\
\text { 4 mg/day; TP4 } \\
\text { PRG 3.5 mg/day } \\
\text { added; TP5: CBG } \\
\text { and PRG } \\
\text { withdrawn; ROP } \\
\text { (self- } \\
\text { administered } \\
\text { 32 mg/day). } \\
\text { DBS:S1 --, S2 -- } \\
\text { Other drugs/ } \\
\text { therapy: S1: Pre- } \\
\text { PD diagnosis } \\
\text { tried ecstasy and } \\
\text { cocaine; TP1: BZ } \\
4 \text { mg/day; TP2: } \\
\text { BZ } 4 \text { mg/day; } \\
\text { TP4: BZ X 10 mg/ } \\
\text { day S2: Used } \\
\text { various } \\
\text { recreational } \\
\text { drugs as young } \\
\text { woman; TP3: } \\
\text { ENC } 4 \text { mg/day; } \\
\text { TP5: } \\
\text { antidepressants, } \\
\text { atypical } \\
\text { neuroleptics, and } \\
\text { psychotherapy }\end{array}$ & $\begin{array}{l}\text { Quality: S1: (--), S2 TP5 continued to paint } \\
\text { successfully } \\
\text { Motivation/creativity: S1: (--), S2 (--) S2: } \\
\text { TP1: After LD introduced, started to paint in an } \\
\text { obsessive manner. TP2: Lacked the creativity } \\
\text { for painting. TP5: She only felt "on"' when } \\
\text { hypomanic with marked dyskinesias which she } \\
\text { incorporated into her painting technique, } \\
\text { "danced pictures; continued to paint } \\
\text { successfully. }\end{array}$ & $\begin{array}{l}\text { Evaluation method: } \\
\text { author assessment and } \\
\text { discussion with } \\
\text { patients. Note that time } \\
\text { periods (far left } \\
\text { column) appear to be } \\
\text { related to age and/or } \\
\text { changes in medication. } \\
\text { However, this is not } \\
\text { clearly specified. }\end{array}$ \\
\hline
\end{tabular}




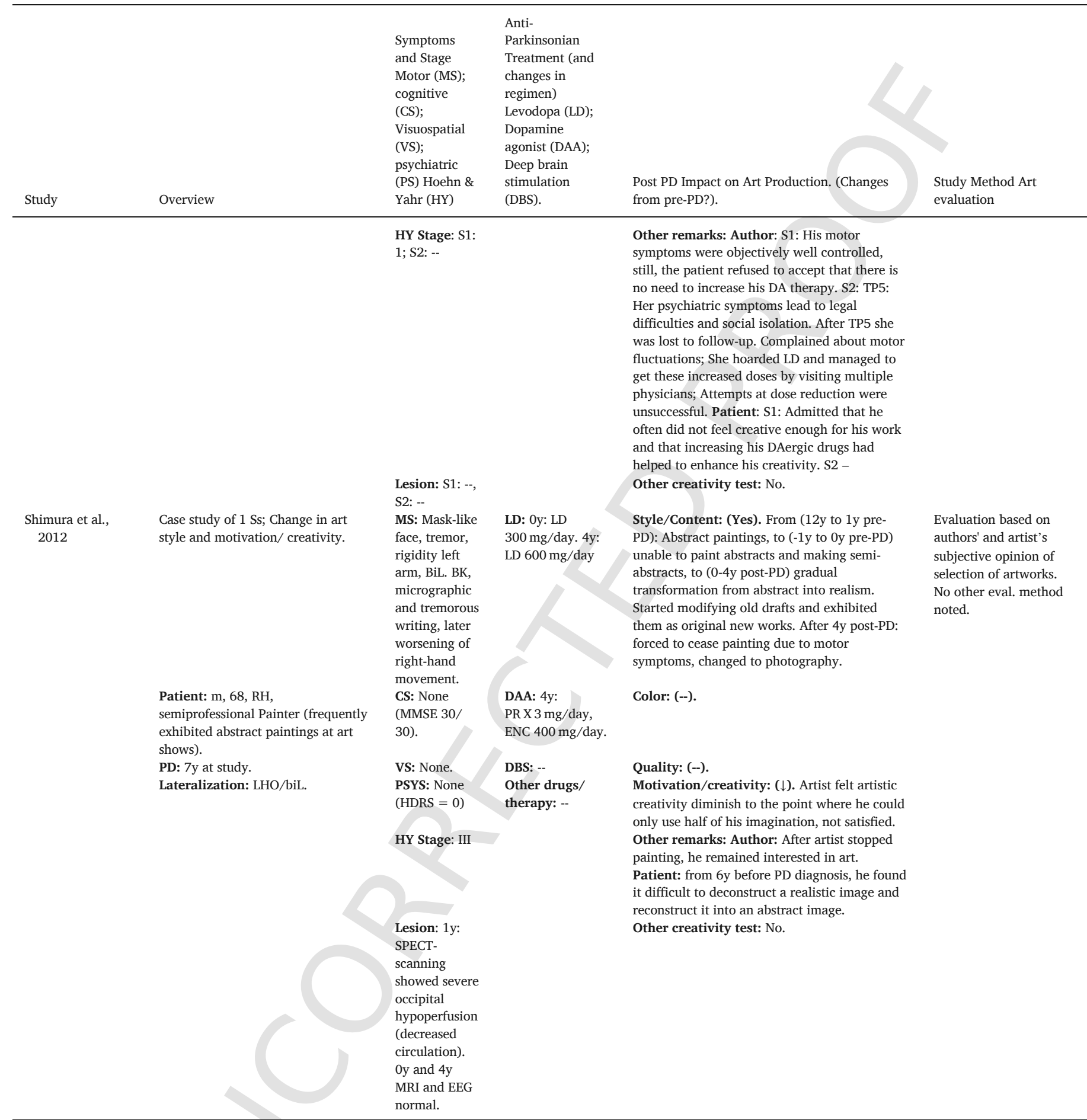




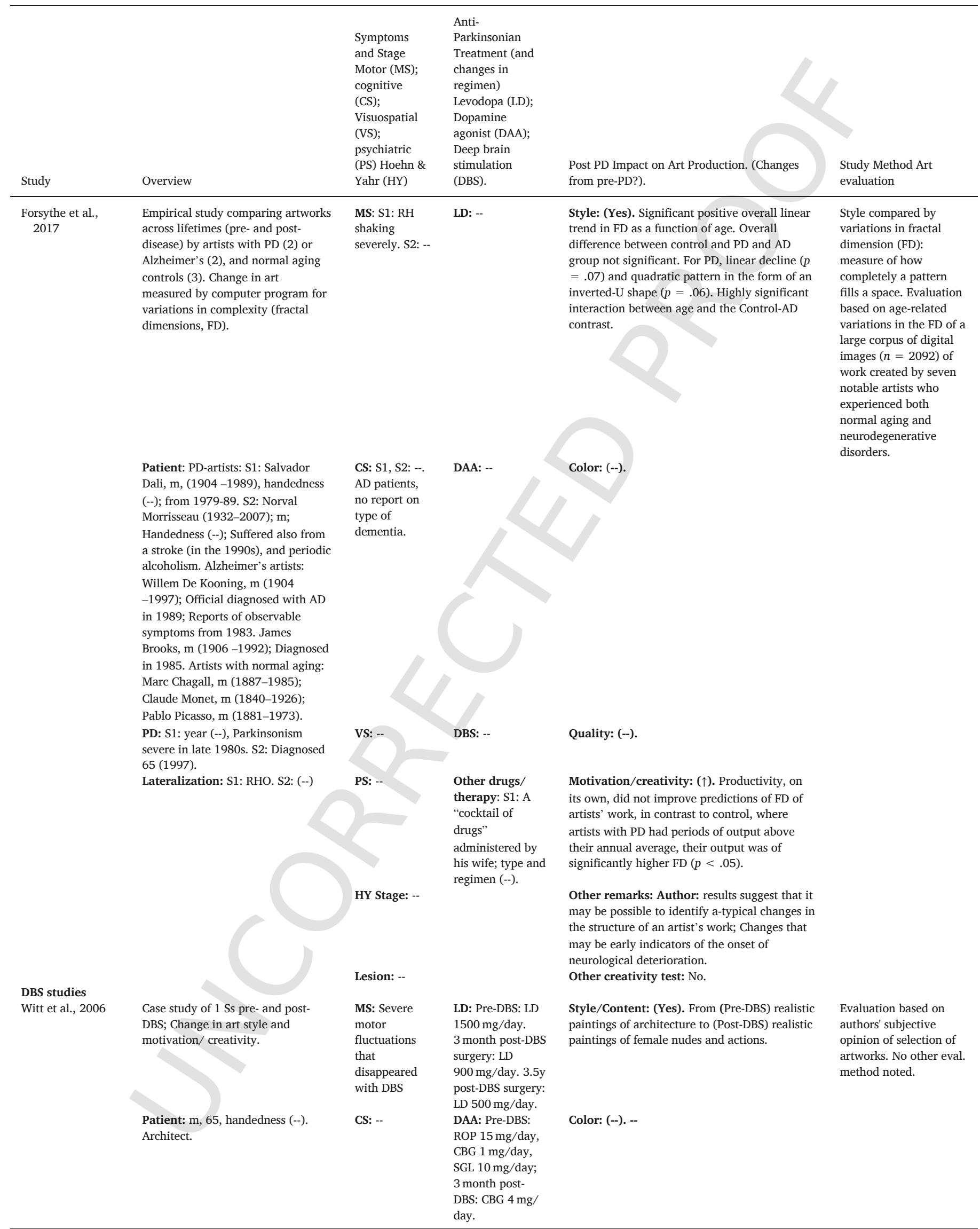


Drago et al., 2009a
Anti-

Parkinsonian

Treatment (and

changes in

regimen)

Levodopa (LD);

Dopamine

agonist (DAA);

Deep brain

stimulation

(DBS).

DBS: Dorsal

border zone of the STN DBS:

Strength

stimulation: $2 \mathrm{~V}$.

$2 y$ post-DBS:

Strength

Lateralization: --

PS: 3 month

stimulation $4 \mathrm{~V}$

Other drugs/

post-DBS:

Mood

therapy: $3.5 y$

post-DBS: COMT

fluctuation

decreased but

was

constantly

elevated: $3.5 y$

post-DBS:

mood was

well balanced

and stable.

HY Stage: --

Lesion: --

MS: RL

Case study of 1 Ss pre- and post-DBS with comparison of produced art over four time periods (Early

Presymptomatic, Later

Presymptomatic, Symptomatic, post-DBS) by panel of judges.

Patient: f, 69, RH, completed two years of college and primarily worked as an artist (painter),
LD: Pre-DBS: N/ A. Post-DBS: CPD/LD 25/100

1.5 tablets $\times 4$ a day

DAA: Pre-DBS: N/A. Post-DBS: MEM $10 \mathrm{mg} /$ day (also anti-

dementia),

PR X 100 mg tremor, DBS improving the

patient's

motor

disabilities,

several

primitive

reflexes (suck,

root, grasp,

Myerson's

sign/glabella

reflex).

UPDRS III, off

medication-off

DBS: 29; On

medication-off

DBS: 25 , on

medication-on

DBS: 23.

CS: Problems

with memory

(Geriatric

Depression

Scale 2/15;

Dementia

Rating Scale

129/144;

MMSE: 27/

30); Mild
Post PD Impact on Art Production. (Changes from pre-PD?).

Quality: (--). --

Quis

\section{Motivation/creativity: $(\uparrow)$. Drawing}

production increased with DBS. Paintings of nudes decreased two years later.
Study Method Art

evaluation
Other remarks: Wife: reported prolific artmaking post-DBS, concentrating exclusively on females, their house being full of these. Had never painted nudes before. Neither he nor wife reported hypersexual behavior after surgery nor any other behavioral changes. Patient: Logorrhoeic and optimistic comments written at bottom of paintings.

Other creativity test: No.

Style/Content: (Yes). From (pre-DBS) less realistic, more colorful and abstract art. (PrePD not clearly explained).

Color: (Yes). post-DBS became less colorful (patient mentioned). a) Assess 59 paintings. Production: divided into four time periods: Early Presymptomatic (14 paintings, 2 years), Later Presymptomatic (9 paintings, 16 years), Symptomatic $(9,14 y)$, post-DBS Symptomatic (27, 4y).
Evaluation of artworks based on 9 judges ( $6 \mathrm{f}$, $3 \mathrm{~m}$; age range 22 to 40y, $\mathrm{M}=31.4$; No information on judges' art experience). Judges not aware of patient's clinical diagnosis or when paintings produced. 


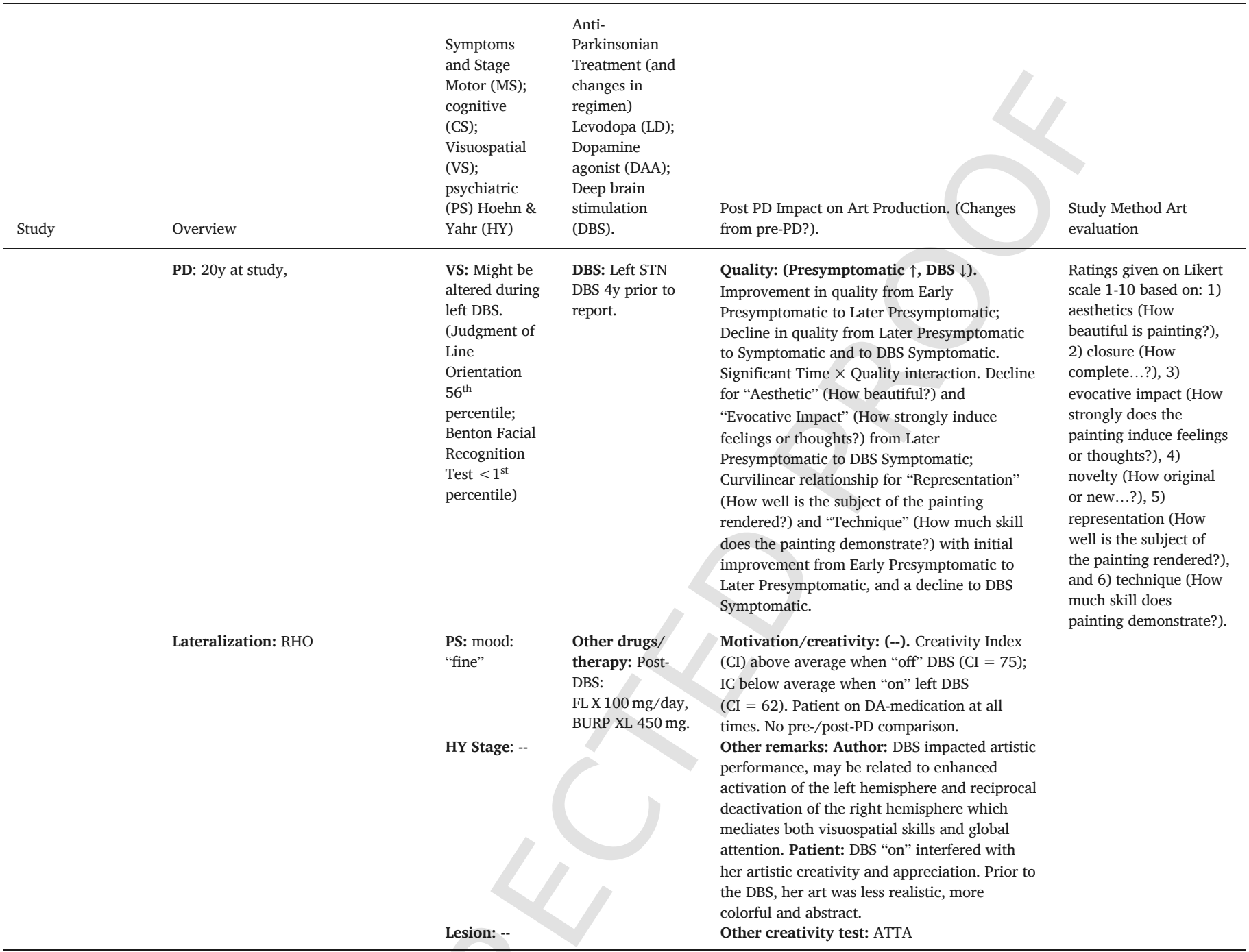

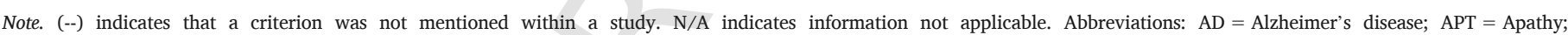

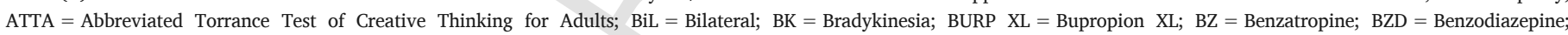

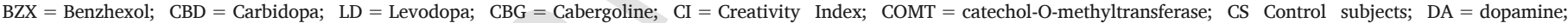

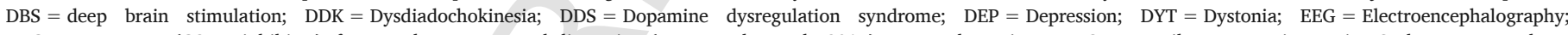

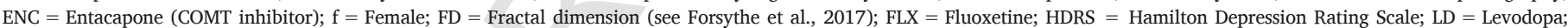

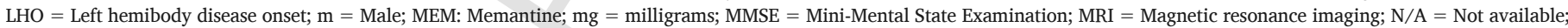

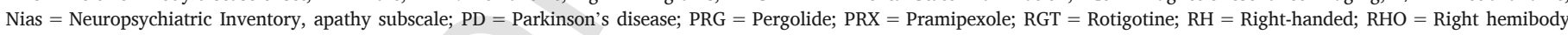

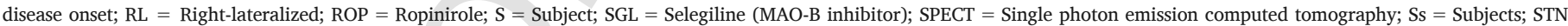
DBS = Subthalamic nucleus deep brain stimulation; t.i.d. = Thrice daily; TP = Time period; UPDRS III = Unified Parkinson'sDisease Rating Scale (III = motor section); V = Voltage

reward processing (Elliott et al., 2000; Takeuchi et al., 2010). The mesocortical pathway transmits DA from the ventral tegmental area to the prefrontal cortex (PFC), especially dorsolateral regions (dlPFC), related more to executive functions, emotional response, or judgment (Ballard et al., 2011), as well as eventually through parietal, occipital and temporal areas. Neuropathological alterations can also concern noradrenergic, serotonergic, or cholinergic systems, and the central and peripheral nervous systems (Lim et al., 2009; Xiao et al., 2016).

In addition, PD also involves accumulation of Lewy bodies-abnormal aggregates of alpha-synuclein protein-which develop inside nerve cells and lead to lesions, which would also disrupt function (see Braak et al., 2003 for stages; also Hawkes et al., 2010; Lim et al., 2009). These lesions often begin appearing up to $20+$ years before diagnosis (Lim et al., 2009), and also involve areas primarily related to DA pathways, spreading via a more or less standardized progression from the brainstem and main seats of DA production to limbic and then cortical areas (Table 1$)^{2}$

\subsection{PD symptoms}

The above changes coincide with a range of symptoms, which also tend to accumulate in a general progression. PD is again usually diagnosed (Table 1) by motor issues (Sveinbjornsdottir, 2016) involving depletion/lesion in neurons in the vSNc. Hallmark symptoms include slowed/impaired movement, rigidity, postural instability, and tremor (Okun, 2012). It is estimated that up to $80 \%$ of the dopaminergic cells in the nigrostriatal system are actually lost before motor symptoms even appear (Chung et al, 2001; Sveinbjornsdottir, 2016), with deterio-

2 Although the validity of staging has gained acceptance, research has shown that lesions can occur in otherwise healthy individuals, perhaps tied to aging. As noted by Lim et al. (2009), even in patients with PD, lesions are difficult to tie to specific symptoms from the disease (see also Cao et al., 2017). 
Table 3

Studies on Parkinson's Disease and spontaneous artistic creativity.

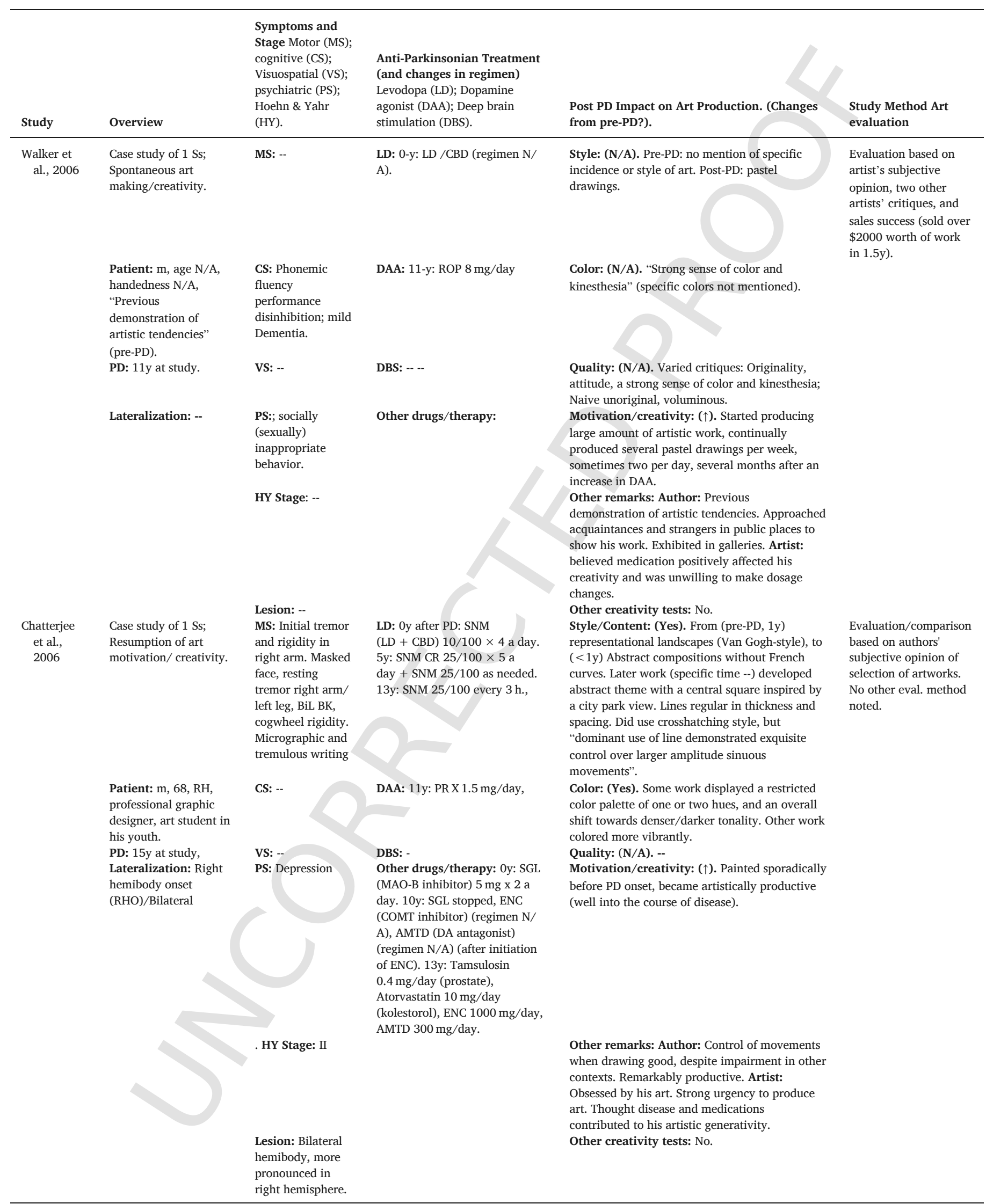




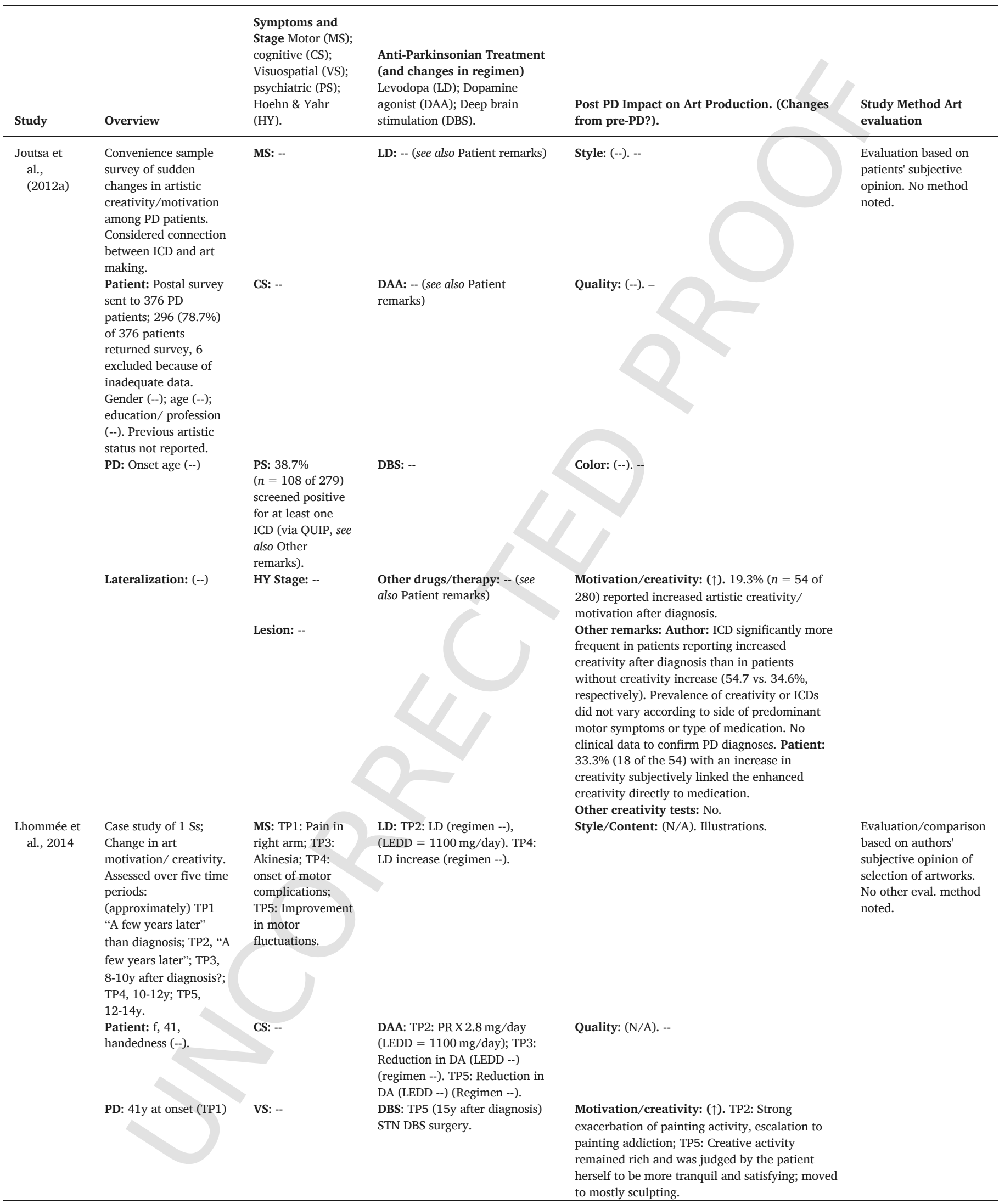




\begin{tabular}{|c|c|c|c|c|}
\hline Study & Overview & $\begin{array}{l}\text { Symptoms and } \\
\text { Stage Motor (MS); } \\
\text { cognitive (CS); } \\
\text { Visuospatial (VS); } \\
\text { psychiatric (PS); } \\
\text { Hoehn \& Yahr } \\
\text { (HY). }\end{array}$ & $\begin{array}{l}\text { Anti-Parkinsonian Treatment } \\
\text { (and changes in regimen) } \\
\text { Levodopa (LD); Dopamine } \\
\text { agonist (DAA); Deep brain } \\
\text { stimulation (DBS). }\end{array}$ & $\begin{array}{ll}\text { Post PD Impact on Art Production. (Changes } & \begin{array}{l}\text { Study Method Art } \\
\text { evaluation }\end{array} \\
\text { from pre-PD?). } & \end{array}$ \\
\hline & Lateralization: $\mathrm{RHO}$ & $\begin{array}{l}\text { PS: TP1: DEP. } \\
\text { TP2: Nocturnal } \\
\text { hyperactivity, } \\
\text { psychosis, DA } \\
\text { addiction, painting } \\
\text { addiction, } \\
\text { compulsive buying } \\
\text { (of painting } \\
\text { material), risk- } \\
\text { taking behavior, } \\
\text { life-style change } \\
\text { (continuous } \\
\text { partying). } \\
\text { HY Stage: -- } \\
\text { Lesion: -- }\end{array}$ & $\begin{array}{l}\text { Other drugs/therapy: TP3: } \\
\text { CZP (antipsychotic drug) } \\
\text { (Regimen --). }\end{array}$ & $\begin{array}{l}\text { Other remarks: Author: Behavioral } \\
\text { modifications upset her social equilibrium. } \\
\text { Patient: Was happy. Was obsessed with } \\
\text { painting. Then, the urge to paint became } \\
\text { uncontrollable. Started painting on the walls, the } \\
\text { furniture, even the washing machine. } \\
\text { Other creativity tests: No }\end{array}$ \\
\hline
\end{tabular}

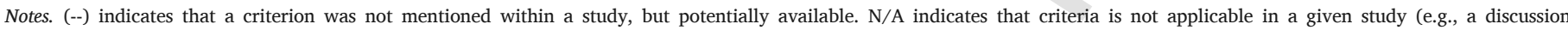

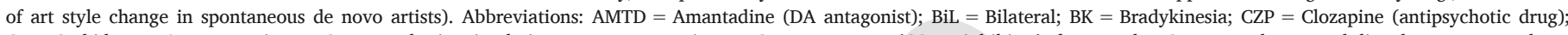

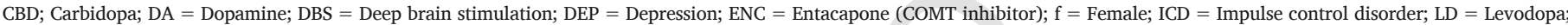

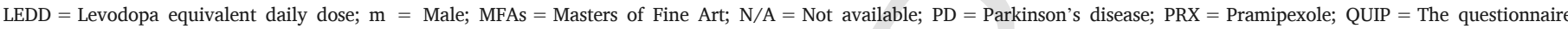

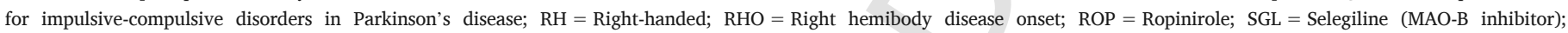
SNM = Sinemet; SNM CR = Sinemet CR (Carbidopa-levodopa Sustained-Release); Ss = Subjects; STN DBS = Subthalamic nucleus deep brain stimulation; TP = Time period.

ration leveling off with subsequent treatment (Jellinger, 2014; Martinez-Martin et al., 2011). Attention has also increasingly been given to non-motor symptoms. These can occur up to 20 years before diagnosis (Table 1), effect $85-90 \%$ of patients (Jellinger, 2014; Martinez-Martin et al., 2011), and often progress in severity with the disease (Hawkes et al., 2010).

Autonomic symptoms relate to damage in the brainstem and thus are some of the first to appear. These include sleep disorder, excess production of saliva, sexual dysfunction, etc. (Bayulkemand and Lopez, 2011; Okun, 2012). Cognitive symptoms include deficits with attention, memory, and language, as well as increased apathy, reduced motivation or capacity to experience pleasure (Connolly and Lang, 2014; Grover et al., 2015; le Bouc et al., 2016). Emotional symptoms include reduced ability to manage emotional information, especially in social situations (Enrici et al., 2015), and reward-related issues noted above. Cognitive and emotional symptoms can presumably be connected to alterations to the various reward-related regions (ventral tegmental area/ventral striatum), as well as to the vSNc/striatum nigrostriatal pathway related to habit formation, and hippocampus (Calabresi et al., 2013) and tend to show more interpersonal differences regarding if and when they arise.

Sensory symptoms include deficits in the sense of smell, often very early in the disease, and, later, vision (Bayulkemand and Lopez, 2011; Chaudhuri et al., 2006; Sveinbjornsdottir, 2016), including reduced contrast sensitivity, color discrimination (both red-green and yellow-blue varieties: Alenicova et al., 2017; Oh et al., 2011), motion detection, and difficulties related to perception of space (Davidsdottir et al., 2005), visual recognition (Bodis-Wollner, 2009), and illusions (Diederich et al., 2014). Psychiatric disorders include depression, anxiety, dementia (Bayulkemand, and Lopez, 2011; Connolly and Lang, 2014; Grover et al., 2015), hallucinations (Connolly and Lang, 2014), and impulse control disorders.

\subsection{Antiparkinsonian treatments}

After diagnosis, one other aspect of PD involves treatments, which may themselves contribute to symptoms or other changes (see Appendix Table A1 for detailed review). Currently there is no proven disease- modifying therapy. Thus, treatments are primarily aimed at symptom relief (Tarsy, 2016). The most common initial therapy involves DA-replacement (Connolly and Lang, 2014; Sveinbjornsdottir, 2016), typically via levodopa, the amino acid precursor to DA (introduced in oral form in 1967; Tolosa et al., 1998). This can cross the protective blood-brain barrier whereas DA itself cannot. As a means of overcoming side effects (motor fluctuations or tremor) and loss of levodopa efficacy, DA agonists also began to be routinely used after the discovery of bromocriptine in 1974. These are typically administered in tandem with levodopa, in some cases several years after initial treatment, and increase receptivity of brain areas to DA. They also tend to impact more tonic DA transmissions, as opposed to levodopa which concerns both tonic and phasic aspects (Schultz, 2016). DA agonists may also have side effects-diminished impulse control, heightened or addictive pleasure, and insomnia. Long-term levodopa/agonist usage may also lead to abuse or addiction (dopamine dysregulation syndrome, 'DDS'). Treatment may also involve combinations with other medications (e.g., MAO-inhibitors), however, these are not typically related to the main artistic results below.

In order to reduce reliance on medication or to combat unresponsive symptoms, doctors may also utilize deep brain stimulation (DBS). This involves implanting electrodes in one or more of three gray-matter structures - the thalamus, the globus pallidus, and most commonly the subthalamic nucleus (Connolly and Lang, 2014). The exact physiological effect of DBS is currently debated, but it is thought that stimulation by high frequency electrical impulses can block or disrupt typical neuronal impulses that lead to motor symptoms (Apetauerova et al., 2006; Moro and Lang, 2006), but can also lead to numbness and some mood or mental changes.

\subsection{PD diagnosis scales and timeline}

The above factors can then be united into a general progression-following Hawkes et al. (2010) who proposed a timeline for PD symptoms (typically scored via the Unified Parkinson's Disease Rating Scale, Fahn et al., 1987; see Goetz et al., 2007 for an update), with the Hoehn and Yahr (HY) staging of treatment and motor issues (Hoehn and Yahr, 1967), and with Braak et al.'s (2003) stages of brain damage/lesions. 
Table 4

Other Studies on PD and general creativity or PD aspects, with artists, or Art viewing.

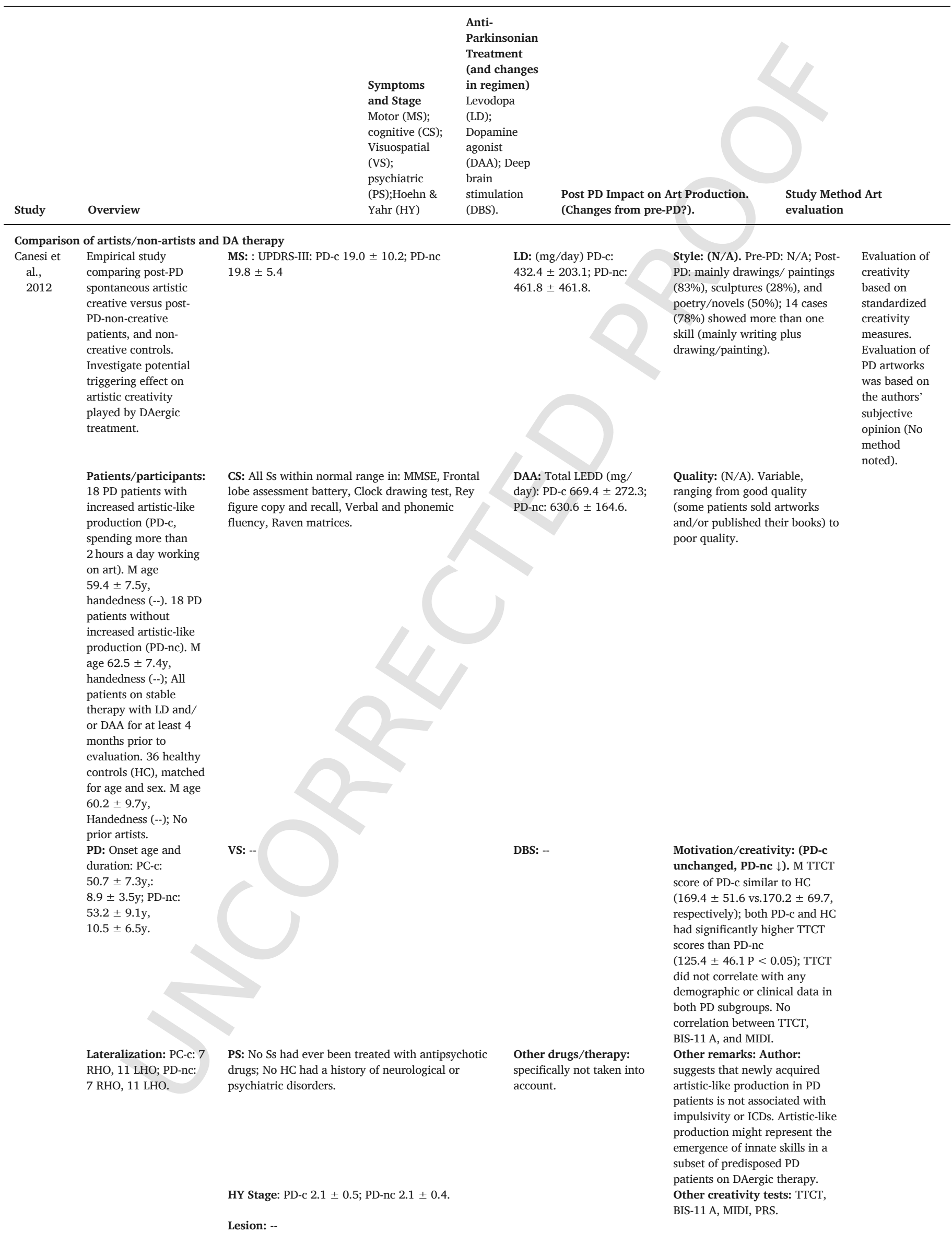




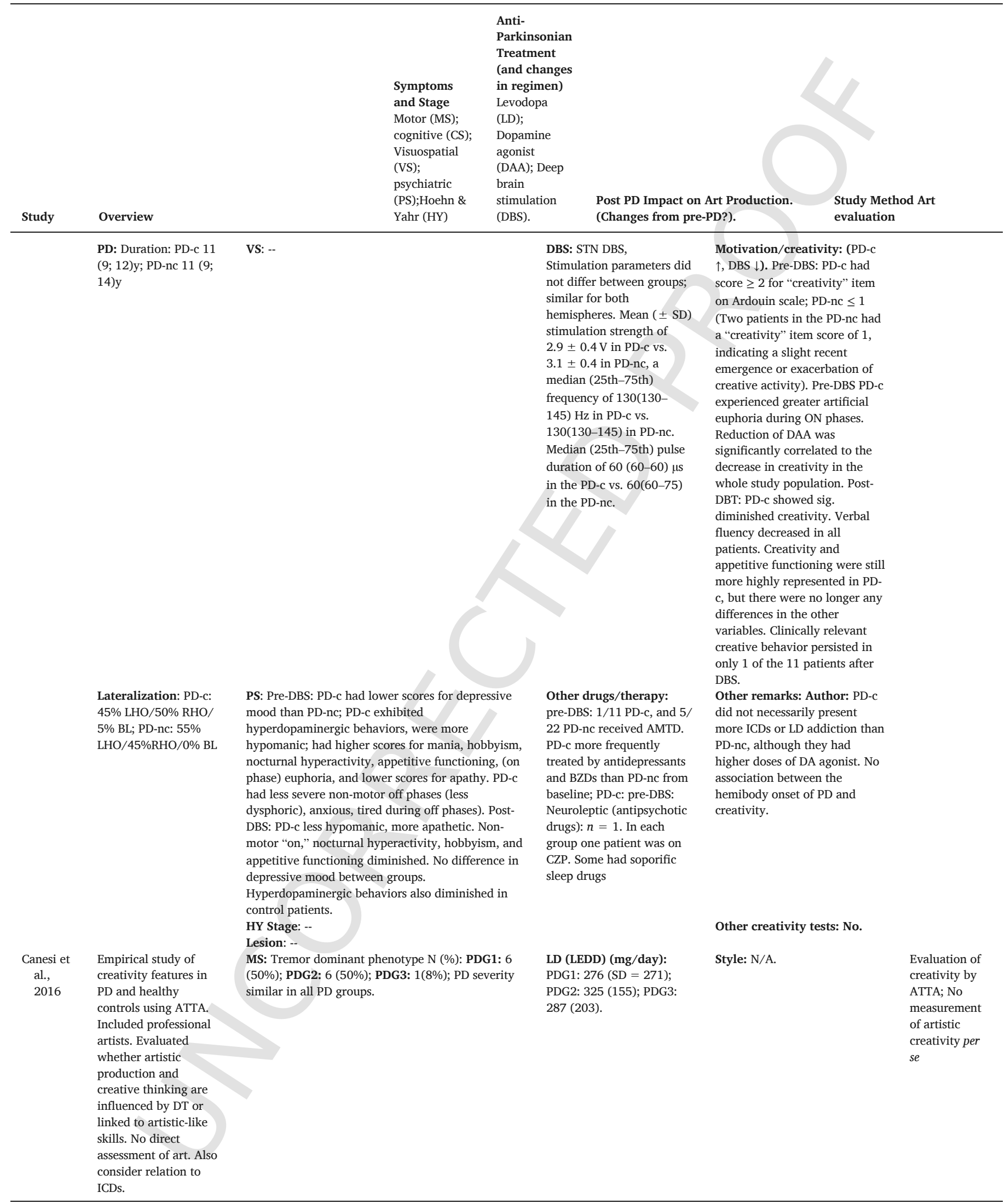




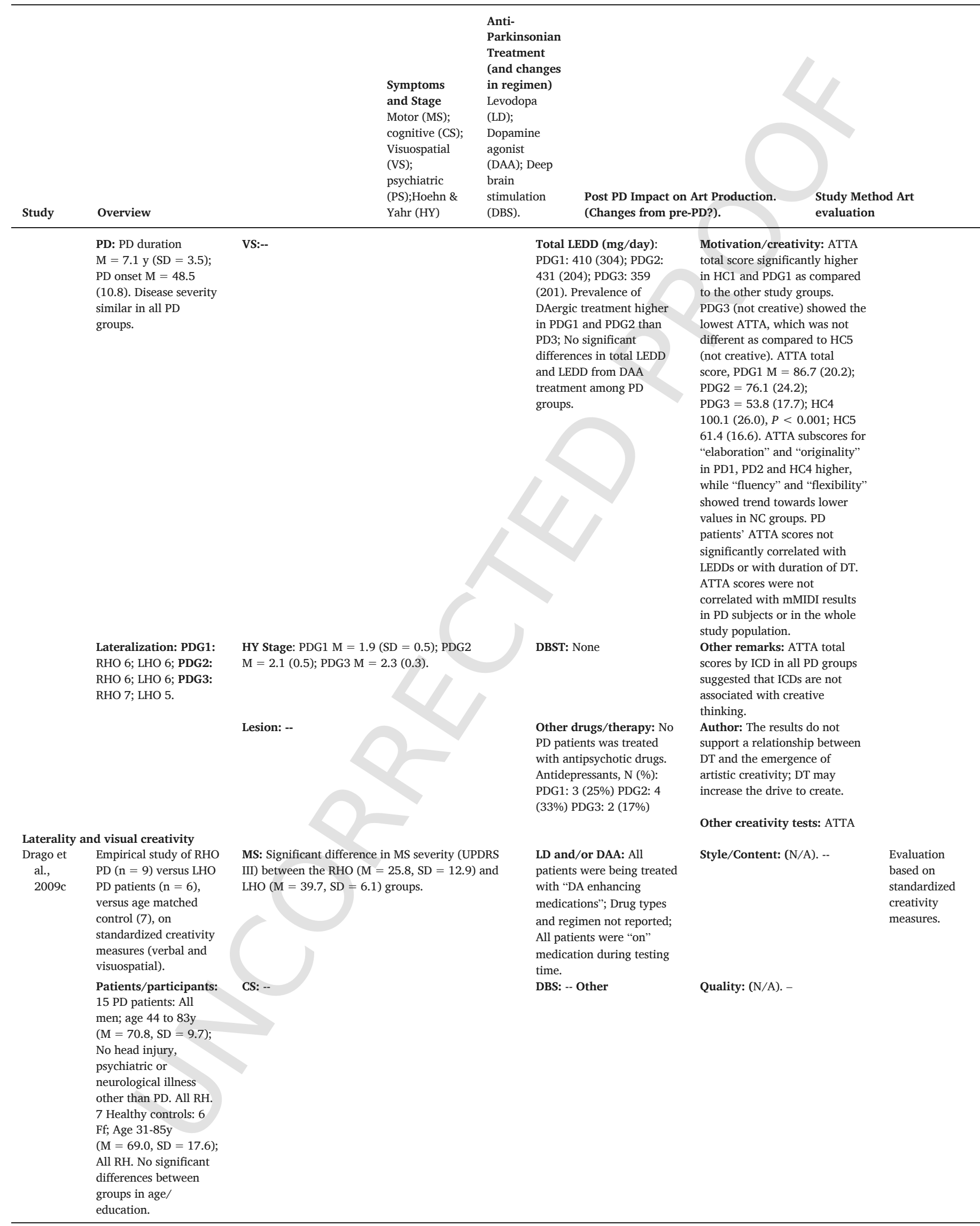




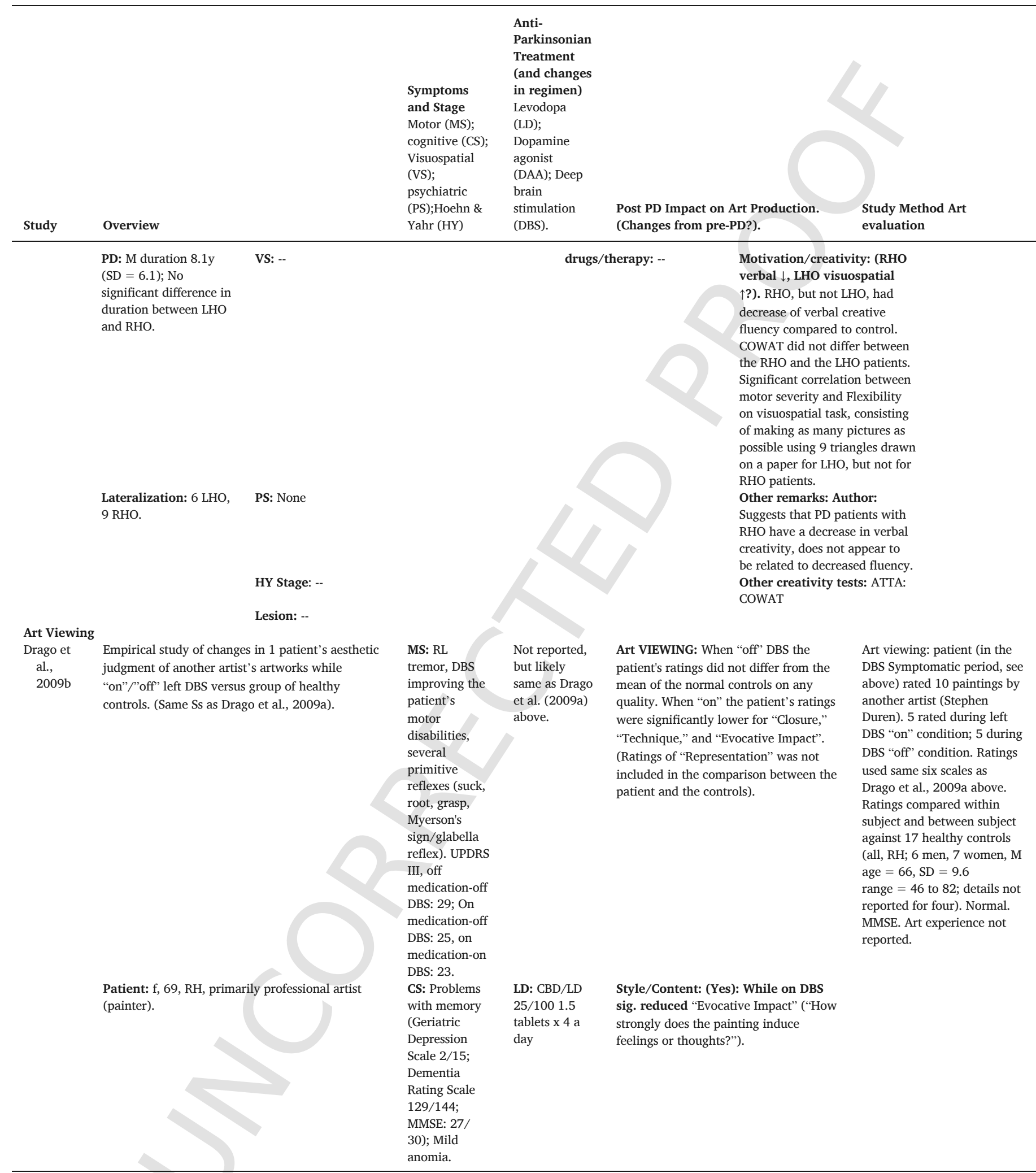




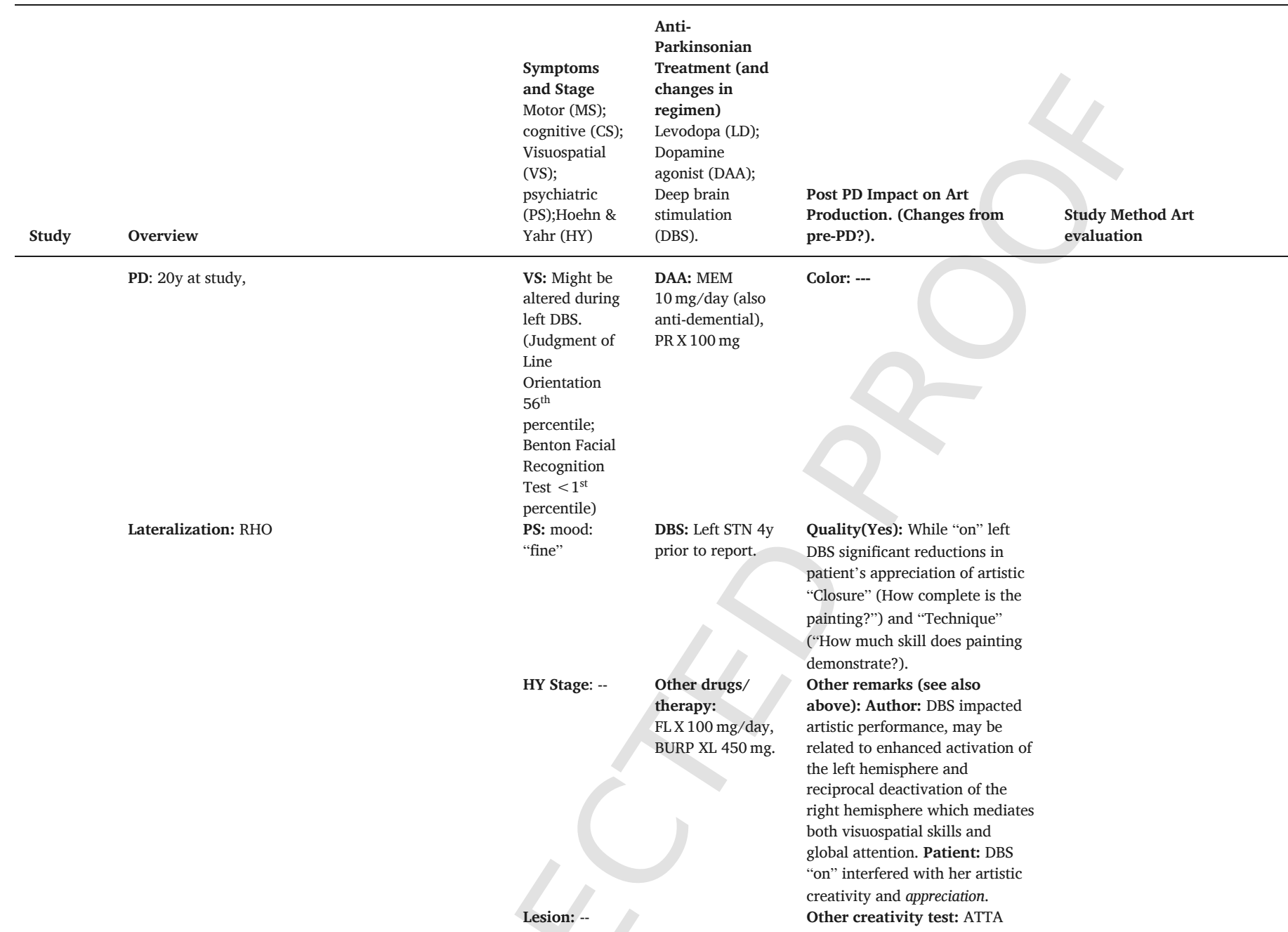

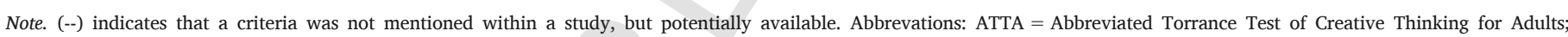

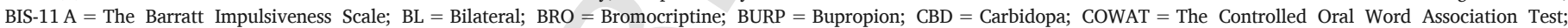

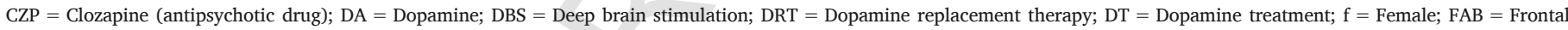

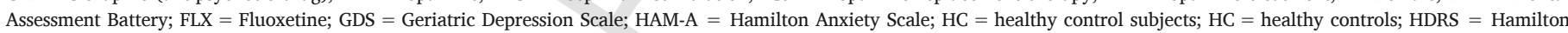

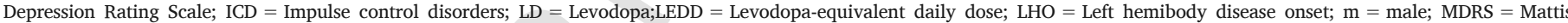

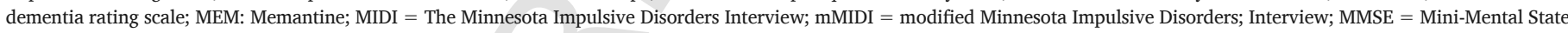

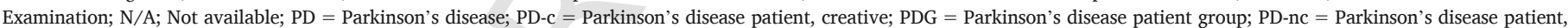

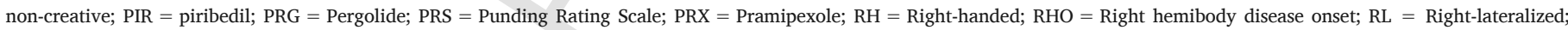

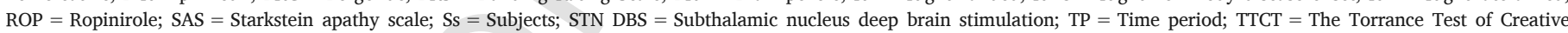
Thinking; UPDRS = Unified Parkinson'sDisease Rating Scale (III = motor section).
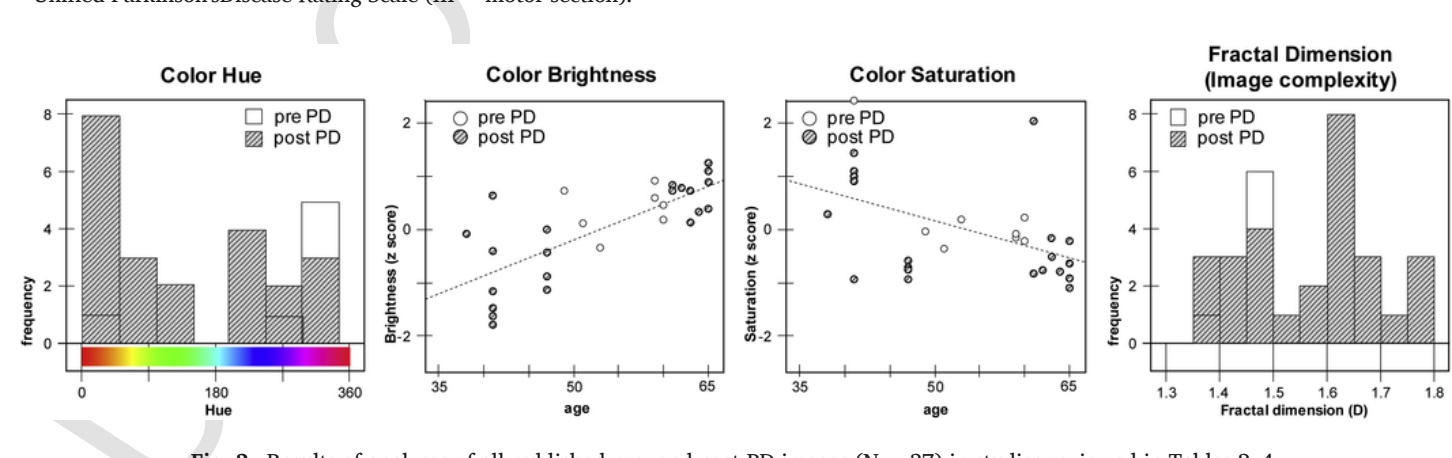

Fig. 3. Results of analyses of all published pre- and post-PD images $(\mathrm{N}=37)$ in studies reviewed in Tables 2-4.

We have combined these, with additional discussions of symptoms relating to premotor issues (Schrag et al., 2015) and pharmacotherapy in Table 1 . This suggests a general timespan of around 40 years: 20 years involving changes in premotor areas of the brain, hallmarked by autonomic symptoms, as well as loss of the sense of smell; followed by cognitive and emotional symptoms typically occurring from 3 years before to several years after diagnosis; followed by eventual onset of motor symptoms/diagnosis/treatment (HY Stage 1, Braak Stage III); and then followed by more cognitive, emotional, and visual issues becoming salient in Stage 4, and up to 20 years of living with recognized PD. It is also important to note that despite certain uniformity, the disease does show asymmetry, especially at onset, in specific motor and cognitive 


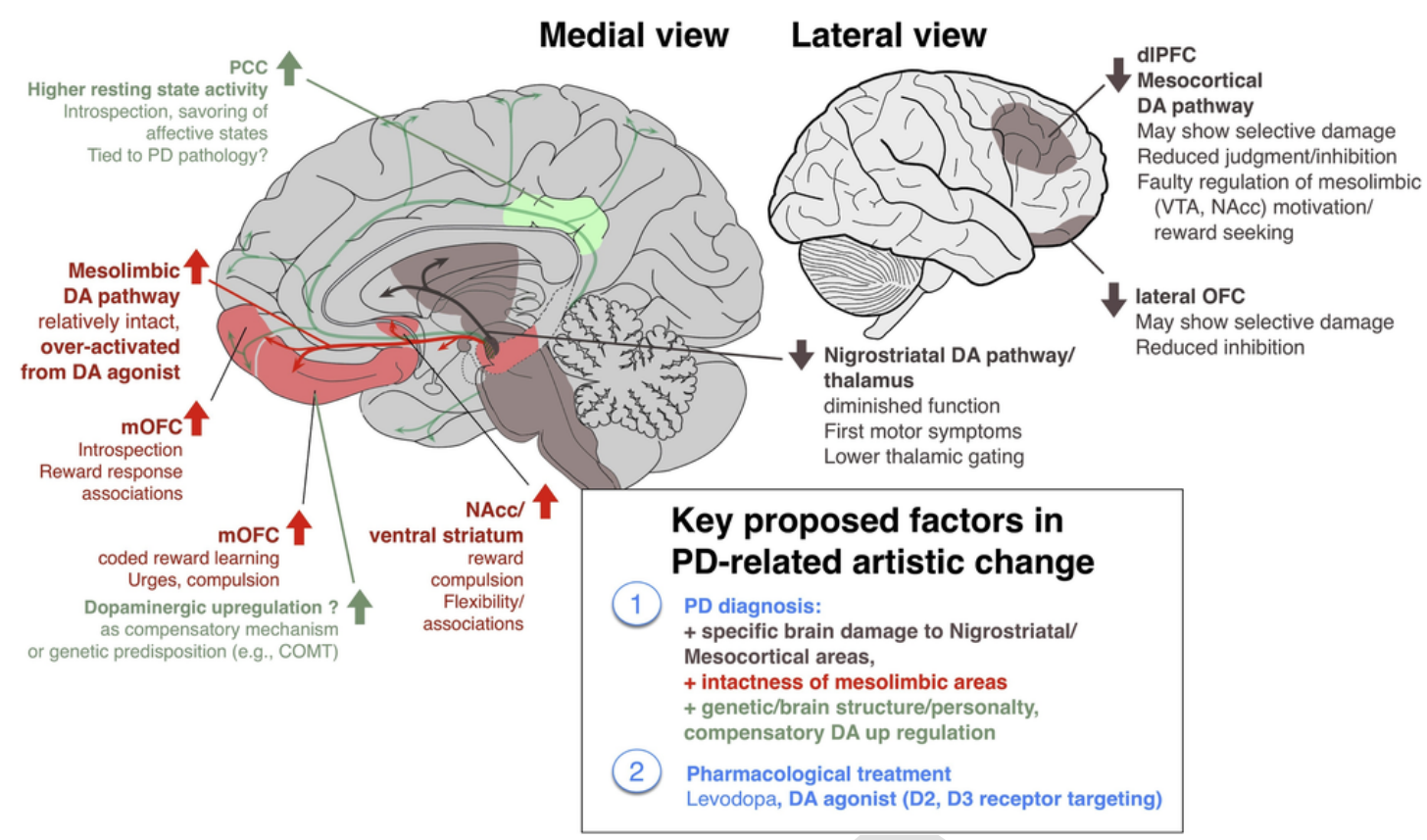

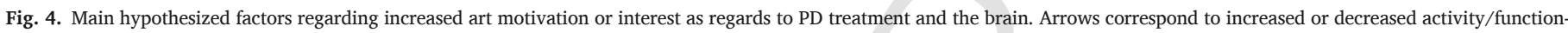
ality.

deficits, indicating lack of one distinctive profile of PD (Verreyt et al., 2011).

\section{Studies on PD and changed or awakened artistic creativity or production}

Embedded within the general symptoms and factors above, an emerging finding then involves a sudden/redoubled interest in or changes with production of visual art. These have typically been documented in the form of clinical case reports, often with one or a handful of patients, and concern changes in the period following diagnosis and treatment (e.g., beginning from HY Stage 1/Braak Stage 3 above). The search procedure, described in the accompanying footnote, ${ }^{3}$ included all known papers to date. PD cases are also reviewed extensively in Tables 2 and 3. In order to provide a systematic review, the tables, as comprehensively as possible, list patient background, PD symptoms, medications/changes, and art assessment methodology. We also consider studies that assessed general creativity or specific PD-related issues, incorporating or assessing visual artists (Table 4).

\subsection{Prior artists and changes in motivation, style, and/or quality}

The first published study (Lakke, 1999), as well as the first published discussion of this topic in general, considered 40 professional artists - with a focus on one sculptor, Horst Aschermann-comparing artworks made before and after onset of PD. Lakke (p. 471) originally hypothesized that, rather than any improvements or maintenance of ability, artists with PD "might be impoverished in originality and creativity," since this requires "organization of knowledge ... novel, unique associations ...with modes of expression," etc. Contrary to ex-

3 To create this review, we employed the search terms "art," "artist," "creativity," "drawing," "painting," "aesthetic," and "artistic production," in databases for social and medical sciences (Scopus, PubMed, Google Scholar). This returned 16 papers. Although connection of PD to art making has probably been noted anecdotally in clinical discussion for at least a century (Lakke, 1999), according to Lakke, such clinical or empirical consideration was not realized prior to his 1999 study. We also found no prior analyses. pectations, no decline in pictorial capacity was reported. Lakke (p. 473) in fact concluded that almost all of the artists showed "continuing and maturing creativity." Lakke also reported other intriguing observations, supported in subsequent studies. Some patients noted a redoubled focus and urge to make artworks, or even experiencing a trancelike state during hyperkinetic periods, often attributing their behavior to antiparkinsonian medication. Lakke (p. 471) also reported some stylistic changes, involving "awkwardness with perpendicular strokes," an "unusual manner of hatching," as well as "changes in format [and] theme" (not further articulated), with the art involving emphasis on mood and reflections. The study also was typical for other methodological issues found below. The comparisons of artworks were based on the author's observation, with no clear set of factors, as well as patients' subjective judgments (as reported by the author), with no record of medication.

This paper was followed by a handful of others showing similar findings. Pinker (2002) reported an exhibition including three visual artists comprised of works completed before and after diagnosis, noting it was again "practically impossible to determine which canvases predate[d] the clinical symptoms" (p. 224). Pinker also noted that one artist stated that she thought that her paintings had improved, involving a change in style which was less precise but more vibrant, and which she felt had become more creative and suggested medication as key in enhancing her imagination.

Kulisevsky et al. (2009) presented an amateur painter whose interest in art had decreased eight months prior to diagnosis, but however following levodopa and DA agonists (the ergoline derivate Cabergoline, CBG, see Table A1), resumed painting. This "was accompanied by a remarkable change in style and attitude" (p. 817), moving from realistic, detailed, figurative art requiring months to complete a painting, to production of more than one painting per week with a more impressionistic emphasis on light and color rather than shape/detail, which the patient attributed to "a need to express refreshed inner emotions" (p. 817). Kulisevsky et al. (p. 818) also remark that the patient showed new commercial success, and withdrawal of DA agonist for six weeks led to worsening apathy, mood, and decrease in painting.

Schwingenschuh et al. (2010) reported one advertising artist/hobby painter and one professional painter, highlighting one other key aspect 
Table A1

Overview of Main PD-related pharmacotherapy and DBS treatments.

\begin{tabular}{|c|c|c|}
\hline $\begin{array}{l}\text { Generic class; Drug } \\
\text { name; Trade/brand } \\
\text { name examples } \\
\text { [main targeted } \\
\text { receptors] }\end{array}$ & Description and clinical use & $\begin{array}{l}\text { Side effects (only } \\
\text { potentially related } \\
\text { to making/viewing } \\
\text { art or creativity) }\end{array}$ \\
\hline $\begin{array}{l}\text { Dopamine (DA) } \\
\text { replacement } \\
\text { Levodopa (L-DOPA } \\
\text { or LD) } \\
\text { Mono-ingredient: } \\
\text { Dopar, Larodopa. } \\
\text { Multi-ingredient } \\
\text { medications: } \\
\text { carbidopa (CBD)/ } \\
\text { entacapone } \\
\text { (ENC)/levodopa: } \\
\text { Stalevo; carbidopa/ } \\
\text { levodopa: Sinemet } \\
\text { (SNM), Rytary, } \\
\text { Sinemet CR (SNM } \\
\text { CR), Duopa. }\end{array}$ & $\begin{array}{l}\text { Amino acid precursor to } \\
\text { neurotransmitters DA, } \\
\text { norepinephrine } \\
\text { (noradrenaline), and } \\
\text { epinephrine (adrenaline), } \\
\text { introduced in 1967; L-DOPA } \\
\text { crosses the protective blood- } \\
\text { brain barrier whereas DA } \\
\text { cannot. Increases DA } \\
\text { concentration in the treatment } \\
\text { of PD. Affects both tonic and } \\
\text { phasic DA transmission. } \\
\text { Carbidopa is a DOPA } \\
\text { decarboxylase inhibitor, which } \\
\text { reduces peripheral adverse } \\
\text { effects of levodopa. Entacapone } \\
\text { is a catechol-O- } \\
\text { methyltransferase (COMT) } \\
\text { inhibitor, which prolongs the } \\
\text { effect of levodopa. }\end{array}$ & $\begin{array}{l}\text { Common: } \\
\text { Dyskinesia, akinesia, } \\
\text { muscular rigidity, } \\
\text { hypotension, } \\
\text { disorientation and } \\
\text { confusion, extreme } \\
\text { emotional states, } \\
\text { anxiety, excessive } \\
\text { libido, vivid dreams } \\
\text { or insomnia, auditory } \\
\text { or visual } \\
\text { hallucinations, effects } \\
\text { on learning, } \\
\text { somnolence } \\
\text { (sleepiness, } \\
\text { drowsiness) and } \\
\text { narcolepsy. }\end{array}$ \\
\hline $\begin{array}{l}\text { DA agonists, ergoline } \\
\text { Bromocriptine } \\
\text { (BRO): main } \\
\text { targeted receptors, } \\
\text { D2, D3-4 } \\
\text { [Parlodel, Cycloset] } \\
\text { Cabergoline (CBG): } \\
\text { D2, D3-4, 5-HT2 } \\
\text { [Caberlin, Dostinex, } \\
\text { Cabaser] } \\
\text { Pergolide (PRG): D2, } \\
\text { D1, 5-HT2, } \\
\text { serotonin receptors } \\
\text { [Permax, Prascen] } \\
\text { Apomorphine } \\
\text { (APO): D2, D1, D3, } \\
\text { D4 } \\
\text { [Apokyn, Ixense, } \\
\text { Spontane, Uprima]. }\end{array}$ & $\begin{array}{l}\text { Earlier form of agonist derived } \\
\text { from Ergot Alkaloids (ergoline) } \\
\text { introduced in 1970s. Typically } \\
\text { used in conjunction with L- } \\
\text { DOPA or as a monotherapy to } \\
\text { delay the institution of L-DOPA } \\
\text { in early to advanced PD. } \\
\text { Generally, binds to and } \\
\text { activates DA receptors (D1 - } \\
\text { D5, depending on drug, see left } \\
\text { column). Minimizes } \\
\text { fluctuations of motor } \\
\text { symptoms. Affects primarily } \\
\text { tonic DA transmission. }\end{array}$ & $\begin{array}{l}\text { Common: asthenia, } \\
\text { dizziness, headache, } \\
\text { blood pressure } \\
\text { decline; fatigue, } \\
\text { resting leg syndrome } \\
\text { (RLS), sedation, } \\
\text { orthostatic } \\
\text { hypotension, } \\
\text { tachycardia, } \\
\text { dyspnoea, visual } \\
\text { disorders, postural } \\
\text { instability, } \\
\text { somnolence, } \\
\text { confusion, } \\
\text { hallucinations, } \\
\text { delusions. }\end{array}$ \\
\hline $\begin{array}{l}\text { DA agonists, non- } \\
\text { ergoline } \\
\text { Ropinirole (ROP), } \\
\text { D2-D3, D4, 5-HT2, } \\
\text { and } \alpha 2 \text {, [Requip, } \\
\text { Repreve, Ronirol, } \\
\text { Adartrel] } \\
\text { Rotigotine (RGT), } \\
\text { D3, D1, D2, > D4, } \\
\text { D5,[ Neupro] } \\
\text { Piribedil (PIR), D2, } \\
\text { D3 } \alpha 2 \text {, } \\
\text { [Clarium, Pronoran, } \\
\text { Trastal Trivastal, } \\
\text { Rivastan, Pronoran, } \\
\text { Retard] } \\
\text { Pramipexole (PRX), } \\
\text { D3 > D2, } \\
\text { D4[Mirapex, } \\
\text { Mirapexin, Sifrol]. }\end{array}$ & $\begin{array}{l}\text { More recent agonist. Binds to } \\
\text { and activates DA receptors (D1 } \\
\text { - D5, 5-HT2, and } \alpha 2 \text {, } \\
\text { depending on drug). Used in } \\
\text { early PD and PD with motor } \\
\text { fluctuations. Can be combined } \\
\text { with L-DOPA in late-stage } \\
\text { treatment. Reduces dyskinesia, } \\
\text { resting leg syndrome (RLS), } \\
\text { fluctuations of motor } \\
\text { symptoms, and extrapyramidal } \\
\text { symptoms (drug-induced } \\
\text { movement disorders), as well } \\
\text { as psychiatric symptoms } \\
\text { including depression associated } \\
\text { with PD-related bipolar } \\
\text { disease. }\end{array}$ & $\begin{array}{l}\text { Common: dizziness, } \\
\text { dyskinesia, confusion, } \\
\text { diaphoresis } \\
\text { (sweating), headache, } \\
\text { sleep disturbances, } \\
\text { somnolence, fatigue, } \\
\text { agitation, } \\
\text { hypotension, } \\
\text { orthostatic } \\
\text { hypotension } \\
\text { (resulting in } \\
\text { dizziness, } \\
\text { lightheadedness, } \\
\text { fainting), syncope } \\
\text { (fainting), asthenia } \\
\text { (weakness), } \\
\text { extrapyramidal } \\
\text { movement. }\end{array}$ \\
\hline
\end{tabular}

Table A1 (Continued)

\begin{tabular}{|c|c|c|}
\hline $\begin{array}{l}\text { Generic class; Drug } \\
\text { name; Trade/brand } \\
\text { name examples } \\
\text { [main targeted } \\
\text { receptors] }\end{array}$ & Description and clinical use & $\begin{array}{l}\text { Side effects (only } \\
\text { potentially related } \\
\text { to making/viewing } \\
\text { art or creativity) }^{\text {a }}\end{array}$ \\
\hline $\begin{array}{l}\text { Deep brain } \\
\text { stimulation (DBS): } \\
\text { Non- } \\
\text { pharmacological } \\
\text { surgery }\end{array}$ & $\begin{array}{l}\text { Surgical technique involving } \\
\text { implanting electrodes in one or } \\
\text { more of three gray-matter } \\
\text { structures: thalamus, globus } \\
\text { pallidus (usually bilaterally), } \\
\text { subthalamic nucleus (usually } \\
\text { bilaterally, most common). } \\
\text { High frequency electrical } \\
\text { impulses are then sent to target } \\
\text { area. Exact physiological effect } \\
\text { debated, but thought that } \\
\text { stimulation can block or } \\
\text { disrupt typical neuronal } \\
\text { impulses that causes tremors. } \\
\text { Used for patients whose } \\
\text { symptoms are resistant to PD } \\
\text { pharmacotherapy or whose } \\
\text { medications have severe side } \\
\text { effects allowing a decrease in } \\
\text { medication. }\end{array}$ & $\begin{array}{l}\text { Rare: ICDs, punding, } \\
\text { hypersexuality, } \\
\text { syncope, compulsive } \\
\text { behavior, visual/ } \\
\text { auditory } \\
\text { hallucinations, } \\
\text { psychosis, } \\
\text { neuroleptic } \\
\text { malignant syndrome } \\
\text { (life-threatening } \\
\text { idiosyncratic } \\
\text { reaction, } \\
\text { characterized by } \\
\text { fever, altered mental } \\
\text { status, muscle } \\
\text { rigidity, autonomic } \\
\text { dysfunctions. } \\
\text { Common: Numbness } \\
\text { or tingling sensations, } \\
\text { muscle tightness of } \\
\text { face/arm, speech } \\
\text { problems, balance } \\
\text { problems, ballism } \\
\text { (abnormal swerving } \\
\text { or jerking } \\
\text { movements), eyelid } \\
\text { apraxia (difficulty } \\
\text { with eye opening and } \\
\text { visual problems), and } \\
\text { corticospinal effects } \\
\text { (problems with } \\
\text { voluntary movement } \\
\text { of one side of the } \\
\text { body or extremities), } \\
\text { lightheadedness, } \\
\text { unwanted mood } \\
\text { changes, mania, } \\
\text { depression. } \\
\text { Rare: seizure, mental } \\
\text { status change, }\end{array}$ \\
\hline
\end{tabular}

Note. ${ }^{\text {a }}$ For discussion on pharmacological side effects, see also: Borovac (2016); Connolly and Lang (2014). For discussion of side effects with DBS, see als Patel, Walker Brooks, Omar, Ditty, and Guthrie (2015).

of antiparkinsonian therapy. In the time of the first two to four years after onset and introduction of levodopa and DA agonist (again CBG), the hobby painter began self-administering double the required dosage. The professional painter as well over-administered levodopa and presumably DA agonists. She started to paint in an obsessive manner. Similarly, the hobby painter refused to accept that there was no need to increase his levodopa therapy and claimed that increasing his drugs had helped to enhance his creativity.

Forsythe et al. (2017) utilized a more objective artwork assessment paradigm, comparing artworks (2092) from across the lifespans of two famous artists diagnosed with PD - Salvador Dali and Norval Morrisseau. These were matched with works by two artists known to have developed Alzheimer's disease and to three control artists-Marc Chagall, Claude Monet, Pablo Picasso. The artworks were analyzed by a computer program to assess fractal dimensions, argued to measure relative formal complexity and suggested to generally exist within a certain range and to denote a personal 'signature' of the artist beyond style or theme. The authors reported a significant positive linear trend in fractal dimension as a function of age among the control artists. Alzheimer's disease showed a significant reduction. In PD artists, while not significant, they reported a quadratic inverted-U increasing and peaking around age 50. Although the method and interpretation is 
open to discussion-for example, the changes could be attributed to aspects of changed style or other artistic developments due to loss of fluid strokes and uptake of crosshatching, or even to changes in the type and manipulation of images - this does again suggest a connection between PD and art. Importantly, they again report in contrast to the controls that PD-artists had periods of output above their annual average, presumably coinciding with the general age (around 50) of typical onset of PD symptoms.

Two studies have also concerned deep brain stimulation (DBS), mainly, however, supporting the above drug- or PD-related findings. Drago et al. (2009a) collected the paintings of one patient from four time phases: early pre- and late-presymptomatic, symptomatic, and post-DBS (left ventral subthalamic nucleus/substantia nigra pars reticulate). A panel of nine judges rated the art based on six artistic qualities, noting a decline in rendering and skill after DBS. Beauty and evoked thoughts/feelings also declined significantly from late presymptomatic to after DBS, which the researchers suggest may have derived from a reduced influence of the right hemisphere, important for artistic creativity. ${ }^{4}$ Note however, that the DBS most probably coincided with a decrease in medication.

Witt et al. (2006) report an architect who received DBS surgery. Before surgery his themes were exclusively architectural (i.e., buildings). These changed to female nudes, which he had never before created. The authors also report postoperative immediate behavioral changes concerning an "increase of hedonism" (not, however, accompanied by general hypersexual behavior) with the patient becoming more prolific in his art production, and a change of painting style (p. 956; although not further described). DBS surgery was accompanied by an increase of DA agonist (once again CBG).

On the other hand, Shimura et al. (2012) provide one of the few examples of creativity diminishment, but which also suggests other notable differences from the above studies. The authors report a semiprofessional painter whose art changed from abstract to realism. Five years before diagnosis, he reported finding it "difficult for him to deconstruct a realistic image" (p. 881), worsening to one year before onset wherein he also complained of diminished artistic creativity. At diagnosis, he was treated with levodopa, and after four years the dose was raised and the patient received DA agonist. At this time, he found it completely impossible to paint abstractions. Importantly, the authors note that the artistic changes occurred at least partially before the initiation of DA pharmacotherapy/diagnosis and thus were unlikely to have been directly related. They further suggest that certain "affected non[-dopaminergic] neurons [may have] first disturbed [the] ability to reconstruct and deconstruct an image" (p. 881), however, the exact brain region "is unknown".

\subsection{Sudden (or resumed) artistic output}

Papers have also begun to consider sudden uptake of art by novices (Table 3). Interestingly, this aspect would seem to be one of PD's more intriguing and salient factors. However, research is only emerging. Walker et al. (2006) report a PD patient who started producing large amounts of pastel drawings - several per week-following an increase in DA agonist (drug not reported), and which the authors specifically hypothesize were connected, "in particular [the art's] apparent obsessive quality" (p. 285). The patient himself believed the medication positively affected his creativity, and thus, as with Schwingenschuh et al. (2010) above, resisted pharmacotherapy changes. The patient's art was

\footnotetext{
4 There is no report of medication in this paper. However, Drago et al. (2009a), most likely concerning the same patient, reports that she was treated with levodopa, carbidopa, pramipexole (non-ergoline DA agonist), and antidepressants.
}

also appreciated by other artists as showing "originality, attitude, and a strong sense of color and kinesthesia" (p. 285).

Chatterjee et al. (2006) report one graphic designer, who had studied art in his youth but who only later painted infrequently. After diagnosis and beginning levodopa/DA agonists, and with the encouragement of a psychologist for his depression, the individual began to paint and draw frequently. Some of his initial art was "representational," but one year later he changed to colored pencils and abstract compositions, using crosshatching and often employing a restricted color palette with a shift towards a denser and darker tonality. The patient produced hundreds of variations of specific themes, and "described himself as being obsessed by his art," with a "sense of bursting forth" when making art (p. 106) and suggesting that both the disease and medication contributed to his artistic generativity.

Joutsa et al. (2012a) again offer one of the largest samples of spontaneous art-making. They sent (via post mail) a self-report survey to 376 patients (eventually using 284) inquiring about artistic creativity. Although admittedly such a survey style may increase risks for over-reporting or self-selection bias, they found that $19.3 \%$ of participants reported increased or sudden artistic production after diagnosis; 33.3\% (18 of the 54) of this group also directly tied their changes to medication. Information regarding how patients assessed their creativity or art changes was not reported; nor were prior artistic activity, antiparkinsonian therapies, or clinical data, while the self-report survey measure may of course introduce volunteer bias affecting especially reported percentages. (See also Lhommée et al., 2014, reported in Table 3, for one more, single individual, case study).

\subsection{General creativity aspects using art or artists}

Finally, studies have provided important supporting evidence, predominantly relating to general creativity but targeting visual artists (Table 4). With the goal of assessing the role of dopaminergic therapy in triggering an "artistic drive" (p. 471), Canesi et al. (2012) compared 18 newly involved artists with 18 non-artist PD patients, and 36 healthy controls. Both the new artist patients and healthy controls showed similar scores on the Torrance Test of Creative Thinking (TTCT; no mention of visual versus verbal subcomponents) and were significantly higher than non-artist patients. On the other hand, although non-artist patients and controls showed the same creative drive, the artists "developed an overproduction" and "spent most of the day producing art disregarding ...other daily life interests" (p. 470), although this was not associated with impulse control disorders. The authors suggest that the burst of art production might represent "emerg[ence] of innate skills" or changes "linked to repetitive and reward-seeking" behavior (p. 171).

Canesi et al. (2016) evaluated the relation between pharmacotherapy, artistic inclination (including prior art-involvement), and creative thinking. They tested three groups: patients who were professional artists before diagnosis/ dopaminergic therapy, previously non art-interested patients who developed artistic output, and patients without artistic-like production before and after PD/therapy. These were further matched against healthy control groups of non-artists and professional artists. Professional artists (both patients and controls) scored significantly higher than non-artists groups on the Abbreviated Torrance Test of creative thinking for Adults (ATTA). However, there was no significant effect of pharmacotherapy (note however that the studies did not compare within-participant changes). The authors also noted that pharmacological treatment may have "triggered artist-like drive" especially in non-professional artists (p. 243).

Similarly, Lhommée et al. (2014) investigated the tie between onset or stopping of dopaminergic therapy (due to deep brain stimulation surgery) and general creativity and behavior with a specific interest in impulse control disorders. They compared 11 creative PD patients (in- 
cluding sculptors and painters) to 22 noncreative patients using a self-made 12-item battery (Ardouin et al., 2009; see Table 4). The authors suggested that creativity (as reported by patients) was induced by dopaminergic treatments in all of their patients, also "accompanied by an addictive driving-force" (p. 2). After surgery and withdrawal of DA agonists, creative activity also tended to disappear (assessed after one year). They also found no connection between creative patients and impulse control or addiction to medication, although the creative patients did have higher agonist doses.

Drago et al. (2009) considered laterality of PD onset and creativity measures. They compared six patients with left-onset PD, nine with right-onset, and seven healthy controls. All patients were treated with "DA enhancing medications" (type/regimen not reported) and assessed with the ATTA (divergent thinking in the visuospatial task component, consisting of making as many pictures as possible using nine triangles drawn on a paper) and the Controlled Word Association Test (a verbal creativity assessment). Correlation was found-for the left- but not for the right-onset patients-between motor severity and "flexibility" on the visuospatial task. On the other hand, right- but not left-onset patients had a decrease in verbal creative fluency compared to controls (no significant difference reported between patient groups). The authors suggest that the right hemisphere may become more dominant following left damage, interacting with visual creativity. Note however, the study also showed significant differences in motor severity and thus potentially disease progression between right- and left-onset populations. The control group was also predominantly female, versus all male PD patients.

\subsection{PD and art viewing}

One study has also considered art viewing. Drago et al. (2009b) asked the same individual artist who was reported on in Drago et al. (2009a) to rate paintings by another artist, assessed while on and off deep brain stimulation. The patient was also taking levodopa and DA agonists throughout all assessments (dosage unchanged between blocks). Ratings were compared against those by 17 healthy controls (no report of art training/experience). When 'off,' the patient's ratings did not differ from controls. While 'on,' ratings for "closure" ("How complete is the painting?"), demonstrated skill, and "evocative impact" ("How strongly does the painting induce feelings or thoughts?") were significantly lower than for controls. The patient's general creativity (measured by ATTA) was also equivalent to healthy controls when 'off' but below average when on. The authors conclude that deep brain stimulation may be related to enhanced activation of the left hemisphere and reciprocal deactivation of the right, which also mediates visuospatial skills and global attention. The patient also noted that the stimulation interfered with both her creativity and art appreciation.

\subsection{Summary of main PD and art case study findings}

This body of evidence, although only emerging and obviously still involving quite small samples and other issues with methodology and reporting standards (see further discussion also in the conclusion), does offer several compelling findings and potential patterns that can be further considered below. First, and primarily, there does appear to be rather consistent support for a general increase in artistic motivation. Patients are described as being remarkably productive artistically following diagnosis. This was often coupled with a felt desire or even 'need' for making, sometimes approaching an addiction or impulse control disorder (ICD) (although note again that a significant correlation was not found between PD-artists and diagnosed ICD itself in Canesi et al., 2012 or Lhommée et al., 2014). This was true both among previous artists and among individuals who took up art spontaneously. The general creativity comparisons as well (Table 4), revealed populations of patients who had never before, but suddenly began, participating in art.

Onset of art making or changed motivation also appear to coincide with PD medication, especially DA agonist therapy. Looking at the cases, this generally appeared to involve the ergoline derivate Cabergoline (CBG, discussed further in the following section below). The drive to make art also tended to diminish with stopping or lowering dosages (Kulisevsky et al., 2009; Lhommée et al., 2014) and with deep brain stimulation, presumably because of the lowered need for medication, although stimulation itself also led to changes in art rating. Medication usage itself also resembled, in some, an addiction (Chatterjee et al., 2006; Joutsa et al., 2012a; Lakke, 1999; Pinker, 2002).

Increased motivation was also routinely mixed with an increased felt creativity in self-reports, with patients reporting that they felt freer, more spontaneous (Chatterjee et al., 2006; Lhommée et al., 2014; Pinker, 2002; Walker et al., 2006), and often exhibiting a felt need for creative expression (Kulisevsky et al., 2009). This was also supported by some evidence using standardized creativity measures, noting at least a lack of creative diminishment in PD-artists (Canesi et al., 2012, 2016) or possible increase tied to medication (Lhommée et al., 2014). Equally intriguing, most case studies with prior artists also noted an increase, or at least no decrease, in art quality. This too was explained as being related to increased creativity, spontaneity, movement to brighter colors and abstract forms, or even to a result of increased art production which allowed refinement of artistic skills. Drago et al. (2009b), using a panel of judges, also showed higher quality ratings initially from early pre-symptomatic stages to introduction of DA pharmacotherapy, followed by a decline after deep brain stimulation/reduced medication.

The productive period for most case study artists also appears to extend for several years. Among papers with suitable studies (nine), the assessments ranged from 0 to 2 years to 20 years after diagnosis, with a Mean of 10.9 years after PD onset at which artists were assessed. This is similar to the survey of 40 individuals by Lakke (1999), which found a mean of 13 years and would suggest, following the timeline in Table 1 , that most individuals showed artistic productivity from HY Stages 1 to 4 (0-15 years), with the above mean coinciding with HY Stage 3/Braak Stage 5 (10 years after diagnosis). The answer to the question of how quickly individuals actually show changes, especially if related to medications, was more muddied. Shimura et al. (2012) reported gradual changes from 0 to 4 years. Similarly, Chatterjee et al. (2006) noted changes in the first year after diagnosis. Lhommée et al. (2014) connected changes in art to their second assessed time-period, coinciding with the beginning of medication and covering three years. Only two studies actually assessed the impact of stopping medication, which would also give important evidence to this question. Kulisevsky et al. (2009) reported changes after six weeks. Witt et al.'s (2006) study post DBS and medication reduction found changes after 3 months. However, both reports coincide with the time of the researchers' actual clinical assessments and hence do not preclude the possibility for changes coming earlier.

When considering specific changes within produced art, results were also more obscure. There was some evidence regarding style. Lakke (1999) reports compositional imbalance, lack of vertical or fluid strokes, and crosshatching that made use of the patients' tremors (see also Chatterjee et al., 2006). Some evidence also points to a movement from realism to abstraction (Chatterjee et al., 2006; Pinker, 2002) or at least more impressionistic mark-making (Kulisevsky et al., 2009), which might also tie to motor issues and/or to other reasons such as a need for emotional expression (however, see Shimura et al., 2012). Forsythe et al. (2017) also noted, if only as a trend, increases in complexity, which could also potentially be due to shorter strokes and crosshatching or to higher conceptual/stylistic change. 
Less evidence was found regarding changes in theme. Only Shimura et al. (2012) and Witt et al. (2006) explicitly reported thematic changes. Both however again represented atypical (e.g., non-medicine- or DBS-related) cases. One other interesting issue may be color usage. Half of the studies assessing previous artists mentioned changes (the remaining $50 \%$ did not mention color at all). Authors report more vibrant colors after diagnosis/therapy (Pinker, 2002) or an emphasis on color and light rather than shape/detail (Kulisevsky et al., 2009). Drago et al. (2009a) also report less use of color following DBS; and several authors report more focus on mood or color/emotion expression (Canesi et al., 2012; Kulisevsky et al., 2009; Lakke, 1999; Shimura et al., 2012).

\subsubsection{Analysis of reported artworks for changes in color saturation, brightness, complexity (Fractal Dimension)}

As a rough analysis of some of the above suggestions, we analyzed all images previously published in the above-reviewed studies using a computer-based assessment of average color hue, saturation, and brightness, as well as fractal dimension (following the technique of Forsythe et al., 2017). This involved 37 images from nine artists, which were compared between pre- and post-PD onset. Full methods for this assessment as well as discussion of limitations are reported in Supplementary Materials (see also a brief description in the footnote). ${ }^{5}$ Although obviously only suggestive, these previously published artworks were presumably chosen by the authors as exhibiting the most salient formal changes. Thus, it was thought that an objective assessment may be useful to further consider or reveal potential differences.

Results are shown in Fig. 3. As can be seen, post-PD images suggest more use of blue/green as well as orange colors, whereas pre-PD used more pink/purple. Saturation increased marginally, along with a great increase in variance. However, a Median Test for differences was non-significant. Brightness declined marginally (differences $n s$ ). Interestingly, we found an even more clear relation between age at which art was made, regardless of diagnosis status, and increasing brightness $(r=.754)$, as well as saturation, which decreased $(r=-.431)$. No such relation was found with $\mathrm{D}$-values. This might suggest that such color changes could also be a result of normal aging. For fractal dimension, images created after PD diagnosis, across all papers, had higher D-values than images painted before $\left(\mathrm{N}=37, \chi^{2}=6,708, \mathrm{p}=.019\right.$; mean difference $=0.086$ ) - see also the histograms. This roughly corresponds with the findings of Forsythe et al. (2017).

\section{From case evidence to new hypotheses: why might PD or treatment cause motivation or changes in art?}

We now move to the main question: Given the above findings, why might there be especially increased artistic motivation or output in some individuals with PD? Secondarily, why might we find some changes in creativity, style, or even quality? We address these questions in two stages: (1) We briefly introduce one more area of evidence, concerning current psychological and neurological discussion of models and key factors of artistic creativity and the processes of making art, as well as contextual or modulating factors and related brain areas. (2) These are then combined with the above findings, as well as a number

\footnotetext{
5 The assessment involved 37 images from nine artists (5 female; 9 images created before PD onset, 28 after; 7 images black and white only, thus not used in color analysis), digitally copied from the above-reviewed papers (see Supplementary Materials for list and full assessment procedure). Fractal dimension values were assessed using FIJI to convert to binary coding, D-values calculated using box count method. Average color values (RGB) were transformed into HSB values (0 to 365). Brightness (0-100) and saturation (0-100). Nonparametric Median Tests were conducted to compare pre- and post-PD. Comparative statistics not conducted for hue due to the 360-degree nature of data.
}

of other supporting studies on PD, brain/DA functionality, and related diseases, towards the construction of a number of hypotheses. This is followed by a general summary and implications from the analysis in the Conclusion.

\subsection{Visual creativity, the art-making process, and modulating factors}

First, it is useful to briefly consider present arguments for important factors in the general task of producing art. The present level of theory on this topic is still rather sparse (see Pelowski et al., 2017b for review), and with most coming from discussions of general creation or visual creativity. However, several theories do highlight important aspects. Campbell (1960) proposed a two-stage model, which essentially holds today (Vartanian, 2015). This suggests that visual production is contingent on a process of "blind variation" (generation of ideas using an open, less-rule governed manner) followed by "selective retention," an analytic assessment and selection of the fittest variants. Niu and Sternberg (2001; also Wallas, 1926) expanded this to four steps of "preparation," "incubation" (thinking of ideas or even entering an "art-generating" mindset), "illumination" (identification of good candidates), and idea "revision". Finally, Tinio (2013) most recently proposed three-steps for actual mark-making or production of art: "blocking in" the first aspects of a form, adding details or changes, and "finalizing" or deciding when art is complete (see also Bogousslavsky, 2005).

Put together, these arguments suggest that the basic process of producing art-regardless of style or quality - requires: (1) an initial ability to adopt a freer mode of idea generation. This might also include the desire and/or ability to even pursue artistic questions; (2) generation of ideas - also referred to in creativity literature as "ideation" (e.g., Runco and Chand, 1995), and related empirically to successful visual design (Sawyers and Canestaro, 1989); (3) acting on or pursuing some outputs; (4) executing an idea through producing art; and (5) investing the time and attention to stick with an artwork once one has begun. When evaluating output, creativity/originality as well as skill/technical quality are typically given as the two main means of assessing success (Newman and Bloom, 2012), and are often highly correlated, especially with adult artists (Chan and Zhao, 2010), although researchers may also consider beauty, visual interest, realism, etc.

\subsubsection{Factors that lead to more or better/creative art}

Specific factors may then also lead to more or 'better'-particularly creative or aesthetically pleasing - artistic outputs (see Pelowski et al., 2018 for review), which themselves feed into potential PD-related hypotheses. Some personality traits are salient in visually creative individuals. These include "openness" (characterized by imagination and insight) and "extraversion" (sociability, assertiveness, emotional expressiveness; Kandler et al., 2016). These traits also coincide with engagement in the arts, as well as enjoying abstract art (Fayn et al., 2015; Myszkowski et al., 2014; Pelowski et al., 2017a). Similar ties have been found between practicing artists versus non-artists and "neuroticism," as well as divergent thinking, and positive-schizotypy—subclinical traits related to full-blown schizophrenia involving mild levels of perceptual aberrations, hallucinations, and eccentric behavior (Burch et al., 2006). Flaherty (2011; see also Chakravarty, 2010) also suggests that artistic creativity requires individuals with novelty seeking, flexible associative networks, as well as perhaps lower inhibition, and of course domain specific skills and knowledge.

Motivation or "passion" for art may also be a major contributor (Lemons, 2011; Flaherty, 2011). Motivation may be due to either extrinsic or intrinsic factors. Individuals who show a certain amount of skill may be motivated by their own experiences, or think of themselves as "artists," leading to higher drive/creativity. The environment-cultural, economic, social factors-may also encourage or inhibit making or improvement (Rostan et al., 2002; Csikszentmihalyi et al., 
2005). Studies show that an encouraging environment-e.g., school or family structure - coincides with propensity to make more and better art (Niu and Sternberg, 2001). Culture can also inform acceptable outlets for the creative process (Lubart and Sternberg, 1998). Self-report survey-based studies also link superior creative outputs and willingness to skip meals or sleep to work on a project (Schaefer and Anastasi, 1968). This phenomenon was of course noted in the case reports by Canesi et al. (2012) and Pinker (2002) above.

Some techniques or individual differences in perception may also be important (Pelowski et al., 2018 for review). Among many possibilities, successful artists may employ top-down schemata ranging from focus on certain features to better understanding of placements or proportions, as well as techniques for visual effects such as foreshortening (Drake and Winner, 2009; Kozbelt and Seeley, 2007; Mottron et al., 2009). Artists may adopt a more global strategy - blocking in a gist or structural forms first—where less successful individuals may worry more about realism (Serafin et al., 2011). Artists may also show ability to bypass or "see past" stereotypical depictions in order to produce more novel or pleasing images (Gombrich, 1960) and may choose freer, less realistic, perhaps even more deviant designs and concepts. It is also important to mention that this does not take into account physical ability (as related to motor issues). This may be an issue (e.g., fluid lines, realistic representation) especially regarding within-individual changes; however, history shows many highly, successful physically limited artists.

\subsubsection{Visual creativity, art, and the brain}

Literature also suggests structural, functional, and even DA-related brain differences - many of which may overlap with the discussion of PD-related brain areas above (see again Fig. 1). Using functional brain imaging, researchers have identified a handful of regions suggested to be recruited in general visual creative activities. These relate to global attention, visuospatial processing, and manipulating spatial representations - e.g., parietal areas (Chavez-Eakle et al., 2007; Sieborger et al., 2007). Studies also highlight the medial temporal lobe, hippocampus, and parahippocampus, which may play a role in novel ideas by recombination of memory and associative processing (Ellamil et al., 2012; Palmiero et al., 2012). The PFC, especially its medial portions, is also argued to be part of a frontal executive network covering flexible co-ordination, goal-directed focus, and is suggested to enable an analytic process required during creative evaluation (Ellamil et al., 2012; Elliott, 2003; see Kowatari et al., 2009 for review).

Comparative studies of more or less successful visual creativity scoring or of the actual task of art making have also shown similar areas of activation. Kowatari et al. (2009), in comparison of expert versus novice designers, identified a right lateralized PFC and parietal regions activation (especially in experts), and a correlation between activity and creativity of finished drawings, as well as higher activity in medial frontal and posterior parietal areas (see also Miall et al., 2009) and hippocampus/parahippocampus (also Ellamil et al., 2012). In structural comparisons, Gansler et al. (2011) also found a positive relation between right parietal gray matter volume and visual creativity scores. Chamberlain et al. (2014) also found positive correlation between higher grey matter density and realistic drawing scores in right medial frontal gyrus and in the left anterior cerebellum, tying to fine motor control and procedural memory (see also Saggar et al., 2015 for a study showing higher cerebellum activity when making drawings). Those with artistic training (art students vs. non-art students) also showed increased grey matter density in the right precuneus, which the authors connected to visual imagery.

Other suggested areas include the Default Mode Network (DMN), including medial prefrontal cortex (mPFC), posterior cingulate cortex (PCC), and temporoparietal junction (TPJ), which may facilitate an associative mode of processing that supports novel idea generation
(Ellamil et al., 2012; Jung et al., 2013; Shulman and Fiez, 1997). The DMN has also been demonstrated to play a role in affective and visceroceptive evaluation and may contribute to creative evaluation by facilitating the formation and awareness/response to "gut" reactions that may direct production (Ellamil et al., 2012). Limb and Braun (2008) also reported higher DMN activation in creative jazz improvisation (however, Saggar et al., 2015).

On the other hand, areas related to analytical judgment, inhibition, or to "self-censorship"- especially lateral OFC and dlPFC (Zald et al., 2012) - may show lowered activation. In the same jazz improvisation study by Limb and Braun (2008) above, reduced activity was found in both regions. Study of creative sketching by Saggar et al. (2015) showed negative correlation between activation in dlPFC, as well as in the anterior cingulate cortex (ACC), and drawing ratings. On the other hand, Ellamil et al. (2012), who compared generative and evaluative modes in creative drawing, found that when designers were explicitly evaluating their designs they had higher activation in dlPFC and dorsal ACC (see also Hare et al., 2011). There is also evidence for high lateral OFC and dlPFC connectivity (Zald et al., 2012). Evidence also suggests some general lateralization (as in the reviewed study by Drago et al., 2009c). In most right-handed people, visuospatial functions are associated with the right hemisphere. Right hemisphere bias has been shown in relation to artistic creativity scores (Bhattacharya and Petsche, 2005; Kottlow et al., 2011; Kowatari et al., 2009; Solso, 2001; however, see Jung et al., 2013).

Research also suggests a relation between creativity and DA production or transmission-again recruiting many of the above regions. Studies again focusing primarily on general creativity or divergent thinking/ problem solving (see Takeuchi et al., 2010) have suggested a positive relation between standardized creativity scoring and grey matter volume of the mesolimbic pathway-related mPFC, OFC, and hippocampus. Similar results have also been found in the mesocortical dopaminergic pathway areas projecting from the ventral tegmental area (VTA) to the PFC and $\mathrm{dlPFC}$, and to the nigrostriatal pathway projecting from the SN also including bilateral basal ganglia (Zabelina et al., 2016; see Boot et al., 2017 for a recent review). DA-receptor levels (DRD) in general have also been associated with ideational fluency (Murphy et al., 2013; Oikkonen et al., 2016; see also Flaherty, 2005; Heilman et al., 2003), while the amount of especially striatal DA receptors (D2 and perhaps also D3, often as measured by spontaneous eye blink as a proxy for D2 receptor levels, see Groman et al., 2014) have been tied to standardized tests of divergent thinking. Convergent (less-creative) responses often show a negative linear correlation to receptor levels and divergent thinking shows a U-shaped pattern, with moderate levels associated with greatest flexibility (e.g., Chermahini and Hommel, 2010), presumably due to higher levels leading to difficulty with concentration. Many of these aspects will be further developed below. To our knowledge, no study has considered these regions in relation to the specific case of producing art.

\subsection{Hypotheses for PD-related artistic change}

Uniting the above lines of research, we can make multiple arguments, for why PD might interact with art production motivation and output. We must of course stress that these can only be speculations. However, they do paint a compelling picture of the complex neurological and contextual basis for making art.

\subsubsection{PD-involved damage, preservation, and $D A$ pharmacotherapy—selectively changing and overmedicating the artistic brain?}

Notably, our argument tends to highlight most of the above DA-related regions, which were also implicated in studies of visual creativity, as well as the general contextual art-making evidence. Our main hypothesis for this phenomenon can be shaped around the above aspects 
of damage, medication, and the unique functionality of the brain. It is broadly suggested - in addition to any other explanation-that one key component of sudden artistic behavior involves dopaminergic pharmacotherapy. This was again noted in several of the case studies, and is also noted in discussions of general creativity, where patients treated with DA agonists and levodopa have shown enhanced verbal and visual creativity compared to healthy controls (Faust-Socher et al., 2014; Weintraub et al., 2006, 2010). We also think it holds at least half of the equation for the artistic changes found with PD.

An argument for why, functionally speaking, medication may lead to higher urge to make art or to higher creativity/quality could then be explained by uniting medication with differing patterns of PD lesion or degeneration, coupled with the impact of medication itself. Most basically, by increasing DA availability (via levodopa), or even more, by increasing receptivity of certain regions to DA (via agonist), medication could both raise already damaged areas back to 'normal' functioning, while leading to over-activity in other presently undamaged brain regions. Thus, if specific regions in the latter group have roles tied to creativity or making art, we could expect corresponding behavioral changes as in the case studies. This general idea has been previously suggested in other reviews of creativity or other behavior-related PD assessments (see Boot et al., 2017; Evans et al., 2009; Joutsa et al., 2012b; Lim et al., 2009), and seems to be a key aspect of PD-involved data. Connecting to the above review of brain areas specifically as they relate to art and visual creativity, and to the stages of PD, several areas come to the fore:

\subsubsection{Damage + pharmacotherapy and increased motivation and reward}

The first candidate may involve areas related to the main salient finding from the case studies-regarding reward or motivation. In those who do become artists, we would expect to find damage to nigrostriatal regions tied to motor control, leading to the initial symptoms, diagnosis and PD medication. Whereas, mesocortical and especially mesolimbic pathways might be left more intact. This idea is specifically suggested by Lim et al. (2009; also Evans et al., 2009), although not for art, who note that in the Braak lesion stage 3 , in which many patients are first diagnosed and medicated, ventral striatal DA may be relatively preserved, resulting in "dopaminergic medication-induced overdosing" of this area, which may drive new reward-driven behaviors (p. 170).

DA, especially related to the mesolimbic dopaminergic circuit connecting the VTA to the ventral striatum/NAcc, is again a crucial modulator of reward processing (Berridge et al., 2009; Salimpoor et al., 2011). DA has also been tied to regulating personal pleasure received from an activity via "hedonic hotspots" located in subcompartments within the NAcc shell, ventral pallidum, as well as the insula and OFC, and with intake of opioid neurotransmitters found to enhance pleasure (Berridge and Kringelbach, 2013, 2015). Many of these areas were again highlighted in the above review of the artistic brain (Fig. 1). Thus, art making - in a subset of individuals - may come to be pursued for its hedonic properties, driving this behavior (Canesi et al., 2012).

Previous studies do connect reward to making art. Especially researchers suggest reward feedback from creating something by oneself (Canesi et al., 2012) or through novelty seeking (Schwingenschuh et al., 2010), and in accordance with the limbic system being involved in hedonic feedback and creative drive (Canesi et al., 2012; Flaherty, 2011; Schwingenschuh et al., 2010). This role of DAergic release and pleasure/reward is also supported by results from studies investigating brain responses to music. Salimpoor et al. (2011) specifically connected intense positive affective response, related in their discussion to musical chills (musical 'reward'), to DA release in the NAcc. They also showed that DA release in the caudate nucleus related the anticipation of musical chills, which they suggest is comparable to 'wanting'. Oth- ers (Berridge, 2007; Berridge \& Kringelbach, 2008; Pessiglione et al., 2006; Schott et al., 2007) argue that opioid neurotransmission in the mesocorticolimbic DA circuit may mediate "reward prediction" driving future decisions to seek out activities or general motivation.

This argument may also be supported by the phenomenon of dopamine dysregulation syndrome (DDS). This resembles a drug addiction state, occurring in up to $4 \%$ of patients, whereby individuals give themselves inappropriately high doses of dopaminergic medication (Weintraub and Nirenberg, 2013)_found also in some case studies above. Other drug abuse has been reported among artists or other creative individuals, who take stimulants or psychedelics in the expectation that they will raise artistic perception and creative performance (Lhommée et al., 2014; Spee et al., 2018). Often this coincides with intense artistic concentration, at the expense of social and daily responsibilities (Bindler et al., 2011; Kulisevsky et al., 2009). This may also, more basically, be experienced simply because artists happened to be involved in making art, which with the introduction of dopaminergic pharmacotherapy becomes increasingly desired or rewarding. Studies of PD patients also reveal similar addictions to for example gambling (Cilia et al., 2008).

It is important to note this tie between DA agonists, brain regions, and reward/motivation does not necessarily explain why ability itself, or art style/quality, would be changed-or if they would. With more focus on art activity or practice, individuals may of course become more skilled or arrive at more novel forms. Alternatively, this urge itself may be an important component of artistic success-e.g., relating to the arguments for practice or perseverance as key components.

\subsubsection{Impulse control and/or latent inhibition}

Relating to both art motivation or propensity toward production as well as to actual changes in artistic success/novelty, pharmacotherapy and selective damage may also impact impulse control or inhibition. Artistic PD individuals have again been described as involving a felt impulse to make art, to the extent that it resembles a disorder or addiction (Chatterjee et al., 2006; Kulisevsky et al., 2009). Impulse control issues are a recognized complication of especially DA agonist therapy at high dosages (Weintraub and Nirenberg, 2013), arising in approximately $15 \%$ of patients (Connolly and Lang, 2014) and comprised of prolonged, compulsive actions, including creative hobbies (Inzelberg, 2013; Schwingenschuh et al., 2010; Weintraub and Nirenberg, 2013). Implicated brain regions include those related to reward-seeking and others identified in creativity-related systems-NAcc (urges and impulsivity), dorsal striatum (compulsivity), OFC, vmPFC, and amygdala (Weintraub and Nirenberg, 2013). In the discussion of impulse control disorders, these areas have, once again, been suggested as candidates for "overdosing" or "excessive" activity from medication in early or mild PD patients (Weintraub and Nirenberg, 2013, p. 65). Although, the above-reviewed case studies by Canesi et al. (2012) and Lhommée et al. (2014) in fact did not show correlations between art making and impulse control disorder itself (a felt urge beyond control of the patient), impulsivity-allowing oneself to experiment, be novel, or even to begin making - may suggest an important creativity/art factor.

Among the above areas, the medial OFC - which again plays an important role in coding learning signals for rewards or losses-may prove especially important. Poletti and Bonuccelli (2012) suggest that in early PD, medial OFC functions are often preserved and dopaminergic drugs result in more compulsive or risky behavior (e.g., gambling). Joutsa et al. (2012b), who employed PET with $\left[{ }^{18} \mathrm{~F}\right]$ fluorodopa, found that PD patients who present impulse control disorders or increased general compulsivity have up to $35 \%$ higher uptake in the medial OFC compared to controls. They argue, once again, that such an increase signifies dopaminergic upregulation/hyperactivity, possibly occurring 
as a compensatory mechanism for the overall DA issues associated with PD.

On the other hand, selective damage to the lateral OFC or dlPFC could be tied to sudden, freer artistic impulses. Although Kobayakawa et al. (2017) recently found a positive correlation between lateral OFC volume in $\mathrm{PD}$ patients and decision-making performance, lowered activity in lateral OFC has again been tied to creative improvisation, and perhaps necessary for art initiation. In addition, the dlPFC (again tied to the mesocortical DA pathway) may serve as a main driver of motivated or reward seeking behavior in mesolimbic DA areas_-VTA and NAcc_-by sending signals about reward anticipation (Ballard et al., 2011). Thus, damage interfering with its ability to correctly filter or identify reward targets might be found in individuals showing art motivation.

\subsubsection{Associative network, striatum, flexibility}

On the opposite side of the coin regarding inhibition, agonist-modulation might also result in increasing activity in areas related to associations or to flexibility/divergent thinking, modulating individuals' ability to come up with novel, creative ideas for visual art. Candidates for similar patterns of DA agonist-induced selectively higher activation might be the $\mathrm{mPFC}$ (reward seeking, associations, introspection) and hippocampus or related areas via mesolimbic DA pathways. This argument, relating to what was termed a associative network, was made for example in general creativity by Canesi et al. (2012) or Faust-Socher et al. (2014).

One other related key candidate area, connected to these mesolimbic regions as well as to mesocortical and nigrostriatal pathways, is the ventral striatum. As noted above, the literature review might tend to suggest that this region, tied to the nigrostriatal pathway, would be damaged with many artists, leading to a diagnosis with PD. Indeed, striatal dopamine and/or D2-3 receptor levels in general have been shown to be lower in PD patients (Canesi et al., 2012; Deuschel and Goddemeier, 1998).

At the same time, the striatum is also involved in making associations or in (cognitive) flexibility, especially as this relates to general divergent thinking tasks (i.e., ability to generate new and novel solutions or uses for a stimulus). A recent review of DA and general creative problem solving suggested a similar underlying connection between selective damage/intactness and DA agonist-induced over-stimulation, highlighted the striatum in addition to prefrontal and memory-related mesocortical regions (Boot et al., 2017). The striatum is noted in connection with positive-schizotypy, again more pronounced in visual artists (Burch et al., 2006) and also connected to enhanced creative flexibility performance on standardized tests versus healthy controls (Boot et al., 2017).

Dopamine release in the striatum has been shown to positively correlate with positive schizotypal traits (Woodward et al. 2011). Similar results are also found for elevated eye blink rate and DA uptake (see Chermahini and Hommel, 2010 for review), as well as for hyperactivity in this region or levels of striatal D2 and D3 receptors (Chen et al., 2012). This region — or again potentially the greater set of implicated areas also discussed in the section above-has also been behaviorally implicated in studies connecting schizotypy to lowered latent inhibition, or ability to conditionally ignore stimuli that one has learned to be irrelevant for predicting certain events, as well as higher resulting associative ability (Baas et al., 2016; Baruch et al., 1988; but see Swerdlow et al., 1996).

Importantly, structural measures of striatal DA receptor presence also tend to support an argument for a key division between those innervating the sensorimotor part of the dorsal straitum/caudate-putamen and those, more ventral regions, which project to limbic (reward) and forebrain (impulse control, introspection) areas discussed above (Björklund and Dunnett, 2007). Thus, it may well be that for some, even following motor-symptom-based PD diagnosis, flexibility/association and reward-related brain regions may be intact and overstimulated by pharmacotherapy, leading along with reduced inhibition to the freer and more creative outputs suggested with artists. The striatum has also been specifically connected to modulation of creativity scores by experimental use of DA agonists. Swerdlow et al. (2003; see also Boot et al., 2017 for review) showed that bromocriptine, an ergoline drug mainly targeting D2 receptors, lowered inhibition compared to a placebo. In healthy individuals, increased DA levels in the striatum also appear to be associated with decreased DA levels in the PFC, a brain region tied to executive control and focus, but perhaps also to inhibition, as discussed in the section above (see Boot et al., 2017).

Perhaps even more intriguing, and relating specifically to evidence for $\mathrm{PD}$, researchers have also found that the number of striatal neurons positive for tyrosine hydroxylase (TH) - a synthesizing enzyme for DA-increases "several-fold" in PD (Porritt et al., 2006). Björklund and Dunnett (2007) suggest that this may reflect a compensatory upregulation of TH in GABAergic interneurons already present in the brain. A similar, shared overactivity might be found in artists/positive-schizotypy individuals and in those who develop PD. Note again, however, that research on standardized creativity scoring suggests that increased activity in this region, and thus flexibility/associations, may have an upward limit, with a U-shaped relation between striatal dopaminergic functioning and creativity scoring (e.g., Chermahini and Hommel, 2010). This is discussed further in the Conclusion below.

It is important to stress that, in our opinion, the striatum/association networks have a key connection to the reward and inhibition regions discussed above. As noted, this can be found in the structural connectivity evidence (Björklund and Dunnett, 2007). Further, the hotspots for TH-positive neuron increase with PD have also been found to be near the nucleus accumbens/reward circuitry regions (Björklund and Dunnett, 2007). The types of DA agonists found in our case studies may also point to the argument for an interrelation between reward and flexibility/association circuitry.

Whereas D1 receptors are abundant in the dorsal striatum, which may mediate especially motor effects, D3 and to a lesser extent D2, which are also abundant in the ventral striatal mesolimbic pathway, and thus agonists targeting these, "may facilitate creative ideas and their expression" (Lhommée et al., 2014, p. 7). This is supported provisionally in the case studies, which highlighted Cabergoline (CBG) - which acts primarily on D2 but is also related to D3-4 receptors (Borovac (2016) - as being tied to increased creativity or creativity changes with its removal from a drug regimen (Kulisevsky et al., 2009; Schwingenschuh et al., 2010; Witt et al., 2006). Preservation of the ventral striatum has also been linked to dopamine dysregulation syndrome and other reward-related effects (Evans et al., 2009; Lim et al., 2009), while tonic DA transmission, as is primarily impacted by DA agonists, is specifically related to motivation and response vigor (Niv, 2007; Niv et al., 2006; Schultz, 2016), with these aspects, and their underlying regions, overly activated by agonists or perhaps some baseline differences in receptor level, connectivity, or functionality, presumably acting in concert to lead to the documented changes with art.

\subsubsection{Other potential regions: DMN, thalamus, lateralization}

Other brain regions that might be mentioned, although with less clear hypotheses, include the default mode network (DMN). Presently, there is a lack of clear understanding regarding the role of DMN and DA neurotransmission in PD patients (Delaveau et al., 2010). In a study by van Eimeren et al. (2009) PD patients were asked to perform an executive task 12-18 h after stopping their PD medication (type/regimen not reported). Results showed that although the mPFC normally deactivated, the posterior cingulate cortex PCC and precuneus failed to do so. Studies with PD patients on levodopa, both alone or in combination with DA agonists, also show reduced deactivation of the vmPFC while 
performing a sequence learning task (Argyelan et al., 2008) and of both the anterior and posterior parts of the DMN network during a resting state (Tinaz et al., 2016; however, see Delaveau et al., 2010). Especially PCC and/or vmPFC areas' activation were again tied to both general creativity and introspection or savoring of emotional information, potentially at the expense of focus on outer events or even obligations. As with the argument for striatal areas above, the PCC may also be a candidate for more direct changes brought about by PD pathology, for example increasing the resting receptivity to DA (see also Nagano-Saito et al., 2009; Tomasi et al., 2009). Especially PCC activity (lack of deactivation) has also been shown to coincide with being particularly moved by art (Vessel et al., 2012). It is also possible that PD itself could lead to alterations of connectivity or function in the other areas reviewed above as well, without necessarily the need for agonists to drive such results (Weintraub and Nirenberg, 2013). The present lack of scanning or connectivity/structural studies in PD patients leave this as an open hypothesis.

Another candidate for lowered functionality may be the thalamus. Studies have shown a negative correlation between divergent thinking scores and regional D2 receptor density (De Manzano et al., 2010). The authors suggested that reduced DA functioning may lower thalamic gating thresholds, increasing information flow and divergent thinking, while also leading to increased excitation of cortical regions through decreased inhibition of prefrontal pyramidal neurons, placing them in a more liable "creatively-biased" state. Similar findings of decreased D2-3 receptor binding (Talvik et al., 2003) and levels (Kessler et al., 2009) in this area have also been found in schizophrenia and might be expected in PD-induced or 'natural' artists. This would also lend further evidence for selective initial damage to the nigrorostral DA path.

Damage/antiparkinsonian therapy could also be modulated, at least partially, by laterality. As noted above, Drago et al. (2009c; Drago and Heilman, 2012) showed that progressively more severe left-sided symptoms led to higher visuospatial task flexibility. Whereas right sided symptoms tend to impair verbal creativity. On the other hand, the case study be Drago et al. (2009a; see also Drago and Heilman, 2012) reported lowered artistic creativity and art appreciation in a PD artist when stimulated with left ventral DBS. This would fit the argument for a right lateralization for visual art ability related to visuospatial function or global attention, versus left-lateralized focal attention/categorical thinking. At motor symptoms onset, PD patients do often in fact show lateralized symptom predominance (Uitti et al., 2005), suggesting we might again find damaged left and unaffected right frontal areas in PD artists (see also Cilia et al., 2008 for similar results in PD patients showing compulsive gambling). By experiencing left-lateralized damage-especially frontal and parietal areas-individuals may shift emphasis to their right brain, overriding left-sided processes that might have tamped down creative ideas or pursuits. This has also been argued in studies on dementia patients who show sudden art interest or improvement (Palmiero et al., 2012; Snyder et al., 2003). Interestingly however, the case studies do not provide strong evidence for laterality. Studies with existing artists showed a rather even split between left side onset (Kulisevsky et al., 2009; Shimura et al., 2012) and right-onset (Lakke, 1999; Drago et al., 2009a), with several others not reporting this information. The survey by Joutsa et al. (2012a) of emerging artistic interest also showed no laterality evidence.

\subsubsection{Damage, pharmacotherapy, and formal/style changes}

Although more speculative, the above argument can also provide explanations for changes in technique or style. Again, one of the most common changes involves mark making (less fluid vertical lines, more cross hatching). This issue would presumably be tied to diminished functionality in the nigrostriatal DA areas, connected to tremors or issue with motor control. This could also explain the change to freer, more impressionistic, less realistic or abstract styles.
The above changes may also relate partially to blurred vision or impaired processing of spatial relations. These are often connected to decreased DA in the retina, but may also tie to issues with visual cortices and pathways as well as with sensory association areas, or to effects of antiparkinsonian medication (Archibald et al., 2013; Diederich et al., 2014; Müller et al., 2002). Drago et al. (2009b) also note diminished ability to identify line orientations in PD patients, presumably due to damage in parietal regions. Other vision issues may also relate to changes in color palette or the heightened color intensity shown in some case studies. Changed blue-yellow color discrimination is again noted as a common issue with PD (Alenicova et al., 2017; Birch et al., 1998; Müller et al., 2002; Oh et al., 2011). This can cause blues to appear greenish, yellows to appear pink, and purple almost black. Especially blue is often difficult for PD patients to perceive (Alenicova et al., 2017). Such changes could perhaps cause artists to either ignore certain colors or to overuse them or increase their intensity (as in blue). The case studies, if only anecdotally, did suggest that PD coincided with a move from reds/purple to blues. This may also explain the more saturated or vibrant use of color, as could reduce contrast sensitivity. It could also be that changes in color focus tie into the above abstraction/move from realism or reward processes. Interestingly however, to date none of the studies have considered potential color vision changes in visual artists (Inzelberg, 2013).

Studies have also focused on PD patients' ability to manage emotional information, which could also coincide with color or abstraction changes or overall thematic focus. PD has been tied to lowered proficiency in emotion recognition (Assogna et al., 2008; Gray and Tickle-Degnen, 2010; Serranová et al., 2011)—i.e., perceiving and classifying emotions depicted in the environment. This is especially the case with negative emotions, as assessed with music (van Tricht et al., 2010; Mattei et al., 2013), but also found with happiness and peacefulness (Lima et al., 2013). Self-reported intensity of negative emotions has also been found to be reduced (Vicente et al., 2009). These symptoms are suggested to tie to damage/change in one or more key emotion-processing areas-basal ganglia, ventral striatum, inferior OFC, ACC, PFC. This has also been found to be independent of cognitive and perceptual abilities in general, and well as ability to identify emotions in the self (Enrici et al., 2015).

As suggested in the case studies, many artists did note increased focus on mood or emotion (e.g., Lakke, 1999) and less use of somber or negative tones (however, see Drago et al., 2009a). PD artists might use their art as a way of exploring emotion specifically due to their felt ambiguity. This could also relate to style and color. Kulisevsky et al. (2009) noted that after DA therapy, their patient displayed an emphasis on color and impressionism, which the patient attributed to "a need to express refreshed inner emotions" (p. 817). Producing particularly happy or joyful art-with bold, bright colors - might both be easier to perceive and might maximize felt reward or pleasure (Strand and Waller, 2010 for this suggestion in PD-related art therapy). This could also relate to the movement to impressionism or abstraction. Drago et al.'s (2009b) study of art viewing also showed that the patient, while receiving deep brain stimulation-typically coinciding with reduced medication and lowered creativity-reported lowered "induced feelings" from paintings. Similar results might also be driven by a more flexible, creative approach.

The combination of changes in style and attitude could also lead to quality improvement. Although we feel that presently this is the most tenuous finding in the case evidence, it would not be surprising that taking a freer, less inhibited approach to mark making or even depictions/content may lead to higher subjective ratings. Artworks that are more colorful, abstract, and impressionistic may also be seen as higher quality, especially by lay judges (such as case study doctors), and if compared again sober realistic depictions. Lay viewers tend to find brighter or saturated colors more positive (Palmer et al., 2013; 
Specker, 2019), tend to prefer highly emotion-laden art, especially if positive (Gerger et al., 2017), and may even prefer the use of blue (Komar and Melamid, 1997). Changes in subjective ratings (by doctors) have also been reported in case studies with artists who showed similar style changes due to stroke or dementia (e.g., Lovis Corinth; see Bäzner and Hennerici, 2006). Note that this may of course speak more to the raters than the artistic merit itself. This may, however, also be subjectively perceived by patients themselves as more impassioned, bold, and successful.

\subsection{Other explanations or modulating factors - person and context}

It of course must be noted that there may be other explanations beyond or in addition to patterns of changes in the brain. Predominantly these might tie to differences in the individual or context (Bachner-Melman et al., 2005; Canesi et al., 2012). According to Zaidel (2014), for example, and although we would argue that this does not perfectly align with the above evidence, the fact that some PD patients exhibit art activity after DA treatment could suggest that this only releases manifestations of premorbid latent talent or interest, rather than stemming from new patterns of changes in the brain.

\subsubsection{Rehabilitation, support, or life changes}

One of the most direct contextual factors may be changes in individual's everyday-life brought about following diagnosis with PD (e.g., Canesi et al., 2016; Joutsa et al., 2012a). This of course would lead to multiple life changes in activity and outlook. A patient may find themselves retiring from work or other family obligations, suddenly with more time for hobbies or art. They may also be encouraged by friends and family to make art as a productive response to being "sick". This would fit into the above general discussions of creativity, which stress importance of environment as a key means of especially artistic improvement and stylistic growth (Csikszentmihalyi, 1999; Rostan et al., 2002), and would align with the finding of changes primarily after diagnoses. This could also be tied to prior interest. Higher amounts of free time and external encouragement could also contribute to art making and artistic improvement.

Caretakers or nurses may suggest art making as a means of rehabilitation. Surprisingly the use and incidence of art with PD is not well-researched. There is some emerging discussion that art is sometimes used as therapy (Bae and Kim, 2018; Chancellor et al., 2014; Strand and Waller, 2010; Wadeson, 2003). However there is currently clear indication that this coincides with the spontaneous changes in motivation or reward above. Notably, a pilot study by Strand and Waller (2010), meant to explore the potential for art therapy in PD, found that while many patients enjoyed art-making, and some used art to express their feelings, they did not report any need to make art or addiction in the experience, and most began and saw the process mostly as therapy itself. Art making-irrespective of whether one is actually skilled or even has interest-may also allow for "sublimation" (Inzelberg, 2013), or a more acceptable outlet for otherwise socially deviant PD-related symptoms such as compulsion or asocial desires (see e.g., the case study by Witt et al., 2006 with a patient moving from buildings to nudes or similar case findings in Walker et al., 2006).

\subsubsection{Personality or biological prerequisites for artistic creativity and $P D$}

Individuals with certain characteristics may also certainly have higher propensity to PD-related onset of visual creativity or interest in art making. For example, in a study with verbal creativity, which investigated the effect of DA agonist/levodopa, Polner et al. (2015) showed that PD patients with positive-schizotypy were more likely to show increased flexibility of divergent thinking after dopaminergic therapy. As noted above, positive-schizotypy, because of its connection to artists (Burch et al., 2006), and in its functional or structural relation to DA functionality and many of the processes discussed above, does appear to be an intriguing candidate for many of the PD-related artistic findings. Notably here, it may be that those who become artists show, for example, higher baseline amounts of DA receptors (e.g., D2-3) in key regions related to flexibility or reward. Similar higher rates may also be found for TH-positive neurons. At the same time, the Polner et al. (2015) study also showed that those with higher past creative achievement also showed higher increases in divergent thinking. Similar results were also found for intelligence. Flexibility scores after treatment were also significantly and positively predicted by baseline flexibility. One might also expect similar relation to "Openness". This might fit the finding in the case studies, wherein even those patients primarily related to sudden uptake of art also tended to have had some past interest or training, even if not utilized for many years. These differences may also of course modulate the above arguments, explaining more or less susceptible artistic brains.

Interestingly, a large-scale survey of 750 male patients, along with a control sample of 1300 males, assessing prior occupation before PD diagnosis (Haaxma et al., 2015; see also Darweesh et al., 2018 for similar non-clinical study) found that those who had artistic jobs later in life (last job), around the time that PD is typically detected, had lower incidence of PD. The authors attributed this to the argument that one common premotor symptom involves lowered novelty seeking, potentially related to a pre-medicated diminishment in the pathways discussed above. Those with artistic occupations earlier in life (first main job), however, showed no difference from other occupations in predicting PD onset. Obviously, this also does not directly explain artistic uptake after $\mathrm{PD}$, but may provide more evidence for the role of dopaminergic therapy.

\subsubsection{Genetic aspects}

Genetic differences could also modulate results. Hundreds of genes would be expected to modulate the factors in creative behavior (Oikkonen et al., 2016). It would certainly not be surprising if certain predispositions could be more expressed by PD-related changes in brain functionality. To our knowledge, no studies have addressed the genetic basis of visual artists in healthy subjects, much less in PD patients (see also Schrag and Trimble, 2001; Zaidel, 2014). ${ }^{6}$ However, a few candidates might be mentioned.

As noted above, the DA-receptor DRD2 would presumably be a primarily starting point. This is implicated in flexibility, ideational fluency (Murphy et al., 2013; Reuter et al., 2006), and also in most of the DA agonist-related evidence from the case studies. Other DA-related genes such as the receptor DRD4, dopamine active transporter (DAT), and catechol-O- methyltransferase (COMT), important for maintaining appropriate levels of DA in prefrontal areas tied to executive functioning and attention, have been associated with ideation/divergent thinking (Murphy et al., 2013; Oikkonen et al., 2016). Especially COMT may also increase the disposition of frontal areas to respond to overstimulation from DA agonist therapy. Zabelina et al. (2016) recently showed that general creativity is predicted, at least partially, by interactions between genetic polymorphisms related to COMT (However, see also Reuter et al., 2006 who did not find a relation between COMT and verbal or visual creativity scoring). They also suggested that general creativity may tie to different genetic patterns between this and other genes such as DAT, the DA transporter gene responsible for DA reuptake in the striatal DA pathways and associated with cognitive flexibility. It may be that, partially due to such genes, individuals who sud-

\footnotetext{
6 Studies with monozygotic twins have looked at verbal forms of creativity or divergent thinking. These have led to mixed results-from very low (5\%, Kandler et al., 2016) to moderate (22\%, Nichols, 1978) to 40-60 percent (Piffer and Hur, 2014; Piffer, 2016) of creativity predicted by heritability (see also Oikkonen et al., 2016 with music-related creativity).
} 
denly improve or begin at art after PD show relatively higher likelihood for preserved functionality in prefrontal areas, tied to COMT, and/or earlier diminished functionality in other regions.

\section{Conclusion: putting it all together-factors at the root of artistic PD, implications, and issues for future research}

The above arguments suggest a fascinating pattern at the root of PD-induced changes in propensity or approach to making art. To conclude, we briefly summarize the above hypotheses, and end with suggestions for future research.

We suggest that (1) degeneration or lesion in the nigrostriatal DA pathway, involving the vSNc and dorsal striatum, and tied to motor control-typically the earliest noticed symptoms in PD-leads to diagnosis and initiation of DA replacement and, perhaps more important, DA agonist therapy. This may then be coupled with (2) relatively minor damage to especially the mesolimbic DA pathway striatal and midline structures. These are connected to introspection, flexibility and associations (ventral striatum), idea generation ( $\mathrm{mPFC}$, DMN, hippocampus), as well as to reward seeking, motivation, and impulsiveness (NAcc and especially $\mathrm{mOFC}$ ). Thus, DA agonist therapy may cause increased (above healthy baseline) activity in these undamaged regions. In addition, (3) especially in the subset of individuals who do spontaneously begin art-making, we might find selective damage/reduced function in the dlPFC (mesocortical pathway) as well as in the lateral OFC (Fig. 4).

This combination of damage and hyper-activity may both increase motivation for, and reward from, visual art. It may also lower inhibition of urges to create or to respond to artistic ideas, while also increasing the likelihood for spontaneity or for otherwise atypical topics. This would also fit the argument for a freer, more open personality of many healthy artists. Individuals who show art interest may also have relatively more damage to their left prefrontal or parietal regions, may have potential compensatory increases in DA receptivity in OFC and PCC, and/or may show genetic differences (e.g., tied to COMT) that could predispose some for PD-related artistic change.

This argument is supported by promising evidence for certain patterns of behavioral and treatment (DA pharmacology) changes in the case studies, in conjunction with literature on artistic creativity and PD's general progression relating to the brain. It is equally compelling that findings from non-art-related PD research tends to fit into this argument-e.g., for relative increases or decreases in damage/functionality of specific regions and tie to compulsion, reward-seeking, spontaneity. The above combination may also drive some general changes in style-looser handling of media, more abstraction, crosshatching (due to reduced motor control), increased color intensity and emotionality (due to some combination of altered color vision, general turn to impressionism or abstraction, difficulty with emotion discernment, higher felt reward, and/or life with PD), and potentially even leading to subjectively better art.

These hypotheses - much as the phenomenon of PD-related artistic creativity itself-then also raise multiple further questions and avenues for research:

\subsection{What does a damage/DA agonist-related explanation tell us about visual creativity and the unique cognitive or neurobiological aspects of artists?}

First, perhaps the major take-home from this paper concerns what these findings can tell us about brain's role in artistic motivation, ability, and creativity. Once again, the changes in some individuals with $\mathrm{PD}$, especially in those with a new drive to make art, presumably are tied to some corresponding brain changes brought about by either damage and/or over-activation. This paper's hypotheses, if supported in future research, would suggest that the collection of areas involved in lowering inhibition (OFC), heightening reward and reward learning (mesolimbic DA pathway, ventral striatum/NAcc), and higher flexibility, association making, and executive thinking (ventral striatum, vmPFC) and introspection (PCC) may hold the seed for visual creativity, artistic motivation, or their improvement. As noted above, it is promising that the identified areas have been previously connected to producing art or visual creativity in general. This was also posited to occur in tandem with the selective de-activation or loss of function in dIPFC and lateral $\mathrm{OFC}$ or other regions (e.g., thalamus) tied to analytic judgment. By connecting these regions to the overall networks of transmitting DA, this provides a compelling case for interconnections that might be further investigated.

It is also interesting to note that the importance of general attitude, spontaneity, and lowered inhibition, found here in conjunction with PD, is in keeping with emerging literature suggesting main drivers of success and pursuit of art making. For example, Pelowski et al. (2018) recently showed that it is predominantly personality and creativity assessments (Openness, Creative Personality Scale scoring), as well as time spent making art, which correlated to relatively more successful artworks. Whereas, aspects involving perception, mental rotation, angle drawing, visual memory, etc., which may play a role in realistic copying, did not tend to coincide with better or more creative art. Thus, the PD evidence provides more support for this collection of features that may underlie the ability of artists to spontaneously create novel and aesthetically pleasing artworks. It also gives potential evidence for a distinction between technical control, motor, or copying ability, and the creative nexus of artists.

These suggestions invite myriad future assessments. Immediate ideas might be the apparent importance of flexibility, ideation, reward, and inhibition in the actual production of artists, matched to structural or functional scanning of the implicated regions. Identification of if, how, and to what extent, areas/functions are actually involved in art making and in the successful or voluminous production of artists, would both help to better unlock this human activity, this would also be instrumental in better understanding the PD evidence and in explaining why PD can, but certainly does not always, lead to sudden/changed artists. Along this line of questioning, it is interesting to consider if there is an order to importance of brain regions and behaviors in terms of producing art. Is there one candidate region that is necessary and sufficient for overstimulation? Are all suggested areas required to operate in concert? Specifically, if we could assess differing levels or patterns of damage-such as those argued in this review-this would help to verify the present hypotheses. Imaging research on PD artists, or comparison between more or less adept art makers may also help to unlock the above findings, as would genetic assessments.

\subsubsection{Relation to general creativity, art/visual versus verbal creativity similarities and differences?}

This review also raises intriguing implications for general creativity, as well as for potential art making/visual creativity uniqueness. The aspects of increased motivation, reward seeking, or resulting reward from the artistic act, with reduced inhibition, increased flexibility, and in tandem with the arguments for underlying brain areas or DA pathways, could reveal important elements for general creativity response. These arguments do seem to highlight some of the key factors previously suggested in general creativity models-specifically the ability to adopt a freer mode of idea generation and to actually generate creative ideas (or ideation), and then to allow oneself to pursue such ideas to fruition without prematurely rejecting impulses. In the case of visual art, the literature appears to suggest a relatively equal importance of these two ideation/motivation factors (Flaherty, 2011; Chakravarty, 2010), and again, we would argue, highlighting DA agonist-related over-stimulation to especially mesolimbic reward regions. This raises the question 
of whether similar areas might be targeted in individuals reporting increased creativity in verbal or other domains.

On the other hand, there may also be intriguing differences. One immediate question arises from a recent theoretical paper by Boot et al. (2017). This makes a similar claim for selective damage to the nigrostriatal DA regions along with intactness of other pathways. However, the authors argue that the main candidate for interaction with DA agonists may be mesocortical areas (PFC), which they connect to persistence (see also the structural findings, for example relating to higher grey matter volume in dlPFC among those scoring higher on divergent thinking, Takeuchi et al., 2010). Whereas, we suggest that this pathway (especially dIPFC and lateral OFC regions), connected also to inhibition and analytic judgments, may be selectively inhibited in PD-artists. This may suggest that differing creativity types, perhaps unsurprisingly, tie to different functional aspects.

\subsubsection{Upward limits on DA-activation; issues with product or process creativity testing?}

Related to this above issue is the topic of DA and especially the upward limits or interrelation of brain activation. Notable here is flexibility, association networks, and the role of D2 receptors and/or their activation of especially the striatum. This region was again implicated in our review through both the functional and especially pharmacological evidence. It has also been related to flexibility in especially verbal problem solving (Boot et al., 2017) and genetic or personality (e.g., positive-schizotypy, see Chen et al., 2012; Woodward et al. 2011) related aspects. At the same time, as noted above, in general creativity studies, over-abundance of D2 receptors is tied to lowered scoring. This was shown to be naturally occurring in healthy populations (Chermahini and Hommel, 2010), with a U-shaped relation between striatal D2 receptor presence and creativity scoring. This finding, would suggest that overstimulation of striatal/D2-rich areas may not lead to more productive/creative art. Too much flexibility or wide associations may be too much - tying to unworkable ideas, or in regards to the above finding of a general inverse relationship between striatal dopamine and PFC areas related to executive control and perseverance (Boot et al., 2017), lack of focus and poor performance (see also Gvirts et al., 2016). This of course raises the question of whether similar results or upwards limits might be found in both the striatal/flexibility or other (reward, inhibition) related regions. This too marks a largely untapped area for future art creativity research.

This limit on flexibility and need for focus may also not be the case for visual art. First, this may have to do with the nature of both art making and standardized creativity assessments. Existing studies that have shown a U-shaped curve have found this specifically with standardized or verbal measures. Typically, these require individuals to come up with as many novel solutions for some item (words, pictures, numbers) within a time limit (for example, see Chermahini and Hommel, 2010). These would seem to require a degree of sustained focus and perseverance. Whereas, the nature of making art, especially when adopting a freer medium or mode of expression, may not require this.

Notably, in a preliminary genetic study of individuals with the DRD2 TAQ IA polymorphism, which occurs in about $28 \%$ of the population and results in a $30-40 \%$ reduction in D2 receptor density (Reuter et al., 2006). Individuals with this polymorphism showed significantly better creativity task performance. However, differences were only found with verbal and not with visual creativity scoring. Other studies that have found similar differences (e.g., Berman and Noble, 1995 with a visuospatial line orientation task; see also Tsai et al., 2002 for testing of intelligence) also have used similar, presumably sustained focus-requiring assessments. Similar findings are also found for PD patients involving standardized tests (Canesi et al., 2012). This might then introduce a rather interesting caveat or key difference to consider when do- ing creativity tests, especially in conjunction with brain or DA assessment, between a standardized test-focused "process" approach and a "product" emphasis on real-world (e.g., artwork) outputs (see also Reuter et al., 2006).

In addition to the obvious methodological questions about creativity testing, this issue also raises interesting questions especially for the PD-related case evidence. This might suggest that after PD diagnosis, we would see changes in the duration given to specific artworks. See again the case study by Kulisevsky et al. (2009) suggesting a much shorter duration for each artwork; notably no other study reports time for each work. It may also tie to the movement to abstraction.

Returning to the underlying biology and functionality of the artist brain, we might also find a more linear relation between higher DA and resulting activation, both in striatum and presumably other regions, and artistic output. This may be tentatively argued through the relation to increases in TH-positive neurons in PD patients, which might reduce standardized creativity scores but be key drivers of new/changed artists. Similarly, positive-schizotypy, found to be higher among healthy artists (Burch et al., 2006), might also suggest such evidence. Literature also has again shown that, among PD patients, positive schizotypy ties to higher increases in flexibility of divergent thinking after dopaminergic therapy versus those without this trait (Polner et al. (2015). This raises the need for future research, and the importance of further considering interindividual differences in response to medication, but also with respect to the impact of PD on artistic and other performance.

The above findings may also tie to the role of reward. The specific intactness/over-activation of reward regions may be an important counterpoint to widening associations, allowing individuals to passionately pursue the art task, but perhaps not to focus for an extended period on only one artwork. It may thus be that such reward-seeking, or a "passion" (Lemons, 2011), may account for both generally high creativity levels, impacting visual but also some verbal creativity assessments, and in PD-artist subgroups, this may become even more pronounced when DA levels become (positively or negatively) modulated, or may even make up for loss of functionality in other general-creativity related areas.

Even within the production or interaction with art, we may find key differences relating to specific stages or tasks and final behavioral outputs. Once again, modification via PD and medication may involve higher flexibility, idea generation, and felt reward, leading to more abundant and novel production of art. However, in its connection to lower persistence, it may also change art towards quick sketches, reduce details, expansion, and realism. Similarly, much as in the general creativity argument above, the prefrontal (especially dlPFC) areas are often tied to aesthetic processes such as art appreciation (e.g., Cattaneo et al., 2014a, 2014b), and thus PD, given the posited selective damage in artists, may reduce ability to make judgments about the quality of any one work. This also raises further questions regarding temporal aspects of the art-making or other creation processes, and the nature of how even artworks are assessed. Empirical studies attempting to tease apart such stages and related behavioral impacts have recently been begun (for example, see Limb and Braun, 2008 with music), but, much as with the present theoretical models, the processes of creating art is still empirically very much under-explored.

\subsubsection{Psychopharmacology or other causative approaches and DA?}

This general topic, the stages and aspects of art making, and art versus other creativity differences also immediately invite causative approaches. By, for example, exciting or repressing activity in the above-noted key regions (via TMS or tDCS) would it be possible to "awaken" the artist in healthy subjects? Of course, this would also be limited to cortical areas (e.g., dlPFC), and thus omit many of the DA pathways especially related to inhibition/flexibility, motivation, or reward. 
other obvious paradigm would involve administering healthy individuals levodopa and/or especially DA agonist and assessing for similar patterns of behavior or brain activation. This is only emerging in use with healthy participants, but has shown promise. Studies have shown ability to modulate cognitive flexibility or reward (van der Schaaf et al., 2012; van Holstein et al., 2011), and should certainly be tried with art (Spee et al., 2018 for review). Furthermore, understanding DA pathways, the specific role of receptors (D2 versus D3-4 or D1), and DA uptake in general, as it relates to art making or art experience, would be an important window into teasing apart many of the questions above. It is important to note that, currently, models of art or aesthetic experience, even those that consider the brain, only tangentially mention the role of DA (e.g., Pelowski et al., 2017c; Chatterjee, 2003).

\subsection{What does PD evidence suggest about artists? Why make art? is art good for us?}

Returning to the specific topic of art, the findings also raise intriguing implications regarding the status and uniqueness of art and artists. Interestingly, this paper could paint a rather cynical idea of art-making itself. Essentially, changes that lead to higher motivation to make art or artistic creativity/ability would include: (1) changes in the brain leading to higher felt or drive for reward, which can in some cases resemble motivation underlying drug addiction, (2) reduced inhibition, allowing individuals to act in ways or pursue activities, ideas, or means of expression where before they might have resisted due to felt personal or social responsibilities, (3) heightened internal focus on creative problems and one's inner emotional or evaluative state, while at the same time looking away from outer concerns and the involvement with society, and (4) higher executive control or ability to come up with, consider, and perhaps execute creative ideas. It could be argued that only the latter factor would generally be considered "positive" or adaptive for productively living in adult society. This raises interesting questions for evolution, sociology, or anthropology.

Could it be that such artistic motivation comes down to an 'atypical' brain operating often in an a-social context? One could also raise parallels between artists and a "sick" individual who withdraws from other social obligations and is often looked out for by a group of handlers allowing one to spend as much time as desired making art (this could fit a modern idea of the diva artist; see also Baas et al., 2016 for similar suggestions for creative geniuses in general). Certainly, another take-home from this review is that there is clearly also an overlap with much of the literature on positive-schizotypy. Differences in the above arguments for less clear upward limits on flexibility/associations, and, transversely, low need for focus and specific task perseverance-perhaps because of social context allowing this-adds further questions.

At the same time, the rather universal emphasis that we do give to art, and the esteem with which we view artists, suggest that ability and drive for visual creativity does hold some important benefit to humans. Notably here, there also is the question of why art making is chosen after diagnosis. The choice for patients who were artists before PD onset is perhaps not surprising, but what about the de novo artists? Certainly, there is evidence for other expressions of creativity following PD. It may be that art merely provides a socially and economically-accessible outlet for creative impulses, which could be similarly expressed via other means. It may also be that the act of art-making might of course also be more easily manipulated given PD motor symptoms or even taken up, compared to, say, suddenly playing a musical instrument (see for example Bae and Kim, 2018 for this argument with clay sculpting). Anecdotally, art-making, perhaps because of its combination of aesthetic and hands-on components, also relates to lessened tremor itself (Schlesinger et al., 2014; see also Sacks, 2006 with music).

Visual art may also hold specific aspects making it particularly resonant. Shimura et al. (2012), for example, suggest that art works repre- sent the mindset, mood, and preoccupation of the artist, which might become especially important when dealing with a life-altering illness. This could tie to both the unique underlying requirements for producing art-focusing, potentially, on flexibility, spontaneity, quick bursts of action; and less on focus and sustained perseverance. It could also tie again to reward. Art-making, especially among a certain sub-group of individuals, could be a particularly rewarding act, and thus driving their art-seeking and even compulsive behavior. This in turn would address the seemingly contradictory finding that $\mathrm{PD}$, in general, tends to reduce motivation to pursue most everyday life tasks. Recent findings by Le Heron et al. (2018), found that DA had an effect on motivating behavior, specifically when high effort for high reward was needed, and suggest "a crucial role" for mesolimbic areas in overcoming the costs of work, by signaling the value of actions. It may be that art, for some, provides such an avenue, and raises again the question of interpersonal differences. It would also be interesting to ascertain whether the small subset of PD patients who make art show other differences in overall physical or psychological health or life quality.

The nature of the case evidence, especially its tie to reward, also calls into question other art theories (e.g., Christensen, 2017) that art is somehow 'special' compared to baser human activities-food, sex-that are only pleasurable and addicting, whereas art making is somehow above mere pleasure. The evidence does not point to this when viewed in the light of PD.

\subsection{PD and art viewing — how does DA modulate aesthetic experience?}

Another largely unexplored facet involves the potential for changes in not only art production but also in how we view art or in general aesthetic experiences. It would be interesting to discover if changes are found in both modalities with PD-i.e., if reward from experiencing art is greater for a creative PD subgroup, or if any other qualities of viewed art such as color temperature or emotionality become more or less salient. Researchers could also assess whether improvements are found in aesthetic discernment (e.g., using a standardized assessment such as by Götz et al., 1979), which would further inform art making. Researchers could also follow other dementia or brain damage studies considering links between disease and preservation or changes in art/ aesthetic preferences (e.g., Chatterjee et al., 2011; Graham et al., 2013).

\subsection{Art making as tool for understanding PD, therapy, or early diagnosis?}

A better understanding of the changes leading to PD artists also offers promise for the general understanding of PD. The changes related to art appear to involve predominantly areas related to the premotor aspects of the disease (perception, cognition, emotion regulation). As noted by Hawkes et al. (2010, p. 82), current understanding suggests that by the time motor issues arise, PD is probably already "neuropathologically severely advanced and possibly irreversible." What is required, for therapy or even prevention, is better understanding of such more subtle changes, and even better identification of key signs in behavior. Art making, or aesthetic response, might be one such tool. Identifying specific art production or rating changes and tying these to damage or modulation of processes in the brain, could offer an important means of future therapy, differential diagnosis, or early PD detection (Bech et al., 2017; Chancellor et al., 2014). Primary candidates might range from higher visual complexity or crosshatching (as in Forsythe et al., 2017), as well as a change to abstraction, more emotionality, or even a shift in color palette to blues. Similarly, as suggested by for example Haaxma et al. (2015; see also Darweesh et al., 2018) artistic occupations, or even art making, may even relate to preventing or delaying onset of PD, or could be used in rehabilitative therapy. Obviously much more systematic analysis is needed. 


\subsection{Caveats and need for more systematic case studies and evidence}

We end with one more technical issue. Because of the present inclusion of only few cases, neuropsychological-aesthetics studies are often considered as merely informative anecdotes (Chatterjee, 2011). There is need for a larger number of reports. In doing so, these should better address a range of issues when reporting. This includes a need for in-depth clinical assessment of PD symptoms, identification of specific stages or laterality, and a clearer history of specific drug dosage, tied to corresponding reports of behavior. If the administered drugs constitute the impetus of the creative awakening in the PD-subgroup, different types of medicine and their role need to be defined (Connolly and Lang, 2014). Cases should also add structural and imaging information, as well as repeated imaging tied to major artistic change.

In addition, reporting the full range of creative endeavors taken up by individuals with PD, as well as their care or rehabilitation situation, would help to explain why many seem to choose art (e.g., Canesi et al., 2016). Interestingly, an aspect as seemingly straightforward as why or where most individuals get the idea to start making art, or whether most are enrolled in a rehabilitation program that involves art making has not presently been reported. Nor is there evidence for how often art is used in PD therapy in general. There is also no clear reporting of how long (days, weeks, hours) artistic urge/activity follows medication or even diagnosis.

There is also need for a much more systematic methodology in assessment of produced art. It is again rare (e.g., only Drago et al., 2009a; Forsythe et al., 2017) for researchers to assess artworks based on anything but subjective opinions or interviews with artists and caretakers. Because extant studies tend to lack a systematic methodology for assessing both style and quality it may be that changes have been obscured. Taking a Devil's advocate position, one could also argue that there are no actual changes in style/quality—a finding which could emerge from a larger systematic analysis. Researchers might consider using existing batteries and techniques from aesthetic psychology (e.g., Pelowski et al., 2018) or designed to systematically detect changes in art features that might reveal underlying changes in the brain (Chatterjee et al., 2010). Researchers might also employ computerized measures for color or complexity as we introduced in this paper. Similarly, longitudinal studies - beginning 20 years before diagnosis - would also be instrumental for assessing more subtle changes.

That said, the evidence for a phenomenon of awakened artistic creativity and PD, coupled with a hypothesis relating changes to specific patterns of brain activation and function, we hope, should indeed compel much future research.

\section{Uncited references}

Berridge and Kringelbach (2015), Forsaa et al. (2010) and Schindelin et al. (2012).

\section{Appendix A.}

\section{Appendix B. Supplementary data}

Supplementary material related to this article can be found, in the online version, at doi:https://doi.org/10.1016/j.neubiorev.2018.12. 016.

\section{References}

Alenicova, O.A, Likhachev, S.A., Davidova, O.I., 2017. Clinical significance and pathogenesis of visual impairment in Parkinson's disease. J. Neurol. Stroke 7 (7), 00266. https: //doi.org/10.15406/jnsk.2017.07.00266.
Apetauerova, D., Ryan, R.K., Ro, S.I., Arle, J., Shils, J., Papavassiliou, E., Tarsy, D., 2006. End of day dyskinesia in advanced Parkinson's disease can be eliminated by bilateral subthalamic nucleus or globus pallidus deep brain stimulation. Mov. Disord. 21 (8), 1277-1279. https://doi.org/10.1002/mds.20896, PMID 16637040.

Archibald, N.K., Hutton, S.B., Clarke, M.P., Mosimann, U.P., Burn, D.J., 2013. Visual exploration in Parkinson's disease and Parkinson's disease dementia. Brain 136 (3), 739-750. https://doi.org/10.1093/brain/awt005.

Ardouin, C., Chereau, I., Llorca, P.M., Lhommée, E., Durif, F., Pollak, P., Krack, P., 2009. Assessment of hyper-and hypo-dopaminergic behaviors in Parkinson's disease. Revue Neurologique (Paris) 165 (11), 845-856. https://doi.org/10.1016/j.neurol. 2009.06. 003, [Article in French].

Argyelan, M., Carbon, M., Ghilardi, M.F., Feigin, A., Mattis, P., Tang, C., Dhawan, V., Eidelberg, D., 2008. DAergic suppression of brain deactivation responses during sequence learning. J. Neurosci. 28, 10687-10695.

Assogna, F., Pontieri, F., Caltagirone, C., Spalletta, G., 2008. The recognition of facial emotion expressions in Parkinson's disease. Eur. Neuropsychopharmacol.: J. Eur. College Neuropsychopharmacol. 18, 835-848. https://doi.org/10.1016/j.euroneuro.2008.07. 004.

Baas, M., Nijstad, B.A., Boot, N.C., De Dreu, C.K., 2016. Mad genius revisited: vulnerability to psychopathology, biobehavioral approach-avoidance, and creativity. Psychol. Bull. $142(6), 668$

Bachner-Melman, R., Dina, C., Zohar, A.H., Constantini, N., Lerer, E., Hoch, S., Sella, S., Nemanov, L., Gritsenko, I., Lichtenberg, P., Granot, R., Ebstein, R.P., 2005. AVPR1a and SLC6A4 gene polymorphisms are associated with creative dance performance. PLoS Genet. 1 (3), e42.

Bae, Y.S., Kim, D.H., 2018. The applied effectiveness of clay art therapy for patients with Parkinson's disease. J. Evid. Integr. Med. 23, 2515690X18765943.

Ballard, I.C., Murty, V.P., Carter, R.M., MacInnes, J.J., Huettel, S.A., Adcock, R.A., 2011 Dorsolateral prefrontal cortex drives mesolimbic dopaminergic regions to initiate motivated behavior. J. Neurosci. 31 (28), 10340-10346.

Barbot, B., Tinio, P.P.L., 2015. Where is the "g" in creativity? A specialization-differentiation hypothesis. Front. Hum. Neurosci. 8 (1041), 1-4. https://doi.org/10.3389/ fnhum.2014.01041.

Baruch, I., Hemsley, D.R., Gray, J.A., 1988. Differential performance of acute and chronic schizophrenics in a latent inhibition task. J. Nerv. Ment. Dis. 176 (10), 598-606.

Bayulkemand, K., Lopez, G., 2011. Clinical approach to nonmotor sensory fluctuations in Parkinson's disease. J. Neurol. Sci. 310, 82-85.

Bäzner, H., Hennerici, H., 2006. Stroke in painters. Int. Rev. Neurobiol. 74, 165-191.

Bech, S., Haugbøl, S., Winge, K., 2017. Challenges in the differential diagnoses of parkinsonism. Ugeskr. Laeg. 179 (33).

Berman, S.M., Noble, E.P., 1995. Reduced visuospatial performance in children with the D2 dopamine receptor A1 allele. Behav. Genet. 25, 45-58.

Berridge, K.C., 2007. The debate over dopamine's role in reward: the case for incentive salience. Psychopharmacology 191 (3), 391-431.

Berridge, K.C., Kringelbach, M.L., 2013. Neuroscience of affect: brain mechanisms of pleasure and displeasure. Curr. Opin. Neurobiol. 23 (3), 294-303. https://doi.org/10. 1016/j.conb.2013.01.017.

Berridge, K.C., Kringelbach, M.L., 2015. Pleasure systems in the brain. Neuron 86 (3), 646-664. https://doi.org/10.1016/j.neuron.2015.02.018.

Berridge, K.C., Robinson, T.E., Aldridge, J.W., 2009. Dissecting components of reward: 'Liking', 'wanting', and learning. Curr. Opin. Pharmacol. 9 (1), 65-73. https://doi. org/10.1016/j.coph.2008.12.014.

Betchen, S.A., Kaplitt, M., 2003. Future and current surgical therapies in Parkinson's disease. Curr. Opin. Neurol. 16 (4), 487-493.

Bhattacharya, J., Petsche, H., 2005. Drawing on mind's canvas: differences in cortical integration patterns between artists and non-artists. Hum. Brain Mapp. 26 (1), 1-14.

Bindler, L., Anheim, M., Tranchant, C., Vidailhet, P., 2011. La créativité du patient parkinsonien. Annales Médico-psychologiques Revue Psychiatrique 169, 104-107. https:// doi.org/10.1016/j.amp.2010.10.001.

Birch, J., Kolle, R.U., Kunkel, M., Paulus, W., Upadhyay, P., 1998. Acquired colour deficiency in patients with Parkinson's disease. Vision Res. 38 (21), 3421-3426.

Björklund, A., Dunnett, S.B., 2007. Dopamine neuron systems in the brain: an update Trends Neurosci. 30 (5), 194-202.

Bodis-Wollner, I., 2009. Retinopathy in parkinson disease. J. Neural Transm. 116 1493-1501. https://doi.org/10.1007/s00702-009-0292-z.

Bogousslavsky, J, 2005. Artistic creativity, style and brain disorders. Eur. Neurol. 54 (2), 103-111.

Boot, N., Baas, M., van Gaal, S., Cools, R., De Dreu, C.K., 2017. Creative cognition and dopaminergic modulation of fronto-striatal networks: integrative review and research agenda. Neurosci. Biobehav. Rev. 78, 13-23. https://doi.org/10.1016/j.neubiorev. 2017.04.007.

Borovac, J.A., 2016. Side effects of a dopamine agonist therapy for Parkinson's disease: mini-review of clinical pharmacology. Yale J. Biol. Med. 89, 37-47.

Braak, H., Del Tredici, K., Rüb, U., de Vos, R.A., Jansen Steur, E.N., Braak, E., 2003. Staging of brain pathology related to sporadic Parkinson's disease. Neurobiol. Aging 24 , 197-211.

Burch, G.S.J., Pavelis, C., Hemsley, D.R., Corr, P.J., 2006. Schizotypy and creativity in visual artists. Br. J. Psychol. 97 (2), 177-190.

Calabresi, P., Castrioto, A., Di Filippo, M., Picconi, B., 2013. New experimental and clinical links between the hippocampus and the dopaminergic system in Parkinson's disease. Lancet Neurol. 12 (8), 811-821. https://doi.org/10.1016/S1474-4422(13)70118-2.

Cameron, I.G., Watanabe, M., Pari, G., Munoz, D.P., 2010. Executive impairment in Parkinson's disease: response automaticity and task switching. Neuropsychologia 48 (7), 1948-1957.

Campbell, D.T., 1960. Blind variation and selective retention in creative thought as in other knowledge processes. Psychol. Rev. 67 (6), 380-400.

Canesi, M., Rusconi, M.L., Isaias, I.U., Pezzoli, G., 2012. Artistic productivity and creative thinking in Parkinson's disease. Eur. J. Neurol. 19, $468-472$ 
Canesi, M., Rusconi, M.L., Moroni, F., Ranghetti, A., Cereda, E., Pezzoli, G., 2016. Creative thinking, professional artists, and Parkinson's disease. J. Parkinsons Dis. 6 (1), 239-246.

Cao, H., Shi, J., Cao, B., Kang, B., Zhang, M., Qu, Q., 2017. Evaluation of the Braak staging of brain pathology with 1H-MRS in patients with Parkinson's disease. Neurosci. Lett. 660, 57-62. https://doi.org/10.1016/j.neulet.2017.08.050.

Cattaneo, Z., Lega, C., Flexas, A., Nadal, M., Munar, E., Cela-Conde, C.J., 2014. The world can look better: enhancing beauty experience with brain stimulation. Soc. Cogn. Affect. Neurosci. 9 (11), 1713-1721. https://doi.org/10.1093/scna/nst165.

Cattaneo, Z., Lega, C., Gardelli, C., Merabet, L.B., Cela-Conde, C.J., Nadal, M., 2014. The role of prefrontal and parietal cortices in esthetic appreciation of representational and abstract art: a TMS study. NeuoImage 99, 443-450. https://doi.org/10.1016/j. neuroimage.2014.05.037.

Cecchetti, L., Kupers, R., Ptito, M., Pietrini, P., Ricciardi, E., 2016. Are supramodality and cross-modal plasticity the yin and yang of brain development? From blindness to rehabilitation. Front. Syst. Neurosci. 10, 89. https://doi.org/10.3389/fnsys.2016.00089.

Chakravarty, A., 2010. The creative brain: revisiting concepts. Med. Hypotheses 74, 606-612.

Chamberlain, R., McManus, I.C., Brunswick, N., Rankin, Q., Riley, H., Kanai, R., 2014. Drawing on the right side of the brain: a voxel-based morphometry analysis of observational drawing. NeuroImage 96, 167-173. https://doi.org/10.1016/j.neuroimage. 2014.03.062.

Chan, D.W., Zhao, Y., 2010. The relationship between drawing skill and artistic creativity: Do age and artistic involvement make a difference?. Creat. Res. J. 22 (1), 27-36.

Chancellor, B., Duncan, A., Chatterjee, A., 2014. Art therapy for Alzheimer's disease and other dementias. J. Alzheimer Dis. 39 (1), 1-11.

Chatterjee, A., 2003. Prospects for a cognitive neuroscience of visual aesthetics. Bull. Psychol. Arts 4, 55-60.

Chatterjee, A., 2011. Neuroaesthetics: a coming of age story. J. Cogn. Neurosci. 23, 53-62.

Chatterjee, A., Hamilton, R.H., Amorapanth, P.X., 2006. Art produced by a patient with Parkinson's disease. Behav. Neurol. 17 (2), 105-108.

Chatterjee, A., Widick, P., Sternschein, R., Smith, W.B., Bromberger, I.B., 2010. The assessment of art attributes. Empir. Stud. Arts 28 (2), 207-222.

Chatterjee, A., Bromberger, B., Smith, W.B., Sternschein, R., Widick, P., 2011. Artistic production following brain damage: a study of three artists. Leonardo 44 (5), 405-410.

Chaudhuri, K.R., Healy, D.G., Schapira, A.H.V., 2006. Non-motor symptoms of Parkinson's disease: diagnosis and management. Lancet Neurol. 5 (3), 235-245.

Chaudhuri, K.R., Sauerbier, A., Rojo, J.M., Sethi, K., Schapira, A.H., Brown, R.G., Antonini, A., Stocchi, F., Odin, P., Bhattacharya, K., Tsuboi, Y., Abe, K., Rizos, A., Rodriguez-Blazquez, C., Martinez-Martin, P., 2015. The burden of non-motor symptoms in Parkinson's disease using a self-completed non-motor questionnaire: a simple grading system. Parkinsonism Relat. Disord. 21, 287-291.

Chavez-Eakle, R., Graf-Guerrero, A., Garcia-Reyna, J., Vaugier, V., Cruz-Fuentes, C., 2007. Cerebral blood flow associated with creative performance: a comparative study. NeuroImage 38, 519-528.

Chen, K.C., Lee, I.H., Yeh, T.L., Chiu, N.T., Chen, P.S., Yang, Y.K., Chen, C.C., 2012. Schizotypy trait and striatal dopamine receptors in healthy volunteers. Psychiatry Res. Neuroimaging 201 (3), 218-221.

Chermahini, S.A., Hommel, B., 2010. The (b)link between creativity and dopamine: spontaneous eye blink rates predict and dissociate divergent and convergent thinking. Cognition 115 (3), 458-465.

Christensen, J.F., 2017. Pleasure junkies all around! Why it matters and why 'the arts' might be the answer: a biopsychological perspective. Proc. Biol. Sci. 284 (1854)https: //doi.org/10.1098/rspb.2016.2837, pii: 20162837.

Chung, K.K., Zhang, Y., Lim, K.L., Tanaka, Y., Huang, H., Gao, J., Ross, C.A., Dawson, V.L., Dawson, T.M., 2001. Parkins upbiquitinates the alpha-synuclein-synphilin-1: implications for Lewy-body formation in Parkinson's disease. Nat. Med. 7, 1144-1504.

Cilia, R., Siri, C., Marotta, G., Isaias, I.U., De Gaspari, D., Canesi, M., Pezzoli, G., Antonini, A., 2008. Functional abnormalities underlying pathological gambling in Parkinson disease. Arch. Neurol. 65, 1604-1611.

Connolly, B.S., Lang, A.E., 2014. Pharmacological treatment of Parkinson disease: a review. JAMA 311 (16), 1670-1683. https://doi.org/10.1001/jama.2014.3654, 23-30.

Csikszentmihalyi, M., 1999. Implications of a systems perspective for the study of creativity. In: Sternberg, R. (Ed.), Handbook of Creativity. Cambridge University Press, Cambridge.

Csikszentmihalyi, M., Abuhamdeh, S., Nakamura, J., 2005. Flow. In: Elliot, A.J., Dweck, C.S. (Eds.), Handbook of Competence and Motivation. Guilford Publications, New York, pp. 598-608.

Darweesh, S.K., Ikram, M.K., Faber, M.J., de Vries, N.M., Haaxma, C.A., Hofman, A., Ikram, M.A., 2018. Professional occupation and the risk of Parkinson Disease. Eur. J. Neurol.

Davidsdottir, S., Cronin-Golomb, A., Lee, A., 2005. Visual and spatial symptoms in Parkinson's disease. Vision Res. 45 (10), 1285-1296.

De Manzano, , Cervenka, S., Karabanov, A., Farde, L., Ullen, F., 2010. Thinking outside a less intact box: thalamic dopamine D2 receptor densities are negatively related to psychometric creativity in healthy individuals. PLoS One 5 (5), e10670.

Delaveau, P., Salgado-Pineda, P., Fossati, P., Witjas, T., Azulay, J.-P., Blin, O., 2010. Dopaminergic modulation of the default mode network in Parkinson's disease. Eur. Neuropsychopharmacol. 20 (11), 784-792.

Deuschel, G., Goddemeier, C., 1998. Spontaneous and reflex activity of facial muscles in dystonia, Parkinson's disease, and in normal subjects. J. Neurol. Neurosurg. Psychiatr. 64, 320-324.

Diederich, N.J., Stebbins, G., Schiltz, C., Goetz, C.G., 2014. Are patients with Parkinson's disease blind to blindsight?. Brain 137 (6), 1838-1849. https://doi.org/10.1093/ brain/awu094.
Drago, V., Heilman, K.M., 2012. Creativity. Encycl. Hum. Behav. 606-617. https://doi. org/10.1016/B978-0-12-375000-6.00112-9.

Drago, V., Foster, P.S., Okun, M.S., Cosentino, F.I.I., Conigliaro, R., Haq, I., Sudhyadhom, A., Skidmore, F.M., Heilman, K.M., 2009. Turning off artistic ability: the influence of left DBS in art production. J. Neurol. Sci. 281, 116-121.

Drago, V., Foster, P.S., Okun, M.S., Haq, I., Sudhyadhom, A., Skidmore, F.M., Heilman, K.M., 2009. Artistic creativity and DBS: a case report. J. Neurol. Sci. 276 (1-2), $138-142$.

Drago, V., Foster, P.S., Skidmore, F.M., Heilman, K.M., 2009. Creativity in Parkinson's disease as a function of right versus left hemibody onset. J. Neurol. Sci. 15, 276.

Drake, J.E., Winner, E., 2009. Precocious realists: perceptual and cognitive characteristics associated with drawing talent in non-autistic children. Philos. Trans. R. Soc. Lond. B, Biol. Sci. 364, 1449-1458. https://doi.org/10.1098/rstb.2008.0295.

Ellamil, M., Dobson, C., Beeman, M., Christoff, K., 2012. Evaluative and generative modes of thought during the creative process. NeuroImage 59, 1783-1794.

Elliott, R., 2003. Executive functions and their disorders. Br. Med. Bull. 65, 49-59.

Elliott, R., Dolan, R.J., Frith, C.D., 2000. Dissociable functions in the medial and lateral orbitofrontal cortex: evidence from human neuroimaging studies. Cereb. Cortex 10 (3), 308-317.

Enrici, I., Adenzato, M., Ardito, R.B., Mitkova, A., Cavallo, M., Zibetti, M., Castelli, L., 2015. Emotion processing in Parkinson's disease: a three-level study on recognition, representation, and regulation. PLoS One 10 (6), e0131470https://doi.org/10.1371/ journal.pone. 0131470 .

Evans, A., Strafella, A., Weintraub, D., Stacy, M., 2009. Impulsive and compulsive behaviors in Parkinson's disease. Mov. Disord. 24 (11), 1561-1570. https://doi.org/10. $1002 / \mathrm{mds} .22505$.

Fahn, S., Elton, R.L., UPDRS Development Committee, 1987. The unified parkinson's disease rating scale. In: In: Fahn, S., Marsden, C.D., Calne, D.B., Goldstein, M. (Eds.), Recent Developments in Parkinson'S Disease Vol 2, Macmillan Health Care Information, Florham Park, NJ, pp 153-163, 293-304.

Faust-Socher, A., Kenett, Y., Cohen, O.S., Hassin-Baer, S., Inzelberg, R., 2014. Enhanced creative thinking under dopaminergic therapy in Parkinson disease. Ann. Neurol. 75 (6), 935-942. https://doi.org/10.1002/ana.24181.

Fayn, K., MacCann, C., Tiliopoulos, N., Silvia, P.J., 2015. Aesthetic emotions and aesthetic people: openness predicts sensitivity to novelty in the experiences of interest and pleasure. Front. Psychol. 6 (1877), 1-11.

Flaherty, A.W., 2005. Frontotemporal and dopaminergic control of idea generation and creative drive. J. Comp. Neurol. 493, 147-153. https://doi.org/10.1002/cne.20768.

Flaherty, A.W., 2011. Brain illness and creativity: mechanism and treatment risks. Can. J. Psychiatry 56, 132-143.

Forsaa, E.B., Larsen, J.P., Wentzel-Larsen, T., Alves, G., 2010. What predicts mortality in Parkinson disease?: a prospective population-based long-term study. Neurology 75 (14), 1270-1276. https://doi.org/10.1212/WNL.0b013e3181f61311.

Forsythe, A., Williams, T., Reilly, R.G., 2017. What paint can tell us: a fractal analysis of neurological changes in seven artists. Neuropsychology 31 (1), 1-10. https://doi.org/ $10.1037 /$ neu0000303.

Gansler, D.A., Moore, D.W., Susmaras, T.M., Jerram, M.W., Sousa, J., Heilman, K.M., 2011. Cortical morphology of visual creativity. Neuropsychologia 49 (9), 2527-2533.

Gardner, H., Winner, E., 1982. First intimations of artistry. In: Strauss, S. (Ed.), U-Shaped Behavioral Growth. Academic Press, New York, NY, pp. 147-168.

Gillies, G.E., Pienaar, I.S., Vohra, S., Qamhawi, Z., 2014. Sex differences in Parkinson's disease. Front. Neuroendocrinol. 35 (3), 370-384.

Goetz, C.G., Poewe, W., Rascol, O., Sampaio, C., Stebbins, G.T., Counsell, C., Giladi, N., Holloway, R.G., Moore, C.G., Wenning, G.K., Yahr, M.D., Seidl, L., 2004. Movement Disorder Society Task Force report on the Hoehn and Yahr Staging Scale: status and recommendations. The Movement Disorder Society Task Force on rating scales for Parkinson's disease. Mov. Disord. 19 (9), 1020-1028. https://doi.org/10.1002/mds. 20213.

Goetz, C.G., Fahn, S., Martinez-Martin, P., Poewe, W., Sampais, C., Stebbins, G.T., Stern, M.B., Tilley, B.C., Dodel, R., Dubois, B., Holloway, R., Jankovic, J., Kulisevsky, J., Lang, A.E., Lees, A., Leurgens, S., LeWitt, P.A, Nyenhuis, D., Olanow, C.W., Rascol, O., Schrag, A., Teresi, J.A., van Hilten, J.J., LaPelle, N., 2007. Sponsored revision of the Unified Parkinson's Disease Rating Scale (MDS-UPDRS): process, format, and clinimetric testing plan. Movement Disord. 22 (1), 41-47.

Gombrich, E.H., 1960. Art and Illusion. A Study in the Psychology of Pictorial Representation. Phaidon., London.

Götz, K.O., Borisy, A.R., Lynn, R., Eysenck, H.J.A, 1979. New visual aesthetic sensitivity test: I. Construction and psychometric properties. Percept. Mot. Skills 49, 795-802.

Graham, D.J., Stockinger, S., Leder, H., 2013. An island of stability: art images and natural scenes-but not natural faces-show consistent esthetic response in Alzheimer's-related dementia. Front. Psychol. 4, 107. https://doi.org/10.3389/fpsyg.2013.00107.

Grahn, J.A., Parkinson, J.A., Owen, A.M., 2008. The cognitive functions of the caudate nucleus. Prog. Neurobiol. 86 (3), 141-155.

Gray, H.M., Tickle-Degnen, L., 2010. A meta-analysis of performance on emotion recognition tasks in Parkinson's disease. Neuropsychology 24 (2), 176-191.

Gretton, C., Ffytche, D.H., 2014. Art and the brain: a view from dementia. Int. J. Geriatr. Psychiatry 29 (2), 111-126. https://doi.org/10.1002/gps.3975.

Groman, S.M., James, A.S., Seu, E., Tran, S., Clark, T.A., Harpster, S.N., ... Elsworth, J.D., 2014. In the blink of an eye: relating positive-feedback sensitivity to striatal dopamine D2-like receptors through blink rate. J. Neurosci. 34 (43), 14443-14454.

Grover, S., Mansi, S., Santhosh, K., Ajit, A., 2015. Psychiatric aspects of Parkinson's disease. J. Neurosci. Rural Pract. 6 (1), 65-76.

Haaxma, C.A., Borm, G.F., van der Linden, D., Kappelle, A.C., Bloem, B.R., 2015. Artistic occupations are associated with a reduced risk of Parkinson's disease. J. Neurol. 262 (9), 2171-2176.

Hare, T.A., Malmaud, J., Rangel, A., 2011. Focusing attention on the health aspects of foods changes value signals in vmPFC and improves dietary choice. J. Neurosci. 31 (30), 11077-11087. 
Heil-

man

et al.,

2003 K.M. Heilman, S.E. Nadeau, D.O. Beversdorf, Creative innovation: possible brain mechanisms, Neurocase 9 (5) (2003) 369-379, https://doi.org/10.1076/neur.9. 5.369 .16553$.

Hoehn, M., Yahr, M., 1967. Parkinsonism: onset, progression and mortality. Neurology 17 (5), 427-442. https://doi.org/10.1212/wnl.17.5.427.

Inzelberg, R., 2013. The awakening of artistic creativity and Parkinson's disease. Behav. Neurosci. 127 (2), 256-261.

Jellinger, K.A., 2014. Parkinson's disease. Pathobiol. Hum. Dis. 2021-2035. https://doi. org/10.1016/B978-0-12-386456-7.04605-0.

Joutsa, J., Martikainen, K., Kaasinen, V., 2012. Parallel appearance of compulsive behaviors and artistic creativity in Parkinson's disease. Case Rep. Neurol. 2012 (4), 77-83.

Joutsa, J., Martikainen, K., Niemel, S., Johansson, J., Forsback, S., Rinne, J.O., Kaasinen, V., 2012. Increased medial orbitofrontal [18F]fluorodopa uptake in Parkinsonian impulse control disorders. Mov. Disord. 27 (6), 778-782.

Jung, R.E., Mead, B.S., Carrasco, J., Flores, R.A., 2013. The structure of creative cognition in the human brain. Front. Hum. Neurosci. 7, 330. https://doi.org/10.3389/fnhum. 2013.00330.

Kalia, L.V., Lang, A.E., 2015. Parkinson's disease. Lancet 386 (9996), 896-912. https:// doi.org/10.1016/s0140-6736(14)61393-3.

Kandler, C., Riemann, R., Angleitner, A., Spinath, F.M., Borkenau, P., Penke, L., 2016. The nature of creativity: the roles of genetic factors, personality traits, cognitive abilities, and environmental sources. J. Pers. Soc. Psychol. 111 (2), 230-249. https://doi.org/ $10.1037 / \mathrm{pspp} 0000087$.

Kessler, R.M., Woodward, N.D., Riccardi, P., Li, R., Ansari, M.S., Anderson, S., ... Meltzer, H.Y., 2009. Dopamine D2 receptor levels in striatum, thalamus, substantia nigra, limbic regions, and cortex in schizophrenic subjects. Biol. Psychiatry 65 (12), 1024-1031.

Kobayakawa, M., Tsuruya, N., Kawamura, M., 2017. Decision-making performance in Parkinson's disease correlates with lateral orbitofrontal volume. J. Neurol. Sci. 372, 232-238.

Komar, V., Melamid, A., 1997. Painting by Numbers: Komar and Melamid's Scientific Guide to Art. University of California Press.

Kottlow, M., Praeg, E., Luethy, C., Jancke, L., 2011. Artists' advance: decreased upper alpha power while drawing in artists compared with non-artists. Brain Topogr. 23 (4), 392-402. https://doi.org/10.1007/s10548-010-0163-9.

Kowatari, Y., Lee, S.H., Yamamura, H., Nagamori, Y., Levy, P., Yamane, S., Yamamoto, M., 2009. Neural networks involved in artistic creativity. Hum. Brain Mapp. 30 (5), 1678-1690. https://doi.org/10.1002/hbm.20633.

Kozbelt, A., Seeley, W.P., 2007. Integrating art historical, psychological, and neuroscientific explanations of artists' advantages in drawing. Psychol. Aesthet. Creat. Arts 1, 80-90. https://doi.org/10.1037/1931-3896.1.2.80.

Kulisevsky, J., Pagonabarraga, J., Martinez-Corral, M., 2009. Changes in artistic style and behaviour in Parkinson's disease: dopamine and creativity. J. Neurol. 256, 816-819. https://doi.org/10.1007/s00415-009-5001-1.

Lakke, J.P., 1999. Art and Parkinson's disease. Adv. Neurol. 80 (471-), 479.

Lauring, J.O., 2015. The theoretical and methodological backdrop of neuroaesthetics. In: Lauring, J.O. (Ed.), An Introduction to Neuroaesthetics: The Neuroscientific Approach to Aesthetic Experience, Artistic Creativity and Arts Appreciation. Museum Tusculanum Press, Copenhagen, pp. 71-114, Chicago: University of Chicago Press.

Le Bouc, R., Rigoux, L., Schmidt, L., Degos, B., Welter, M.L., Vidailhet, M., Daunizeau, J., Pessiglione, M., 2016. Computational dissection of dopamine motor and motivational functions in humans. J. Neurosci. 36 (25), 6623-6633. https://doi.org/10. 1523/JNEUROSCI.3078-15.2016.

Le Heron, C., Plant, O., Manohar, S., Ang, Y.S., Jackson, M., Lennox, G., Husain, M., 2018. Distinct effects of apathy and dopamine on effort-based decision-making in Parkinson's disease. Brain 141 (5), 1455-1469.

Lemons, G., 2011. Diverse perspectives of creativity testing controversial issues when used for inclusion into gifted programs. J. Educ. Gift. 34, 742-772.

Lhommée, E., Batir, A., Quesada, J.-L., Ardouin, C., Fraix, V., Seigneuret, E., Chabardès, S., Benabid, A.-L., Pollak, P., Krack, P., 2014. Dopamine and the biology of creativity: lessons from Parkinson's disease. Front. Neurol. 5 (55), 1-10.

Lim, S.Y., Fox, S.H., Lang, A.E., 2009. Overview of the extranigral aspects of Parkinson disease. Arch. Neurol. 66 (2), 167-172. https://doi.org/10.1001/archneurol.2008.561.

Lima, C.F., Garrett, C., Castro, S.L., 2013. Not all sounds sound the same: parkinson's disease affects differently emotion processing in music and in speech prosody. J. Clin. Exp. Neuropsychol. 35 (4), 373-392.

Limb, C.J., Braun, A.R., 2008. Neural substrates of spontaneous musical performance: an fMRI study of jazz improvisation. PLoS One 3 (2), e1679.

Lubart, T.I., Sternberg, R.J., 1998. Creativity across time and place: life span and cross-cultural perspective. High Abil. Stud. 9, 59-74.

Martinez-Martin, P., Rodriguez-Blazquez, C., Kurtis, M.M., Chaudhuri, K.R., NMSS Validation Group, 2011. The impact of non-motor symptoms on health-related quality of life of patients with Parkinson's disease. Mov. Disord. 26 (3), 399-406. https://doi.org/ $10.1002 / \mathrm{mds} .23462$.

Mattei, T.A., Rodriguez, A.H., Bassuner, J., 2013. Selective impairment of emotion recognition through music in Parkinson's disease: Does it suggest the existence of different networks for music and speech prosody processing?. Front. Neurosci. 7, 161. https:// doi.org/10.3389/fnins.2013.00161.

McManus, I.C., Chamberlain, R., Loo, P.W., Rankin, Q., Riley, H., Brunswick, N., 2010. Art students who cannot draw: exploring the relations between drawing ability, visual memory, accuracy of copying, and dyslexia. Psychol. Aesthet. Creat. Arts 4, 18 .

Miall, R.C., Gowen, E., Tchalenko, J., 2009. Drawing Cartoon Faces: A Functional Imaging Study of the Cognitive Neuroscience of Drawing. Cortex 45 (3), 394-406.

Moro, E., Lang, A.E., 2006. Criteria for deep-brain stimulation in Parkinson's disease: review and analysis. Expert Rev. Neurother. 6 (11), 1695-1705. https://doi.org/10. 1586/14737175.6.11.1695, PMID 17144783..
Mottron, L., Dawson, M., Soulieres, I., 2009. Enhanced perception in savant syndrome: patterns, structure and creativity. Philos. Trans. R. Soc. Lond. B: Biol. Sci. 364 1385-1391. https://doi.org/10.1098/rstb.2008.0333.

Müller, T., Woitalla, D., Peters, S., Kohla, K., Przuntek, H., 2002. Progress of visual dysfunction in Parkinson's disease. Acta Neurol. Scand. 105 (4), 256-260.

Murphy, M., Runco, M.A., Acar, S., Reiter-Palmon, R., 2013. Reanalysis of genetic data and rethinking dopamine's relationship with creativity. Creat. Res. J. 25, 147-148. https://doi.org/10.1080/10400419.2013, 752305.

Myszkowski, N., Storme, M., Zenasni, F., Lubart, T., 2014. Is visual aesthetic sensitivity independent from intelligence, personality and creativity?. Pers. Individ. Dif. 59, 16-20. https://doi.org/10.1016/j.paid.2013.10.021.

Nagano-Saito, A., Liu, J., Doyon, J., Dagher, A., 2009. Dopamine modulates default mode network deactivation in elderly individuals during the Tower of London task. Neurosci. Lett. 458 (1), 1-5. https://doi.org/10.1016/j.neulet.2009.04.025.

Newman, G.E., Bloom, P., 2012. Art and authenticity: the importance of originals in judgments of value. J. Exp. Psychol. Gen. 141 (3), 558-569. https://doi.org/10.1037/ a0026035.

Nichols, R.C., 1978. Twin studies of ability, personality and interests. Homo 29, 158-173.

Niu, W., Sternberg, R.J., 2001. Cultural influences on artistic creativity and its evaluation. Int. J. Psychol. 36 (4), 225-241.

Niv, Y., 2007. Cost, benefit, tonic, phasic. Ann. N. Y. Acad. Sci. 1104 (1), 357-376.

Niv, Y., Daw, N.D., Dayan, P., 2006. How fast to work: response vigor, motivation and tonic dopamine. Advances in Neural Information Processing Systems. 1019-1026.

Oh, Y.S., Kim, J.S., Chung, S.W., Song, I.U., Kim, Y.D., Kim, Y.I., Lee, K.S., 2011. Color vision in Parkinson's disease and essential tremor. Eur. J. Neurol. 18 (4), 577-583.

Oikkonen, J., Kuusi, T., Peltonen, P., Raijas, P., Ukkola-Vuoti, L., Karma, K., Onkamo, P., Järvelä, I., 2016. Creative activities in music - a genome-wide linkage analysis. PLoS One 11 (2), e0148679https://doi.org/10.1371/ journal.pone.0148679.

Okun, M.S., 2012. Deep-brain stimulation for Parkinson's disease. N. Engl. J. Med. 367 (16), 1529-1538. https://doi.org/10.1056/NEJMct1208070.

Palmer, S.E., Schloss, K.B., Sammartino, J., 2013. Visual aesthetics and human preference. Annu. Rev. Psychol. 64 (1), 77-107.

Palmiero, M., Di Giacomo, D., Passafiume, D., 2012. Creativity and dementia: a review. Cogn. Process. 13 (3), 193-209. https://doi.org/10.1007/s10339-012-0439-y.

Pelowski, M., Gerger, G., Chetouani, Y., Markey, P.S., Leder, H., 2017. But is it really art? The classification of laboratory-presented images as "art"/"not art" and correlations with appraisal and viewer interpersonal differences. Front. Psychol. 8, 1729. https:// doi.org/10.3389/fpsyg.2017.01729.

Pelowski, M., Leder, H., Tinio, P.P., 2017. Creativity in the domain of visual art. In: Kaufman, J.C., Baer, J., Glaveanu, V. (Eds.), Cambridge Handbook of Creativity Across Different Domains, Cambridge University Press, Cambridge, UK, pp. 80-109.

Pelowski, M., Markey, P.S., Forster, M., Gerger, G., Leder, H., 2017. Move me, astonish me... delight my eyes and brain: the Vienna Integrated Model of top-down and bottom-up processes in Art Perception (VIMAP) and corresponding affective, evaluative and neurophysiological correlates. Phys. Life Rev. 21, 80-125.

Pelowski, M., Markey, P.S., Goller, J., Förster, E.L., Leder, H., 2018. How can we make Art? A new approach to the study of artistic production versus realistic copying, and the perceptual advantages of artists. Psychol. Aesthet. Creat. Arts

Pessiglione, M., Seymour, B., Flandin, G., Dolan, R.J., Frith, C.D., 2006. Dopamine-dependent prediction errors underpin reward-seeking behaviour in humans. Nature 442 (7106), 1042-1045.

Piffer, D., 2016. The heritability of creative potential. figshare https://doi.org/10.6084/ m9.figshare.3498107.v1.

Piffer, D., Hur, Y.-M., 2014. Heritability of creative achievement. Creat. Res. J. 26 (2), 151-157. https://doi.org/10.1080/10400419.2014.901068.

Pinker, S., 2002. Art movements. Can. Med. Assoc. J. 166, 224.

Poletti, M., Bonuccelli, U., 2012. Orbital and ventromedial prefrontal cortex functioning in Parkinson's disease: neuropsychological evidence. Brain Cogn. 79 (1), 23-33.

Polner, B., Nagy, H., Takáts, A., Kéri, S., 2015. Kiss of the muse for the chosen ones: de novo schizotypal traits and lifetime creative achievement are related to changes in divergent thinking during dopaminergic therapy in Parkinson's disease. Psychol. Aesthet. Creat. Arts 9 (3), 328.

Porritt, M.J., Kingsbury, A.E., Hughes, A.J., Howells, D.W., 2006. Striatal dopaminergic neurons are lost with Parkinson's disease progression. Movement Disord. 21 (12), 2208-2211.

Reuter, M., Roth, S., Holve, K., Hennig, J., 2006. Identification of first candidate genes for creativity: a pilot study. Brain Res. 1069, 190-197. https://doi.org/10.1016/j. brainres.2005.11.046.

Rostan, S.M., Pariser, D., Gruber, H.E., 2002. A cross-cultural study of the development of artistic talent, creativity and giftedness. High Abil. Stud. 13 (2), 125-155. https://doi. org/10.1080/1359813022000048789.

Runco, M.A., Chand, I., 1995. Cognition and creativity. Educ. Psychol. Rev. 7, 243-267.

Sacks, O., 2006. The power of music. Brain 129 (10), 2528-2532.

Saggar, M., Quintin, E.M., Kienitz, E., Bott, N.T., Sun, Z., Hong, W.C., Chien, Y.H., Liu, N., Dougherty, R.F., Royalty, A., Hawthorne, G., Reiss, A.L., 2015. Pictionary-based fMR paradigm to study the neural correlates of spontaneous improvisation and figural creativity. Sci. Rep. 5, 10894. https://doi.org/10.1038/srep10894.

Salimpoor, V.N., Benovoy, M., Larcher, K., Dagher, A., Zatorre, R.J., 2011. Anatomically distinct dopamine release during anticipation and experience of peak emotion to music. Nat. Neurosci. 14 (2), 257-262.

Sawyers, J.K., Canestaro, N.C., 1989. Creativity and achievement in design course- work. Creat. Res. J. 2, 126-133.

Schaefer, C.E., Anastasi, A., 1968. A biographical inventory for identifying creativity in adolescent boys. J. Appl. Psychol. 52 (1, Pt.1), 42-48. https://doi.org/10.1037/ h0025328.

Schindelin, J., Arganda-Carreras, I., Frise, E., Kaynig, V., Longair, M., Pietzsch, T., Cardona, A., 2012. Fiji: an open-source platform for biological-image analysis. Nat. Methods 9, 676-682. https://doi.org/10.1038/nmeth.2019. 
Schlesinger, I., Benyakov, O., Erikh, I., Nassar, M., 2014. Relaxation guided imagery reduces motor fluctuations in Parkinson's disease. J. Parkinsons Dis. 4 (3), 431-436. https://doi.org/10.3233/JPD-130338.

Schott, B.H., Niehaus, L., Wittmann, B.C., Schütze, H., Seidenbecher, C.I., Heinze, H.J., Düzel, E., 2007. Ageing and early-stage Parkinson's disease affect separable neural mechanisms of mesolimbic reward processing. Brain 130 (Pt 9), 2412-2424.

Schrag, A., Trimble, M., 2001. Poetic talent unmasked by treatment of Parkinson's disease. Mov. Disord. 16, 1175-1176. https://doi.org/10.1002/mds.1239.

Schrag, A., Horsfall, L., Walters, K., Noyce, A., Petersen, I., 2015. Prediagnostic presentations of Parkinson's disease in primary care: a case-control study. Lancet Neurol. 14 (1), 57-64. https://doi.org/10.1016/S1474-4422(14)70287-X.

Schultz, W., 2016. Dopamine reward prediction-error signalling: a two-component response. Nat. Rev. Neurosci. 17 (3), 183.

Schwingenschuh, P., Katschnig, P., Saurugg, R., Ott, E., Bhatia, K.P., 2010. Artistic profession: A potential risk factor for dopamine dysregulation syndrome in Parkinson's disease?. Mov. Disord. 25 (4), 493-496.

Serafin, J., Kozbelt, A., Seidel, A., Dolese, M., 2011. Dynamic evaluation of high- and low-creativity drawings by artist and nonartist raters: replication and methodological extension. Psychol. Aesthet. Creat. Arts 5 (4), 350-359. https://doi.org/10.1037/ a0023587.

Serranová, T, Jech, R., Dušek, P., Sieger, T., Růžička, F., Urgošík, D., Růžička, E., 2011. Subthalamic nucleus stimulation affects incentive salience attribution in Parkinson's disease. Mov. Disord. 26 (12), 2260-2266. https://doi.org/10.1002/mds.23880.

Shimura, H., Tanaka, R., Urabe, T., Tanaka, S., Hattori, N., 2012. Art and Parkinson's disease: a dramatic change in an artist's style as an initial symptom. J. Neurol. 259 (5), 879-881.

Shulman, G.L., Fiez, J.A., 1997. Common blood flow changes across visual tasks: II. Decreases in cerebral cortex. J. Cogn. Neurosci. 9 (5), 624-647.

Sieborger, F., Ferstl, E., von Cramon, Y., 2007. Making sense of nonsense: an fMRI study of task induced inference processes during discourse comprehension. Brain Res. 1166, 77-91. https://doi.org/10.1016/j.brainres.2007.05.079.

Snyder, A.W., Mulcahy, E., Taylor, J.L., Mitchell, D.J., Sachdev, P., Gandevia, S.C., 2003. Savant-like skills exposed in normal people by suppressing the left fronto-temporal lobe. J. Integr. Neurosci. 2 (02), 149-158.

Solso, R., 2001. Brain activities in a skilled vs a novice artist: an fMRI study. Leonardo 34 (1), 31-34. https://doi.org/10.1162/002409401300052479.

Specker, E., (in press). The Universal and Automatic Association Between Brightness and Positivity. Acta Psychologica.

Spee, B., Ishizu, T., Leder, H., Pelowski, M., 2018. Neuropsychopharmacological aesthetics: a theoretical consideration of pharmacological approaches to causative brain study in aesthetics and art. Prog. Brain Res.

Strand, S., Waller, D., 2010. The experience of Parkinson's: words and images through art therapy—a pilot research study. Int. J. Art Ther. Inscape 15 (2), 84-93.

Sveinbjornsdottir, S., 2016. The clinical symptoms of Parkinson's disease. J. Neurochem. 139 (suppl., 318-324)https://doi.org/10.1111/jnc.13691.

Swerdlow, N.R., Braff, D.L., Hartston, H., Perry, W., Geyer, M.A., 1996. Latent inhibition in schizophrenia. Schizophr. Res. 20 (1), 91-103.

Swerdlow, N.R., Stephany, N., Wasserman, L.C., Talledo, J., Sharp, R., Auerbach, P.P., 2003. Dopamine agonists disrupt visual latent inhibition in normal males using a within-subject paradigm. Psychopharmacology 169, 314-320.

Takeuchi, H., Taki, Y., Sassa, Y., Hashizume, H., Sekiguchi, A., Fukushima, A., Kawashima, R., 2010. Regional gray matter volume of dopaminergic system associate with creativity: evidence from voxel-based morphometry. NeuroImage 51 (2), 578-585.

Talvik, M., Nordström, A.L., Olsson, H., Halldin, C., Farde, L., 2003. Decreased thalamic D2/D3 receptor binding in drug-naive patients with schizophrenia: a PET study with [11C] FLB 457. Int. J. Neuropsychopharmacol. 6 (4), 361-370.

Tarsy, D., 2016. In: Hurtig, H.I., Dashe, J.F. (Eds.), Neuroprotective Therapy for Parkinson Disease. https://www.uptodate.com/contents/ neuroprotective-therapy-for-parkinson-disease, Latest update 2016.

Tinaz, S., Lauro, P., Hallett, M., Horovitz, S., 2016. Deficits in task-set maintenance and execution networks in Parkinson's disease. Brain Struct. Funct. 221 (3), 1413-1425.

Tinio, P.P.L., 2013. From artistic creation to aesthetic reception: the mirror model of art. Psychol. Aesthet. Creat. Arts 7 (3), 265-275. https://doi.org/10.1037/a0030872l.

Tolosa, E., Martí, M.J., Valldeoriola, F., Molinuevo, J.L., 1998. History of levodopa and dopamine agonists in Parkinson's disease treatment. Neurology 50 (6 Suppl 6), S2-10, discussion S44-48.

Tomasi, D., Fowler, J., Tomasi, D., Volkow, N.D., Wang, R.L., Telang, F., Wang, Chang, L., Ernst, T., Fowler, J.S., 2009. Dopamine transporters in striatum correlated with deactivation in the default mode network during visuospatial attention. PLoS One 4 (6), e6102.

Tsai, S.J., Yu, Y.W., Lin, C.H., Chen, T.J., Chen, S.P., Hong, C.J., 2002. Dopamine D2 receptor and $\mathrm{N}$-methyl-D-aspartate receptor $2 \mathrm{~B}$ subunit genetic variants and intelligence. Neuropsychobiology 45, 128-130.

Uitti, R.J., Baba, Y., Whaley, N.R., Wszolek, Z.K., Putzke, J.D., 2005. Parkinson disease-handedness predicts asymmetry. Neurology 64, 1925-1930.

van der Schaaf, M.E., van Schouwenburg, M.R., Geurts, D.E., Schellekens, A.F., Buitelaar, J.K., Verkes, R.J., Cools, R., 2012. Establishing the dopamine dependency of human striatal signals during reward and punishment reversal learning. Cereb. Cortex 24 (3), 633-642.

van Eimeren, T., Monchi, O., Ballanger, B., Strafella, A.P., 2009. Dysfunction of the default mode network in Parkinson disease: a functional magnetic resonance imaging study. Arch. Neurol. 66, 877-883.

van Holstein, M., Aarts, E., van der Schaaf, M.E., Geurts, D.E., Verkes, R.J., Franke, B., Cools, R., 2011. Human cognitive flexibility depends on dopamine D2 receptor signaling. Psychopharmacology 218 (3), 567-578.

van Tricht, M.J., Smeding, H.M.M., Speelman, J.D., Schmand, B.A., 2010. Impaired emotion recognition in music in Parkinson's disease. Brain Cogn. 74 (1), 58-65.

Vartanian, O., 2015. Generating aesthetic products in the scanner: fMRI studies of drawing, story writing, and jazz improvisation. In: Lauring, J.O. (Ed.), An Introduction to Neuroaesthetics: The Neuroscientific Approach to Aesthetic Experience, Artistic Creativity and Arts Appreciation. Museum Tusculanum Press, Copenhagen, pp. 341-353, Chicago: University of Chicago Press.

Verreyt, N., Nys, G., Santens, P., Vingerhoets, G., 2011. Cognitive differences between patients with left-sided and right-sided Parkinson's disease: a review. Neuropsychol. Rev. 21 (4), 405-424.

Vessel, E.A., Starr, G.G., Rubin, N., 2012. The brain on art: Intense aesthetic experience activates the default mode network. Front. Hum. Neurosci. 6, 66. https://doi.org/10. 3389/fnhum.2012.00066

Vicente, S., Biseul, I., Péron, J., Philippot, P., Drapier, S., Drapier, D., Sauleau, P., Haegelen, C., Vérin, M., 2009. Subthalamic nucleus stimulation affects subjective emotional experience in Parkinson's disease patients. Neuropsychologia 47 (8-9), 1928-1937.

Wadeson, H., 2003. Art as therapy for Parkinson's disease. Art Ther. 20 (1), 35-38.

Walker, R.H., Warwick, R., Cercy, S.P., 2006. Augmentation of artistic productivity in Parkinson's disease. Mov. Disord. 21, 285-286. https://doi.org/10.1002/mds.20758.

Wallas, G., 1926. The Art of Thought. Cape, London.

Weintraub, D., Nirenberg, M.J., 2013. Impulse control and related disorders in Parkinson's disease. Neurodegener. Dis. 11 (2), 63-71. https://doi.org/10.1159/000341996.

Weintraub, D., Siderowf, A.D., Potenza, M.N., Goveas, J., Morales, K.H., Duda, J.E., Moberg, P.J., Stern, M.B., 2006. Association of dopamine agonist use with impulse control disorders in Parkinson disease. Arch. Neurol. 63, 969-973.

Weintraub, D., Koester, J., Potenza, M.N., Siderowf, A.D., Stacy, M., Voon, V., Whetteckey, J., Wunderlich, G.R., Lang, A.E., 2010. Impulse control disorders in Parkinson disease: a cross-sectional study of 3090 patients. Arch. Neurol. 67 (5), 589-595. https://doi. org/10.1001/archneurol.2010.65.

Witt, K, Krack, P., Deuschl, G., 2006. Change in artistic expression related to subthalamic stimulation. J. Neurol. 253, 955-956.

Xiao, C., Cho, J.R., Zhou, C., Treweek, J.B., Chan, K., McKinney, S.L., Yang, B., Gradinaru, V., 2016. Cholinergic mesopontine signals govern locomotion and reward through dissociable midbrain pathways. Neuron 90 (2), 333-347. https://doi.org/10.1016/j. neuron.2016.03.028.

Zabelina, D.L., Colzato, L., Beeman, M., Hommel, B., 2016. Dopamine and the cre ative mind: individual differences in creativity are predicted by interactions between dopamine genes DAT and COMT. PLoS One 11 (1), e0146768https://doi.org/10. 1371/journal.pone.0146768.

Zaidel, D.W., 2014. Creativity, brain, and art: biological and neurological considerations Front. Hum. Neurosci. 8 (389), 1-9. https://doi.org/10.3389/fnhum.2014.00389.

Zaidel, D.W., Nadal, M., Flexas, A., Munar, E., 2013. An evolutionary approach to art and aesthetic experience. Psychol. Aesthet. Creat. Arts 7, 100-109.

Zald, D.H., McHugo, M., Ray, K.L., Glahn, D.C., Eickhoff, S.B., Laird, A.R., 2012. Meta-analytic connectivity modeling reveals differential functional connectivity of the medial and lateral orbitofrontal cortex. Cereb. Cortex 24 (1), 232-248.

Zhao, Y.J., Wee, H.L., Chan, Y.H., Seah, S.H., Au, W.L., Lau, P.N., Pica, E.C., Li, S..C., Luo, N., Tan, L.C., 2010. Progression of Parkinson's disease as evaluated by Hoehn and Yahr stage transition times. Movement Disord. 25 (6), 710-716. https://doi.org/10. $1002 /$ mds.228. 